\title{
Effects of a curricular model on skill development, knowledge, and game performance
}

\author{
Tony Pritchard \\ West Virginia University
}

Follow this and additional works at: https://researchrepository.wvu.edu/etd

\section{Recommended Citation}

Pritchard, Tony, "Effects of a curricular model on skill development, knowledge, and game performance" (2004). Graduate Theses, Dissertations, and Problem Reports. 2569.

https://researchrepository.wvu.edu/etd/2569

This Dissertation is protected by copyright and/or related rights. It has been brought to you by the The Research Repository @ WVU with permission from the rights-holder(s). You are free to use this Dissertation in any way that is permitted by the copyright and related rights legislation that applies to your use. For other uses you must obtain permission from the rights-holder(s) directly, unless additional rights are indicated by a Creative Commons license in the record and/ or on the work itself. This Dissertation has been accepted for inclusion in WVU Graduate Theses, Dissertations, and Problem Reports collection by an authorized administrator of The Research Repository @ WVU.

For more information, please contact researchrepository@mail.wvu.edu. 
Effects of a Curricular Model on Skill Development, Knowledge, and Game Performance

Tony Pritchard, M.S., C.S.C.S.

Dissertation submitted to the

School of Physical Education

at West Virginia University

in partial fulfillment of the requirements

for the degree of

Doctor of Education

in

Physical Education Teacher Education

Andrew Hawkins, Ph.D., Chair

Lynn Housner, Ph.D.

Robert Wiegand, Ed.D.

Richard Walls, Ph.D.

Guyton Hornsby, Ph.D.

School of Physical Education Teacher Education

Morgantown, WV

2004

Keyword: Sport Education Curricular Model

Copyright 2004 Tony Pritchard 


\begin{abstract}
Effects of a Curricular Model on Skill Development, Knowledge, and Game Performance
\end{abstract}

Tony Pritchard

Being able to play a sport has been a primary goal of any physical education program (NASPE, 1995). A tool used by physical education teachers in promoting sport has been the use of curricular models. Two models that have been of interest have been the Sport Education Curricular Model (SECM) and a multi-activity model. With little research investigating how these two models influence game play in the secondary level; the purpose of this study was to investigate how the SECM and a longer version of the multi-activity model called the Extended Multi-Activity Model (EMAM) would affect skill development, knowledge, and game performance for the sport of volleyball at the secondary level.

A 2 × 2 x 3 (group x gender x time) research design was utilized on forty-seven secondary students testing volleyball skills (i.e., serve, set, and pass), knowledge, and game performance. Participants were tested on the dependent variables pre, mid, and post of the twenty lesson intervention. Results revealed no group x time interaction but data there were improvement in skills for both models. There were also no significant differences for knowledge although there was some improvement for both curricular models. There was an interaction effect for group $x$ time when dealing with game performance, $F(2,86)=8.06, p<.01$. The SECM group overall made more correct decisions, executed skill more proficiently, and adjusted to the ball better than the EMAM group. In conclusion, if the goal of the physical education program is to promote game play, the SECM is more efficient in enhancing game play than an extended version of the multi-activity model (i.e., EMAM). 


\section{DEDICATION}

This document is dedicated to my parents who have supported me throughout my life in all of my decisions in becoming an educator. I would never have completed my accomplishments without them.

This document is also dedicated to physical education teachers and teacher educators who know the value of physical activity and how physical education can be a positive influence in today's youth. 


\section{ACKNOWLEDGEMENTS}

I would like to first acknowledge my family in how they supported me throughout my years in higher education. They were always encouraging me to accomplish the goals that I set for myself. If it was not for them, I could not have made it this far in life.

I would also like to thank Dr. Andrew Hawkins who guided me through the dissertation process. Without your support, I would never have completed this document. Thank you.

To the other committee members, Dr. Robert Wiegand, Dr. Lynn Housner, Dr. Richard Walls, and Dr. Guyton Hornsby, who were critical and fair in guiding me throughout this process, thank you for all of your expertise and knowledge.

To my colleagues: Rachel Gurvitch, Matt Dell’Orso, Scott Dietrich, Ha Young Kim, Scott Townsend, Jack Sager, Barbara Olmstead, and Matt Mathias. You were always there to help me in so many ways that it would take another document to mention.

And finally, to Bill Bryson and Brian Yensen. Your help in this project did not go unnoticed. I would never have completed this project without you. Thank you so much for all of your time, patience, and help. 


\section{TABLE OF CONTENTS}

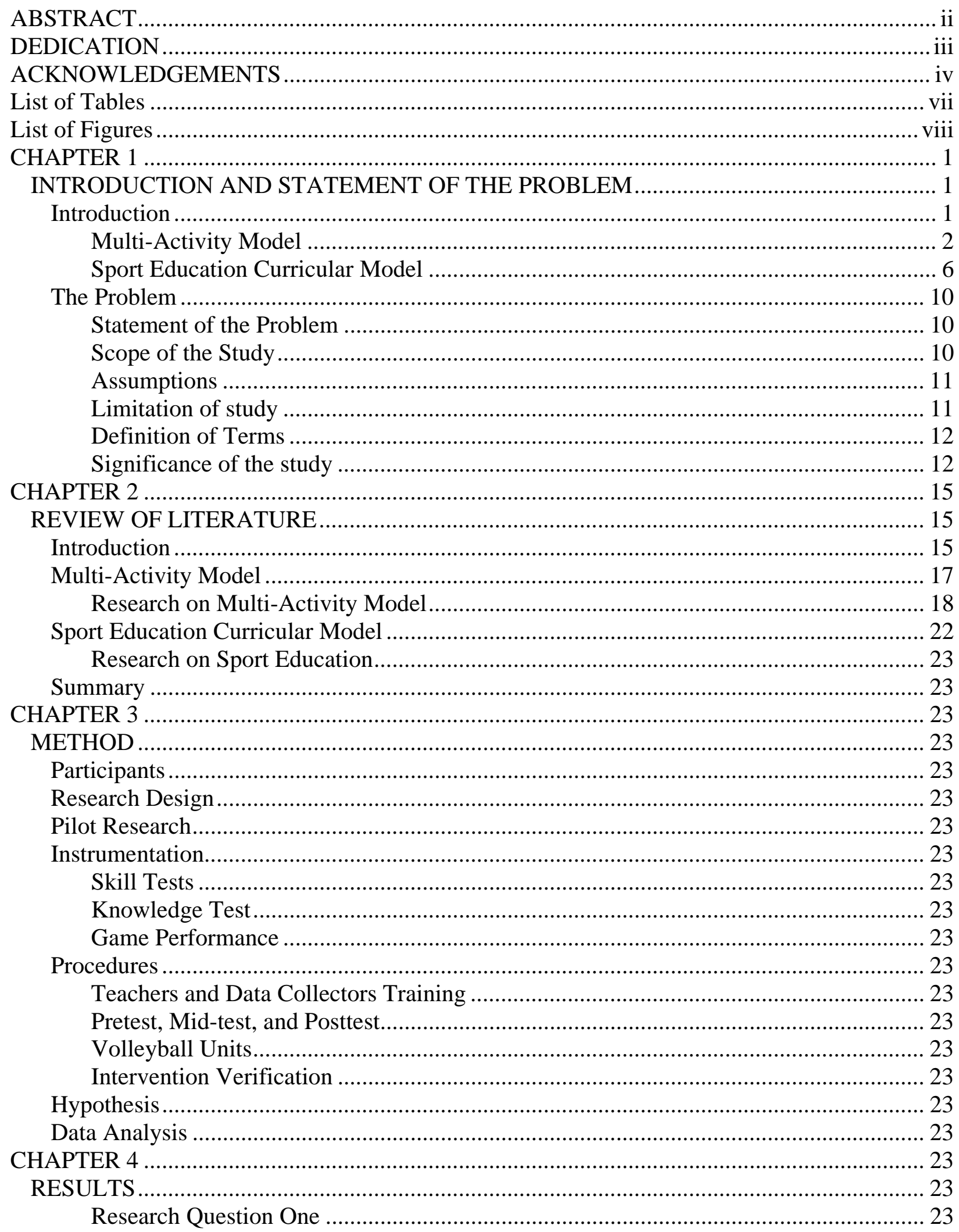




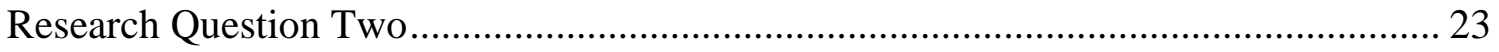

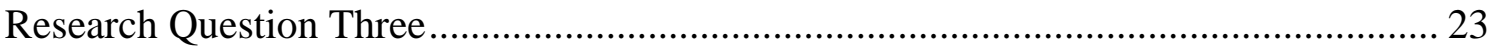

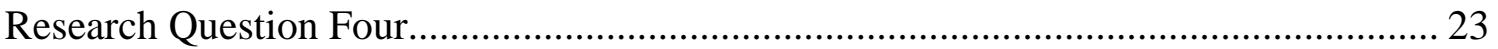

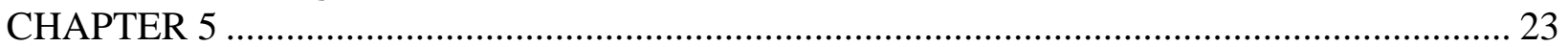

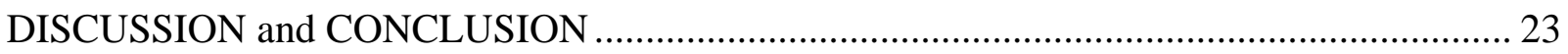

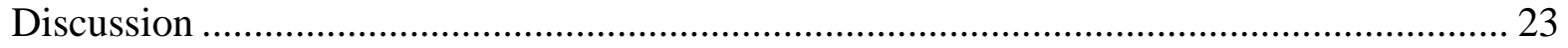

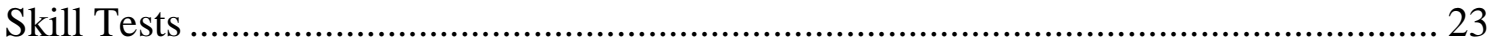

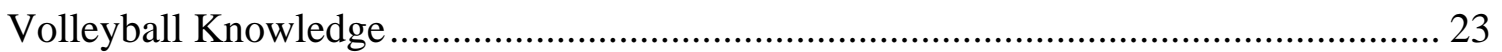

Game Performance ............................................................................................ 23

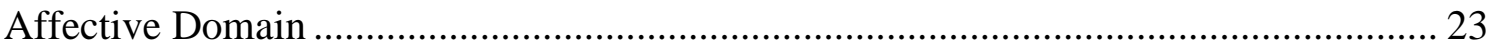

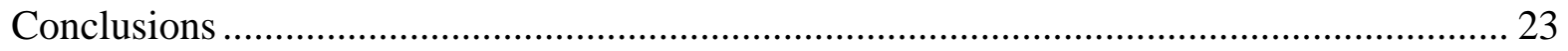

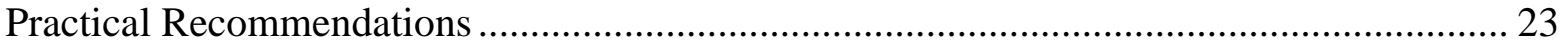

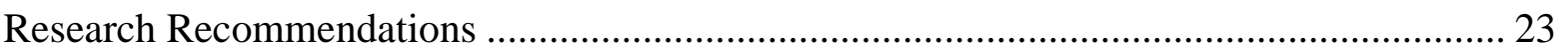

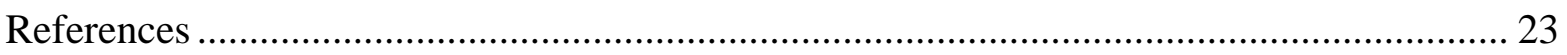

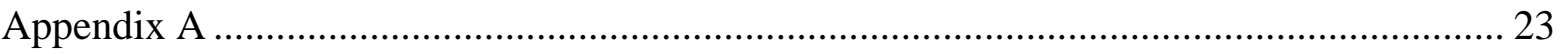

Letter to High School Assistant Principal ................................................................. 23

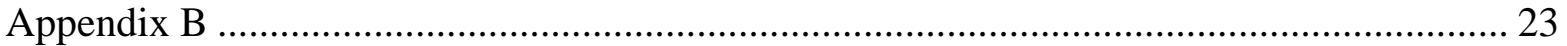

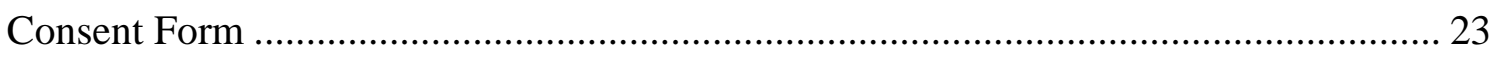

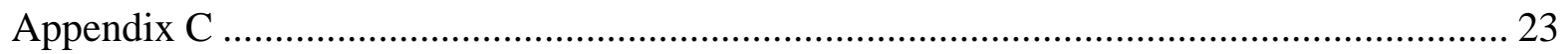

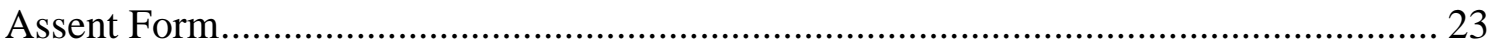

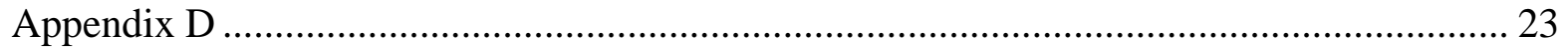

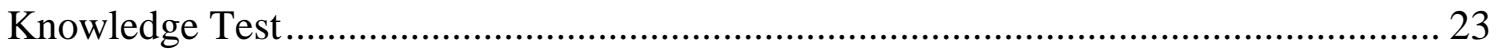

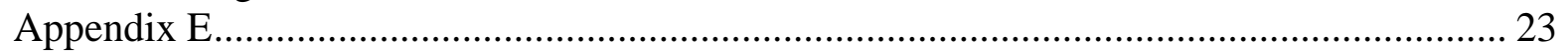

Volleyball Game Performance Assessment Instrument ............................................. 23

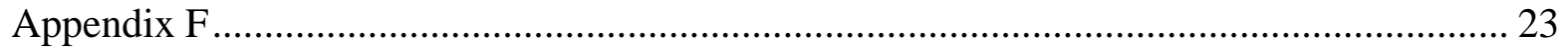

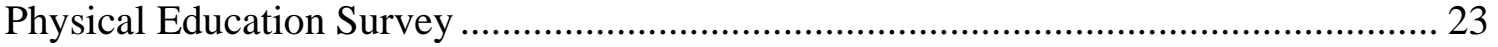

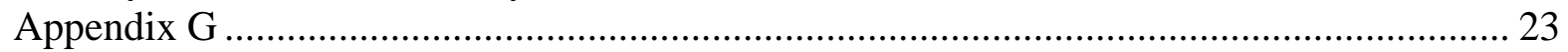

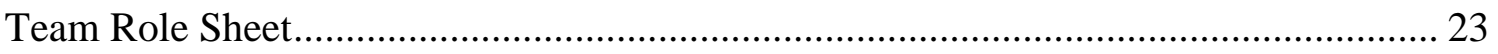

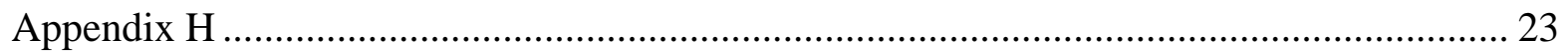

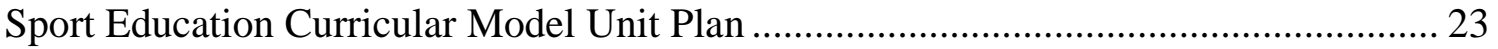

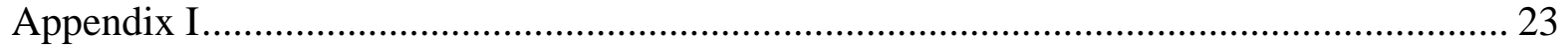

Sport Education Curricular Model Point System ...................................................... 23

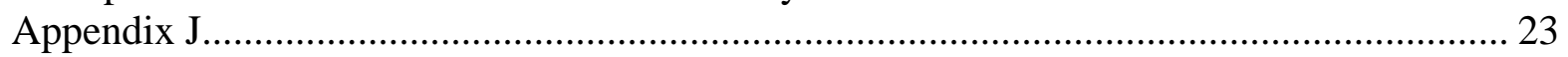

Extended Multi-Activity Model Unit Plan .............................................................. 23

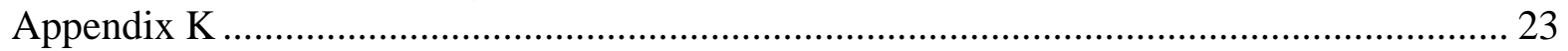

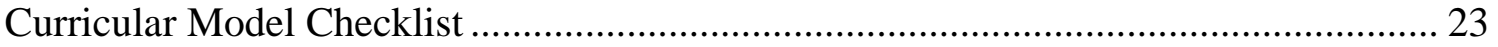

Appendix L......................................................................................................... 23

West Virginia University Teaching Evaluation System Student and Teacher Behavior

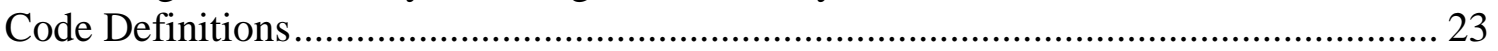




\section{List of Tables}

Table

Title

Page

1

Pilot Skill Test Scores......

36

2

Pilot Knowledge Test Scores............................ 36

$3 \quad$ Pilot Game Performance Scores.................................. 37

$4 \quad$ Student Behaviors..................................... 52

$5 \quad$ Teacher Behaviors.................................... 53

$6 \quad$ Skill Test Scores....................................... 57

$7 \quad$ Knowledge Test Scores........................................ 67

$8 \quad$ Game Performance Scores................................ 79 


\section{List of Figures}

Figure

Title

Page

1 Research design of the independent and dependent variables.........

$2 \quad$ Point zones for the AAHPERD volleyball serving test............... 39

3 Diagram for the AAHPERD volleyball set-up test.................. 40

$4 \quad$ Diagram for the AAHPERD volleyball passing test................. 41

$5 \quad$ Serve skill test for gender.................................... 59

$6 \quad$ Pass skill test for time........................................ 60

$7 \quad$ Pass skill test for gender $\mathrm{x}$ time............................... 61

$8 \quad$ Serve skill test for group $\mathrm{x}$ time............................. 62

$9 \quad$ Set skill test for group $x$ time.................................. 62

$10 \quad$ Pass skill test for group $\mathrm{x}$ time.............................. 63

11 Serve test for group $x$ gender $x$ time........................... 64

12 Set skill test for group $x$ gender $x$ time......................... 65

13 Pass skill test for group $\mathrm{x}$ gender $\mathrm{x}$ time......................... 66

$14 \quad$ Procedural test scores for group................................ 70

15 Procedural test scores for gender............................. 71

16 Declarative test scores for time.............................. 71

17 Total knowledge test scores for time........................ 72

18 Declarative test scores for group $x$ time......................... 73

19 Procedural test scores for group x time........................ 74

20 Total knowledge test scores for group $x$ time..................... 74

21 Declarative test scores for group x gender $\mathrm{x}$ time.................... 75 
22 Procedural test scores for group $\mathrm{x}$ gender $\mathrm{x}$ time.

23 Total knowledge test scores for group $\mathrm{x}$ gender $\mathrm{x}$ time.

24 Skill execution for group.

25 Adjust for group

26 Skill execution for gender.

27 Adjust for gender.

28 Decision made for time

29 Skill execution for time.

30 Adjust for group $\mathrm{x}$ time.

31 Decision made for group $\mathrm{x}$ time.

32 Skill execution for group $\mathrm{x}$ time.

33 Decision made for group $\mathrm{x}$ gender $\mathrm{x}$ time.

34 Skill execution for group $\mathrm{x}$ gender $\mathrm{x}$ time.

35 Adjust for group $\mathrm{x}$ gender $\mathrm{x}$ time

36 Game involvement for gender.

38 Game involvement for group x time.

39 Game involvement for group $\mathrm{x}$ gender $\mathrm{x}$ time.

Game performance for group.

41 Game performance for gender.

42 Game performance for time 
44 Game performance for group $x$ time............................

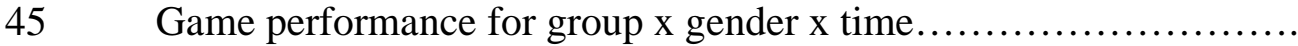




\title{
CHAPTER 1
}

\section{INTRODUCTION AND STATEMENT OF THE PROBLEM}

\author{
Introduction
}

Secondary physical education may be considered a failure when it comes to promoting physical activity. The U.S. Department of Health and Human Services (1996) has indicated that physical activity of American youth ages 12-21 has shown a steady decline. One reason why physical activity has plummeted could be associated with how physical education is being taught in schools. Teachers keep their students busy with isolated skill development or even let students play full-sided games without any practice to keep the students happy. This busy environment helps the teacher look respectable, especially to administration. By promoting a busy environment, most physical education curricula consists of teaching students how to play sports due to the emphasis that sports receive in today's society.

The National Association for Sport and Physical Education (NASPE) has recognized the value of the development of competence and proficiency in games and sports. Thus playing sport has been a primary goal of any physical education program (NASPE, 1995). If students are competent in games and sport then they are more likely to be active throughout their lives (Rink, French, \& Tjeerdsma, 1996). By using this logic, physical education programs incorporate sports and games in the hopes of educating students so that they will continue to be active.

One-way physical educators teach students to be competent during particular games and sports are by having tactical awareness of them. Tactical awareness during game play is essential for one to perform adequately in any sport. Skill alone can help but it is the knowledge of what to do that is the key for students to be successful when playing a game. Griffin, Mitchell, and Oslin (1997) stated, "tactical awareness, critical to game performance, is the ability 
to identify tactical problems that arise during a game and to select the appropriate responses to solve them" (p. 9).

\section{Multi-Activity Model}

Teaching tactics to students is a part of the instructors' role if the instructor wants the students to succeed during game play. A problem that has occurred over the years is that physical education teachers will only teach skill development without teaching how to play the game (Siedentop, Doutis, Tsangaridou, Ward, \& Rauschenbach, 1994; Siedentop \& Tannehill, 2000). This style of teaching does not allow the students to understand why they are learning the skills (Bunker \& Thorpe, 1982). With only teaching skill development, students do not have the opportunity to experience game situations, and thus are unable to execute a skill in a game. If students have learned to dribble a basketball with no one guarding them, will they be able to execute the dribble when guarded by opponents? By only teaching the skill, the likelihood of transferring the skill to a game is diminished.

Some physical educators have taken the stand that students must become proficient in the skills that are associated with that game before they can become competent in game play (Rink, French, \& Tjeerdsma, 1996). Game play alone will not develop proficient physical skills. One needs to play a sport competently so the instructor must incorporate skills into the lessons (French \& Thomas, 1987). A problem with this line of thinking is that students can become very bored if skill development is taught without game play, so arguably, a balance should be established. The traditional technique of teaching physical education entails the teacher instructing the students on the motor skills for a certain period then playing full games at the end of the unit (Siedentop \& Tannehill, 2000). This traditional style of teaching has also been called the multi-activity model (i.e., traditional, technique, or skill-development). The goal of a multi- 
activity curriculum is to provide students with a variety of sport experiences in the hope that students will enjoy at least one sport that they will continue to participate in throughout their lives (Darst, \& Pangrazi, 2001). The teacher is in total control of the learning environment by being responsible for the management of lessons that includes presenting tasks, holding students accountable, and developing student learning (Hastie, 1998a). The instructional strategy is usually a command style that allows the teacher to guide students through the entire lesson (Darst, \& Pangrazi, 2001). This multi-activity approach to teaching, which is very repetitive, allows students to become very bored with physical education very quickly, especially those who cannot play the game or sport (Siedentop \& Tannehill, 2000).

Several studies have compared the multi-activity model (i.e., traditional, technique, or skill-development) to a tactical approach with variables dealing with the cognitive and psychomotor domains (Allison \& Thorpe, 1997; Lawton, 1989; Mitchell, Oslin, \& Griffin, 1995; Rink, 1996; Turner \& Martinek, 1992, 1999). The results have varied but this variation can be attributed to the methodologies that were employed (Rink, 1996). Research that has been conducted measuring the differences in skill, game performance, or knowledge did not have significant differences between the two models but did show some improvement for both groups (Lawton, 1989; Turner \& Martinek, 1992). The short units of both studies (Lawton, 1989; Turner \& Martinek, 1992) may explain the lack of significant findings even though both models (i.e., technique and tactical) did have some improvement. Turner and Martinek (1992) compared the tactical and technique approaches for 10 weeks but the participants only met once a week for 35-minutes, while Lawton (1989) studied the differences in the two models for six lessons. With so little time in the treatment, a significant difference between the two treatments may not have been seen. 
Studies that did find differences between the tactical and technique approach had different overall results. One theme that emerged from the literature was that skill instruction might enhance game play in some sports (French, Werner, Rink, Taylor, \& Hussey, 1996; French, Werner, Taylor, Hussey, \& Jones, 1996; McPherson \& French, 1991). French, Werner, Rink, et al. (1996) conducted a three-week study on the net/wall game of badminton. The skillonly (i.e., technique) group exhibited decision-making components during game play that can be supported by the findings of French, Werner, Taylor, et al. (1996) and McPherson and French (1991). French, Werner, Taylor, et al. found that the skill-only group improved in game performance decisions that are similar to the tactical group during a six-week badminton study, but one must note that these studies dealt with sports in the net/wall category (badminton and tennis). Turner and Martinek (1999) did not find improved game performance for the skill group in the invasion sport of field hockey. The differences between these studies might be attributed to the differences in the tactical awareness one would need for the different categories of sports (i.e. net/wall and invasion). A net/wall game such as badminton allows one or two students to play having more opportunities to respond than an invasion type game where a student is part of a team. The student usually will not be as active in a team sport because of the number of students placed on an invasion team. An individual sport such as badminton allows the student to have more playing time because he or she does not have to rely on teammates.

Another theme that emerged from studies dealing with tactical and technique approaches was that tactical instruction alone could improve skill execution (Allison \& Thorpe, 1997; French, Werner, Rink, et al., 1996; French, Werner, Taylor, et al., 1996; Griffin, Oslin, \& Mitchell, 1995; Turner \& Martinek, 1999). By working on tactical awareness, students are performing the skills that one would learn to play the game. This skills learning through tactical 
awareness gives students practice time on the motor skills, thus skill execution can improve over time. With improved skill execution through tactical learning, students can enhance game play. Rink (2002) stated a level of proficiency of skills is also important to implement strategies. Thus one must not forget to teach the skills, so a combination of teaching skills and tactics would be the solution for improving game playing decision-making.

French, Werner, Rink, et al. (1996) did not see much improvement in skill for the combination group that received skill and tactical instruction in the three-week study. The same results were found at the mid-point of the six-week study conducted by French, Werner, Taylor, et al. (1996), but the combination group did see improvement on skills from weeks three through six. The post-test revealed that the combination groups' skill tests were similar to the tactical group except for the badminton clear shot (French, Werner, Taylor, et al., 1996). The longer intervention for the badminton study allowed the combination group to learn the skills and thus improve game performance. Turner and Martinek (1999) also found that an extended intervention allowed the skill groups and the tactical groups to be significantly different on game performance execution of field hockey skills and procedural knowledge. The skill group did not improve as much as the tactical group due to the isolation of skill development that entailed participants to practice skills without the benefit of using those skills in game situations. By improving procedural knowledge and skills during game play, students have the capacity to make more decisions during game play. Rink, French, and Graham (1996) stated, “not only do players who have more skill execute skills better in the tactics they chose, but they also have more strategies to chose from” (p. 491).

By teaching skills in isolation, students do not have the opportunity to transfer those skills to game play. The multi-activity model promotes practicing skills absent of game 
situations, which could inhibit the students in learning how to play an actual game. Extending the multi-activity model may allow participants more practice time to improve skills thus hopefully game performance. This extended multi-activity model (EMAM) could allow students to gain the skill development they would need to transfer their skill development to game performance.

\section{Sport Education Curricular Model}

Another model that may promote game performance through tactical knowledge and skill development is the Sport Education Curricular Model (SECM). Siedentop (1994) noticed that students were not playing sports to the extent that one should play during physical education; thus game play was decontextualized. Siedentop (1994) stated:

Skills are taught in isolation rather than as a part of the natural context of executing strategy in game-like situations. The rituals, values, and traditions of a sport that give it meaning are seldom even mentioned, let alone taught in ways that students can experience them. The affiliation with a team or group that provides the context of personal growth and responsibility in sport is notably absent. [In summary] physical education teaches only isolated sport skills and less-than-meaningful games. Students are not educated in sport. (p. 7).

Influenced by the "teaching games for understanding”, Siedentop (2002) developed the SECM in the 1980s basing the model on the play education theory. According to Siedentop (1994), the SECM was designed to educate students in sport by simulating a more authentic experience of sport. When students are taught through the SECM, the primary goals are for the students to become competent, literate, and enthusiastic toward the sport chosen by the teacher. A competent player will have sufficient skills to participate in games by understanding and 
executing strategies plus having knowledge of the game. A literate player will understand and value the rules, rituals, and traditions of sport, plus understand the difference between good and bad sport. An enthusiastic player will participate and behave so that the sport culture is preserved, protected, and enhanced. If students become competent, literate, and enthusiastic in a sport then the likelihood of them to continuing to participate in that sport may increase.

Implementing the SECM is different than a usual physical education unit due to six unique characteristics: 1) seasons, 2) culminating event, 3) affiliation, 4) record keeping, 5) formal competition, and 6) festivity.

Numerous studies have investigated the SECM in the attempt to examine the benefits of the curricular model. Hastie (1998a) stated that students benefit from the SECM by increasing levels of responsibility and being part of an environment that reinforces specific interpersonal behavior. Hastie and Sharpe (1999) reported an increase in positive interactions and a decrease in negative interactions of students during a SECM season. Students, especially with lower skill levels, also have more opportunities to learn the sport by understanding how to play the game (Hastie, 1998a, 1998c). Hastie (1998a, 1998c) found that marginalized students have more opportunities to respond, plus Carlson (1995) reported that lower skilled students believe that they can achieve success. Hastie (1998b) discovered that girls have as many opportunities to play and practice as the boys. There was also improvement in play for lower skilled students after a season of frisbee (Hastie, 1998c). Incorporating small team sizes that remain intact for an entire season (longer than a regular physical education unit) benefits the marginalized students (Hastie, 1998a). The SECM also benefits teachers by giving them freedom from direct instruction and the opportunities to focus on student behaviors (e.g., skill development) by 
having the students more involved with the teaching process (i.e., the coaching role) (Hastie, 1998a).

Other investigations of the SECM have reported high levels of student engagement (Hastie, 1996, 2000), high levels of congruent behaviors in non-playing roles (Hastie, 1996), minimal off-task (Hastie, 1996), overall student enjoyment (Carlson, 1995; Hastie, 1998b, 1998c), and opportunities for developing moderate to vigorous physical activity (Hastie \& Trost, 2002). Game performance was also enhanced by the SECM (Hastie, 1998c; Ormond, Christie, Barbieri, \& Schell, 2002; Ormond, DeMarco, Smith, \& Fisher, 1995) along with skill development (Townsend et al., 2004).

Townsend et al. (2004) report significant gains in basketball skills in 89 sixth grade students following an 18-lesson SECM unit but game performance and knowledge were not measured. Hastie (1998c) found sixth grade students involved in a SECM season improved in game performance by choosing appropriate skills and game strategy such as making shorter passes in the game of ultimate frisbee. The six-member team improved on team efficiency scores from early season to late season (Hastie, 1998c). One must be aware that this study only followed one team with six members while 18 teams were in the class. Ormond, DeMarco, et al. (1995) found that a SECM high school class played a better game of basketball than the skills-togame-play approach (i.e., traditional approach). SECM students shared the ball with teammates, utilized strategies, and the high skilled students included lower skilled students. A limitation of the study was that one class was assigned to the SECM and the second class was assigned to the traditional approach, which weakens the unit of analysis. The differences in the class may be the cause of the changes in basketball play rather than the curricular models. Another study by Ormond, Christie, et al. (2002) found similar results for a SECM group of tenth graders that was 
compared to a traditional group of ninth graders during a season of basketball. The SECM group had a greater number of shot attempts indicating more distribution of the basketball, game play was more organized, showed more activity, and an increase in knowledge tests scores compared to the traditional style of teaching. These differences in the two styles of teaching may have been seen due to differences in the two different classes or differences in maturity (i.e., ninth graders compared to tenth graders).

As for gender differences, little research has investigated how the SECM or multi-activity model influence game play in a physical education setting. Allison and Thorpe (1997) investigated the skill only (i.e., multi-activity model) with 40 ninth grade boys participating in six one hour lessons of basketball and 56 eighth grade girls participating in the same time of field hockey. The short intervention of the model did show an improvement in skill development and knowledge in the group of boys and girls except for one skill test for the girls. The girls actually did worse on the skill test of shooting after the unit. Hastie (1998c) did have two girls that improved in game play during a SECM season of frisbee, but this is a small number of subjects to be able to generalize that the SECM does promote improve game play in females.

Concerns with the methodology of the previous SECM studies dealing with game performance raise the question, “Does the SECM allow students of both genders to improve in skill execution, knowledge, and game performance compared to the technical curricular model?” In conclusion, teaching effective game play should be one of the goals of any physical education program, thus choosing a curricular model that promotes effective game play would benefit the students of both genders. The SECM may be the curricular model that promotes game play by enhancing skill development and knowledge of a sport. 
The Problem

\section{Statement of the Problem}

One purpose of this study was to investigate the effectiveness of the Sport Education Curricular Model and the Extended Multi-Activity Model on skill development, knowledge, and game performance in a secondary school setting. A second purpose of this investigation was to examine any differences in gender when measuring skill development, knowledge, and game performance of the two curricular models.

The following research questions have been generated to fulfill the purposes of the study:

1) The first research question asked which model would best improve skills when utilizing skill tests?

2) The second research question asked which model would best improve knowledge (i.e., declarative and procedural) of the sport of volleyball?

3) The third research question asked which model would best improve game involvement, game performance and the subscales of game performance (i.e., decision made, skill execution, and adjust)?

4) The fourth research question asked how participants would feel about the two models after the intervention?

\section{Scope of the Study}

The participants consisted of male and female secondary school students $(\mathrm{N}=47)$ enrolled in two physical education classes located in the state of West Virginia. The independent variable of this study was the type of curricular model that was utilized in the sport unit (i.e., Sport Education Curricular Model or Extended Multi-Activity Model). Participants were be randomly assigned to one of the curricular models with gender being stratified. The effects of 
the curricular models were measured across the dependent variables of skill development, knowledge (i.e., procedural knowledge and declarative knowledge), and game performance, which were measured before, in the middle, and at the end of the sport unit. The participants' skill levels were measured utilizing a battery of skill tests that included the American Alliance for Health, Physical Education, Recreation, and Dance (AAHPERD) volleyball serve test, the volleyball-passing test, and the volleyball set-up test (AAHPERD, 1969). Knowledge was evaluated via a 45-question test measuring declarative (i.e., first 20 questions) and procedural knowledge (i.e., last 15 questions) adapted from the McGee and Farrow (1987) volleyball test battery. Game performance was measured by videotaping participants playing an actual game and was analyzed by the primary investigator through the Game Performance Assessment Instrument (GPAI; Oslin, Mitchell, \& Griffin, 1998). Assumptions

1. The AAHPERD, volleyball serve test, the volleyball-passing test, and the volleyball set-up test (AAHPERD, 1969) are valid and reliable.

2. The Game Performance Assessment Instrument (Oslin, Mitchell, \& Griffin, 1998) was valid in measuring game performance.

3. The McGee and Farrow (1987) volleyball test battery for procedural and declarative knowledge in volleyball have content validity.

4. The teachers were trained in implementing the Sport Education Curricular Model (SECM) and the Extended Multi-Activity Model (EMAM).

\section{Limitation of study}

1. Participants in this study represented only the secondary school population from a particular city located in the state of West Virginia. The results of the study may not 
be generalized to students at different levels of public school (i.e., elementary or middle school).

2. The sport of volleyball was utilized in this study so the results may not be generalized to other types of sports (e.g., invasion sports, target sports, etc.).

3. Teachers utilized in the study are considered to be novice due to their lack of experience in public schools.

\section{Definition of Terms}

Game Performance was measured by utilizing the Game Performance Assessment Instrument (GPAI; Oslin, Mitchell, \& Griffin, 1998). The instrument measures game performance by calculating the sum of the decision-making index (DMI), skill execution index (SEI), and support index (SI) divided by three [DMI + SEI + SI] $\div 3$.

Declarative Knowledge is the rules, goals, and subgoals of a sport (French \& Thomas, 1987). Declarative knowledge was measured by utilizing the McGee and Farrow (1987) volleyball test battery.

Procedural Knowledge is characterized as the selection of an appropriate action within the context of the game (McPherson \& French, 1991). Procedural knowledge was measured by utilizing the McGee and Farrow (1987) volleyball test battery.

\section{Significance of the study}

Physical education teachers are displeased about the status of physical education programs (Locke, 1992; Siedentop, 1987a; Tinning \& Fitzclarence, 1992). With the trend of health problems that are affecting today's youth (e.g., obesity), the physical education class would be a promising environment to promote lifetime activity. A problem with most physical education programs is that they are failing to promote physical activity and health-related fitness 
among young people (Bulger, Mohr, Carson, \& Wiegand, 2001). A problem with physical education class is the way the subject matter is taught.

The traditional physical education class stresses skill development in the hopes that students will be able to play full-sided games later in the unit (Siedentop, Doutis, Tsangaridou, Ward, \& Rauschenbach, 1994; Siedentop \& Tannehill, 2000). If physical educators are to promote physical activity then developing game performance would allow students to be proficient in playing sports. A way to develop game performance is to emphasize tactical knowledge along with skill development instead of skill development alone. A curricular model that may promote the declarative and procedural knowledge along with skill development is the Sport Education Curricular Model (SECM). The SECM has been shown to benefit both students and teachers (Hastie, 1998a). Studies conducted on the SECM found some improvement in game performance (Hastie 1998c; Ormond, DeMarco, et al., 1995; Ormond, Christie, et al., 2002). Hastie (1998c) followed a sixth grade team of six students through a sport season but only investigated how one team of six improved and not the entire class. The team only had two females and they did show some improvement but is this improvement typical with the SECM when gender is involved? Hastie (1998b) did report that females have the same opportunities to respond as the boys at the beginning of a season but was less during the competition phase. By having girls getting more opportunities to respond, improvement in game play may happen but further research must be conducted on how females respond in developing skill, knowledge, and game play.

Ormond, DeMarco et al. (1995) and Ormond, Christie, et al. (2002) investigated the SECM to a traditional model in secondary classes but each study had two different classes that were assigned to one of the models plus one study measured differences between ninth graders 
and tenth graders. The difference may have been attributed to the differences in classes or due to maturity and not the models. With a dearth of research conducted on how the SECM will promote skill development, knowledge of the sport, and game performance, it is prudent to investigate how the model prepares students to play actual games.

By promoting game play through the use of skill development and knowledge using the SECM, students may become competent enough in a specific sport (i.e., volleyball) that they will continue to participate in this sport after graduation. With physical levels declining and obesity increasing, physical education can be an instrument to reverse these trends. The multi-activity model is the most widely used curricular model so one may conclude that the model is not promoting lifetime activity. An alternative in enhancing lifetime activity is the SECM due to its unique characteristics and goals. Researching the SECM in how it affects students at the secondary level of public school must continue if we are to promote this model to teachers and administrators. 


\title{
CHAPTER 2
}

\section{REVIEW OF LITERATURE}

\author{
Introduction
}

Physical education in public schools has been around for years and teaching students how to be active are the physical education teachers. Secondary physical education is the last chance teachers can influence students in becoming physically active. According to the U.S. Surgeon General (U. S. Department of Health and Human Services USDHHS, 1996), students are not as active as they should be. The USDHHS report states the following:

- Only about one-half of U.S. young people (aged 12-21) regularly participate in vigorous physical activity- one-fourth report no vigorous physical activity.

- Approximately one-fourth of young people walk or bicycle nearly every day.

- About $14 \%$ of young people report no recent vigorous or light to moderate physical activity. This indicator of physical activity is higher among females than males and among African American females than white females.

- Males are more likely than females to participate in vigorous physical activity, strengthening activities, and walking or bicycling.

- Participation in all types of physical activity declines strikingly as age or grade in school increases.

- Among high school students, enrollment in physical education remained unchanged during the first half of the 1990s. However, daily attendance in physical education declined from approximately $42 \%$ to $25 \%$. 
- The percentage of high school students who were enrolled in physical education and who reported being physically active for at least 20 minutes in physical education classes declined from approximately $81 \%$ to $70 \%$ during the first half of the 1990 s.

- Only 19\% of all high school students report being physically active for 20 minutes or more in daily physical education classes.

With health epidemics continuing to rise and physical activity levels falling as students age, teachers must decide on how to teach students to become physically active. One possible solution is for teachers to promote game play, which allows students to become competent in sports to continue being physically active after graduation.

Teachers decide on how to provide students the knowledge needed to continue to be active in sports when students are no longer in school by choosing a curriculum. Teachers will select curricular models to achieve the goals of the program. There are many curricular models teachers may choose when designing their program. Darst and Pangrazi (2001) describe five curricular models a teacher may choose from that include the following: 1) Skill Development (i.e., Multi-Activity Model), 2) Sport Education, 3) Knowledge Concepts, 4) Fitness Education, and 5) Social Development. The model a teacher chooses is determined by the goals and objectives of the physical education program. If the goals and objectives of the curriculum are to promote skill development for sports and how to play those sports, then a teacher may choose either a multi-activity model or a Sport Education Curricular Model (SECM). This chapter is a review of the literature pertaining to the description of the multi-activity model, research dealing with the multi-activity model, the SECM, and the research dealing with the SECM. 


\section{Multi-Activity Model}

The Multi-Activity Model has also been described as the skill development model (Allison \& Thorpe, 1997; French, Werner, Rink, Taylor, \& Hussey, 1996; French, Werner, Taylor, Hussey, \& Jones, 1996; Darst, \& Pangrazi, 2001), traditional model (Ormond, DeMarco, et al., 1995), or technique (Mitchell, Oslin, \& Griffin, 1995; Turner \& Martinek, 1992, 1999). According to Darst and Pangrazi (2001), this model is the most commonly used model especially at the secondary level. It entails the promotion of many activities during the school year in the hope that students will experience a wide variety of skills and activities so they will discover activities that they enjoy and will pursue them the rest of their life (Darst \& Pangrazi, 2001). But with the rise of health problems associated with today's youth and the steady decline of physical activity levels, one could say that this curricular model is not working.

Hastie (1998a) describes the teacher of a multi-activity model as being responsible for the management of lessons that entails presenting tasks, holding students accountable, and develop student learning. By having the majority of the responsibility of the students, the teacher is in total control of the learning environment by utilizing a direct style of instruction. Darst and Pangrazi (2001) describe this style as being teacher controlled in that the teacher guides students through the entire lesson.

Siedentop and Tannehill (2000) refer to this model as being a "smorgasbord curriculum" in that many activities are chosen thus the units must be shorter. Skills are taught in isolation of actual game play then students are placed on teams later in the unit then a few lessons contain a tournament or a series of games. Students do not enjoy game play due to the poor quality of play due to the lack of practice in developing game performance skills. 


\section{Research on Multi-Activity Model}

Several studies have investigated the multi-activity model to a tactical approach of teaching measuring variables dealing with the cognitive and psychomotor domains (Allison \& Thorpe, 1997; Griffin, Oslin, \& Mitchell, 1995; Lawton, 1989; Rink, 1996; Turner \& Martinek, 1992, 1999). Research that has been conducted measuring the differences in skill, game play, or knowledge did not have any significant differences between the two models but did show some improvement for both groups (Lawton, 1989; Turner, \& Martinek, 1992). Turner and Martinek (1992) studied the two approaches for 10 weeks during a field hockey unit but the 44 sixth and seventh grade students that only met once a week for 35-minutes. The technique group $(n=22)$ did not have a significant difference in knowledge scores, improvement in skill tests, nor game playing ability after the intervention, which is consistent with Lawton (1989). Lawton investigated a skill-based approach to a tactical approach for twelve and thirteen year olds during a six-lesson badminton unit. Although there were no significant differences, the technique groups in both studies did show some improvement in playing ability, skill development, and knowledge. Allison and Thorpe (1997) investigated the two models with separated classes of 40 ninth grade boys participating in basketball while 56 eighth grade girls participated in field hockey. The short intervention (i.e., six one hour lessons) did show an improvement in skill development and knowledge for the skill only group of boys and girls except for one skill test for the girls. Skill only girls did not improve on the shooting test of field hockey but actually regressed.

Another study by Mitchell, Oslin, and Griffin (1995) investigated game performance using the Game Performance Assessment Instrument by comparing a tactical approach that was based on the Teaching Games for Understanding (see Bunker and Thorpe, 1982) to a more 
technical style of teaching soccer. After the eight lessons were taught by one teacher to two classes that were assigned to either the technical or the tactical approach, results revealed that the tactical group $(n=20)$ performed better during game performance than the technical group $(n=$ 21) for sixth grade students. The technical group only improved on decision-making and skill execution from pretest to posttest but decreased in game involvement and support, which led to a decrease in overall game performance. Mitchell, Oslin, and Griffin (1995) stated the difference in this study and the study by Turner and Martinek (1992) was due to the off the ball movements that was measured using the Game Performance Assessment Instrument. Mitchell, Oslin, and Griffin also had only one teacher was teaching two different classes while Turner and Martinek had two teachers that taught both models to two classes. The small units that are a characteristic of the multi-activity model may not have allowed any significant difference between the two treatments to be found.

Other studies that did find a difference between the tactical approach and the technical approach had different overall results. One theme that emerged from the literature was that skill instruction (i.e., technical approach) might enhance game play in some sports (French, Werner, Rink, Taylor, \& Hussey, 1996; French, Werner, Taylor, Hussey, \& Jones, 1996; McPherson \& French, 1991). French, Werner, Rink, et al. (1996) conducted a three-week study on the net/wall game of badminton that measured game performance, skill development, and knowledge for a skill group ( $n=12)$, tactical group $(n=12)$, and a combination group that received both skill and tactical instruction $(n=12)$. Posttesting revealed that there were differences in groups for some of the skill tests (i.e., drop, clear, and serve) and game performance measures but not for the smash skill test or the 45-question knowledge test. The skill group exhibited decision-making components during game play although they did not receive any instruction in this area. French, 
Werner, Rink et al. attribute this finding due to "the high correlation between the ability to produce forceful shots and make shots selections (decisions) that forced opponents to move or play a defensive shot.” (p. 435). By being able to perform those shots to move the opponents, the skill group was able to identify what shots to perform during game play that moved their opponents.

French, Werner, Taylor, et al. (1996) followed up the three week badminton study with a six week study on skill development, knowledge, and game performance on three different groups of ninth graders $(N=52)$ that either received skill instruction only, tactical instruction, or a combination of skill and tactical instruction. Testing occurred at the three-week mark and after the six-week intervention. Results revealed that the skill group improved significantly between the third and sixth week on the clear and smashes tests but not the serve and drop. The skill group along with the tactical group performed better on game performance measurements (i.e., forceful shots, cooperative shots, game decisions, and serve decisions) and exhibited a 10 to $15 \%$ advantage over the tactical group when measuring forceful shots and cooperative shots at the third and sixth week. This study supports French, Werner, Rink et al. (1996) in that the skill group improves in skills, knowledge, and game performance compared to the control group. The longer units compared to other investigations suggest that improvement in skills, knowledge, and game performance may be achieved using a traditional teaching approach of teaching skills only.

Although the studies conducted by French, Werner, Rink, et al. (1996) and French, Werner, Taylor, et al. (1996) found that the skill only groups improved in skills, knowledge, and game performance, they did not utilize pretesting of the dependent variables but compared the posttesting to a control group that received instruction on another sport other than badminton. Although the skill group did perform better than the control group on the dependent variables, 
pretesting could have been utilized to ensure there were no differences between groups before the studies were conducted and investigate if time was a variable.

Turner and Martinek (1999) did not find an enhancement in game play for the technique group in the invasion sport of field hockey during a 15-lesson unit of middle school students ( $N$ $=71$ ). The technique group did not perform any better than the control group on measures of game performance, which may be attributed to the isolation of skill instruction. Learning skills in isolation does not allow players to transfer those skills into game performance (Rink, 1996). The technique group did improve on skill tests of the field hockey unit compared to the control group due to the emphasis on appropriate skill execution during instruction, which is similar to the findings of French, Werner, Rink, et al. (1996) and French, Werner, Taylor, et al. (1996). Skill instruction during the technique approach allows participants to practice skills in isolation, which is similar to skill tests. Unlike playing a game where the environment is constantly changing, skill practice is in isolation so transferring the skills to game play is minimal.

The technique group in Turner and Martinek (1999) did improve on declarative and procedural knowledge proving that the technique style of teaching can promote knowledge. The improvement in procedural knowledge could have been attributed to game play at the end of each lesson. The technique lesson allowed game play at the end after skill instruction took place. This format was also followed by Turner and Martinek (1992), French, Werner, Rink, et al. (1996), French, Werner, Taylor, et al. (1996), and Mitchell, Oslin, and Griffin (1995), which could explain why there was some improvement in game performance for the technical groups. By playing, the technical group could have learned tactics that are involved to improve their procedural knowledge. 
By improving procedural knowledge and skills, students will have the capacity to make more decisions during game performance. Rink, French, and Graham (1996) stated, “not only do players who have more skill execute skills better in the tactics they chose, but they also have more strategies to chose from” (p. 491). Students have more options to attack their opponents when they are skillful and knowledgeable. If students only have a few skills and knowledge, then they are limited in their decisions during game play.

In conclusion, the multi-activity model (i.e., traditional, technique, or skill instruction) promotes teaching students sport skills in isolation (Siedentop, Doutis, Tsangaridou, Ward, \& Rauschenbach, 1994; Siedentop \& Tannehill, 2000). This curricular model allows the teacher to promote many activities during a school year but students may not be receiving the necessary skills to play an actual game. One answer in promoting game play may be choosing the Sport Education Curricular Model.

\section{Sport Education Curricular Model}

Daryl Siedentop who was influenced by the "teaching games for understanding” approach developed the Sport Education Curricular Model (SECM) during the early 1980s (Siedentop, 2002). According to Siedentop (2002), both models (i.e., TGFU and SECM) emphasize tactical awareness along with skill development in game situations instead of the isolated skill development promoted by the multi-activity model. Rooted in the play theory, the SECM is based on the play education theory, which was developed during Siedentop’s dissertation (Siedentop, 1968). Siedentop (2002) argued that “cultures of physically active play were fundamentally important to collective social life, and that bringing children and youth into contact with those cultures through educationally sound practices was sufficient to justify physical education as a school subject” (p.411). He also stated that physical education should be 
classified as play, thus he defines it as “any process that increases human abilities to play competitive and expressive motor activities” (Siedentop, 1987b, p. 80).

According to Siedentop (1994), the goals of SECM are to produce students who are competent, literate, and enthusiastic toward sport. A competent player will have the sufficient skills to participate in games by understanding and executing strategies plus having knowledge of the game. A literate player will understand and value the rules, rituals, and traditions of sports plus understand the difference between good and bad sport. An enthusiastic player will participate and behave so that the sport culture is preserved, protected, and enhanced.

Implementing the SECM is different than a usual physical education unit due to several unique characteristics.

Seasons. Instead of shorter units characterized by the multi-activity model, the SECM provides units that are longer called seasons. The season includes practice and competition along with an end of season event that finalizes the sport unit. Teams are allowed to practice to improve skills and tactical awareness at the beginning of a season similar to an athletic team would before a season. The teams have a set schedule of teams to play during the midseason followed by some type of tournament for the post season.

Seasons have been known to exceed 30 lessons for one sport (Hastie, 1998c). Mohr, Townsend, and Bulger (2001a, 2001b) planned a sport education season that incorporated 20 lessons on a block plan schedule. The actual number of lessons depends on the sport and the teacher. By extending the sport unit to be longer, skill development and tactical knowledge can be promoted in context of actual game play (Rink, 1996). The longer seasons can give the physical education teacher more opportunities to teach students how to play the sport and not just develop skills in the hope that students will learn to play on their own. 
Affiliation. To ensure fairness, the teacher or a student committee places the students on teams at the beginning of the season. Students will stay on the team for the entire season or in some cases, the entire year. Teams will have the opportunity to choose their team name, color, cheer, and high five to give the students a sense of unity (Siedentop, 1994; 1996). By having students on teams early in the unit, the students can practice with their team in preparation for the season.

Siedentop (1994) proposes placing students in roles that they must perform each lesson (e.g., coach, fitness trainer, manager, statistician, and referee). By learning every aspect of the sport through performing different roles, students are experiencing sport to the fullest. The roles teach students about responsibility and team unity by having a role for every student on the team.

Formal Competition. The formal competition will be interspersed throughout the season. It includes a league schedule along with a tournament at the end of the season. Teams practice early in the season to prepare themselves for the competition. As the season progresses, there is less time for practice and more time for formal competition but this does not mean that the formal competition is a full-sided game. Games are still modified (e.g., number of players, rules of the games) according to player skill levels until players have the understanding and the ability to play a full-sided game.

Culminating Event. The culminating event provides goals toward which teams see who is the best for that particular season. It should come at the end of the season and must incorporate every aspect of the sport. Players should have an understanding of the rituals associated with the sport thus it should be ceremonial.

Keeping Records. Records help to provide feedback to the students on how well they are performing during the season. Records can include individuals' statistics along with the teams' 
statistics so improvement can be celebrated. Records can be posted on the bulletin board of the gym to allow students to keep track of their team's progress toward the overall championship. Teams can earn points to the overall championship through appropriate behavior (e.g., good sportsmanship), performing team roles, winning the application contest for that particular day, or by earning affiliation points by wearing team colors, executing team cheer, etc. The teacher must stress that the team who has the most points earned after a season is the rightful champion and not the team who wins the culminating event.

Festivity. The festivity should be a celebration coming on the last day of the season. It should include all of the rituals of the sport including music, decorations, and awards ceremony.

By following these characteristics, the goals of the SECM are to provide students with a more authentic experience of play thus allowing students to become competent, literate, and enthusiastic about sport (Siedentop, 1994). According to Siedentop (1994), a competent player is one who will have the sufficient skills to participate in games by understanding and executing strategies plus having knowledge of the game. A literate player will understand and value the rules, rituals, and traditions of sports plus understand the difference between good and bad sport. An enthusiastic player will participate and behave so that the sport culture is preserved, protected, and enhanced.

\section{Research on Sport Education}

Numerous studies have investigated the SECM in the attempt to examine the benefits of the curricular model. Hastie (1998a) stated that students benefit from the SECM by increasing levels of responsibility and being part of an environment that reinforces specific interpersonal behavior. Hastie and Sharpe (1999) reported that 20 at-risk boys responded to the model by 
increasing compliant behavior later in the season along with increases in interpersonal positive interactions. Negative interactions decreased due to the intervention of the SECM.

Hastie (1998b, 1998c) found that marginalized students have more opportunities to respond during a SECM season. Marginalized students are usually those who are low skilled or are female. Hastie (1998c) discovered that lower skilled students have improvement in skill, game performance, and knowledge of a sport. This study is supported by Hastie (1998b) in which he investigated how a cohort of 35 sixth grade girls participated in a 20-lesson season of floor hockey. Results revealed that there was no significant difference in the opportunities to respond (OTR) for boys and girls until the formal competition phase. The boys did have significantly more OTR during this phase but the girls did have significantly higher success rates at the end of the season than the beginning of the season. The girls reported enjoyment of the SECM unit by being more engaged with the unit by performing roles, being a part of the team, and competing in team competitions. Carlson (1995) reports lower skilled students believed that they could contribute to their team and improve their skill. Six students in the sixth grade that were followed during a 30-lesson unit in a sport called ultimate frisbee also reported enjoying being on the same team and felt that they had improved in playing plus were a useful part of the team (Hastie, 1998c). Marginalized students having more opportunities to respond in a season may lead to improvement in skill and game play.

By having more responsibility during a SECM season, students will exhibit lower levels of off-task behaviors (Hastie, 1996). Hastie investigated student role involvement of 37 sixth grade boys during a 12-lesson season on speedball. Data were collected on student task accomplishment during lessons, questionnaires to students performing duty roles to gain insight on how they felt about their roles, formal interviews after the season to gather information about 
the effectiveness of student coaches, comparisons with previous physical education, students' perceptions of their development of skills, students' feelings about team affiliation, and students' likes and dislikes about nonplaying roles. Results revealed high levels of motor-appropriate practice when it was run by the student coach than in skill sessions delivered by the teacher. Students had high levels of on-task behavior during their duty roles (e.g., referee, statistician), plus they reported an enjoyment of carrying out these roles. The students also reported a preference for student coaches leading practices instead of the dominating teacher who usually leads the entire class in practice. By giving the students more responsibility during the physical education unit, they are less likely to be off-task especially if they feel that they are contributing to the unit.

The SECM has shown to improve skills during a basketball unit for 89 sixth grade students (Townsend et al., 2004). Townsend et al. found that basketball skills improved on isolated skill tests (i.e., speed spot shooting, passing, control dribble, and defensive movement) after the eighteen-lesson unit. Another benefit of the SECM reported by Hastie (1998a) is that the model helps to promote game play by improving skills and tactical knowledge. Hastie and Trost (2002) discovered that 19 seventh grade boys increased in skill performance of floor hockey while averaging over $60 \%$ of lesson time in moderate to vigorous physical activity. Hastie (1998c) also found an improvement in efficiency scores of six sixth graders during a frisbee season that were determined by the Grehaigne, Godbout, and Bouthier's efficiency index (1997). Team efficiency scores showed an increase from the early stages (1.33) to the later stages (2.68) of the season. Team catching competency scores increased significantly from $72.3 \%$ to $91.3 \%$ but no single member of the team had any significant differences. 
When investigating tactical refinement, there was an increase in the medium and high skilled players ( $50 \%$ vs. $\sim 85 \%$ ). A correlation was utilized to show the relationship between short passing and game efficiency $(r=.89)$, and a second correlation was found between short passing and successful catches $(r=.93)$. By making shorter passes, the team was able to keep position of the frisbee and increase their chances of scoring based on the rules of the sport.

Ormond, DeMarco, et al. (1995) investigated the effects of the SECM and a traditional approach on knowledge, attitudes, and quality of game play during a 12-lesson basketball unit at the secondary level. There were no significant differences in knowledge tests and the SECM group was concerned with strategy and team unity while the traditional group was concerned with having fun. Game play that was analyzed via videotape found that the SECM group had improvement in team play, overall participation, and utilization of defensive and offensive strategies while the traditional group was identified as being a "run and gun” style of play. Another study by Ormond, Christie, et al. (2002) found that the SECM promoted more shot attempts in a 12-lesson basketball unit of ninth graders $(n=36)$ compared to a class of tenth graders $(n=40)$ who were taught using a traditional style. Game play during the traditional style was described as "street ball” while the SECM was more organized.

In concluding the effects of the SECM when measuring knowledge, skill improvement, and game play, the SECM seems to promote these dependent variables but there are some methodological concerns. Overall, Hastie (1998c) discovered that the SECM could benefit students in promoting game performance, skill development, and tactical awareness. But, the study only investigated the effects of the SECM in six students who were a member of one team. One must be aware that 18 teams were included in this unit so will the same effects be seen with those teams when measuring game performance, skill development, and tactical awareness? 
Ormond, Christie, et al. (2002) and Ormond, DeMarco, et al. (1995) found that the SECM class improved in knowledge, and game play compared to a traditional class. These findings may be misleading due to two different classes were either assigned to the SECM or traditional unit. The differences that were found could have been attributed to the differences in class instead of the differences in the curricular models. Ormond, Christie, et al. also compared ninth graders to tenth graders in measuring the dependent variables thus the differences could have been attributed to maturity.

The Sport Education Curricular Model is different than the standard physical education unit due to its unique characteristics. Students, especially with lower skill levels, have more opportunities to learn the sport by understanding how to play the game (Hastie, 1998c; Ormond, Christie, et al., 2002; Ormond, DeMarco, et al., 1995). Incorporating small team sizes that remain intact for an entire season (longer than a regular physical education unit) benefits the marginalized students (Hastie, 1998b, 1998c). The SECM also benefits teachers by giving them freedom from direct instruction and the opportunities to focus on student behaviors (e.g., skill development) by having the students to be more involved with the teaching process (i.e., the coaching role) (Hastie, 1998a). By having students to become a part of the teaching process, teachers are allowed to move throughout the learning environment providing feedback to students especially the marginalized students.

\section{Summary}

In summary, as students age, physical activity levels begin to fall thus losing the benefits of being active. A way that teachers can promote physical activity is to promote game play during physical education class. Two curricular models that promote game play are the multiactivity model and the SECM. The multi-activity model wants students to experience a variety 
of activities or sports in the hope that the students will enjoy at least one of those sports and continue to participate once graduated. Teachers teach students the skills in isolation of actual game play and play full-sided games later in the very short unit (Siedentop \& Tannehill, 2000). Research conducted on the model which has also been called the traditional or technique have found that skills may be improved along with some game play if the units are longer (French, Werner, Taylor, et al. 1996; French, Werner, Rink, et al. 1996; Mitchell, Oslin, \& Griffin 1995; Turner \& Martinek 1992).

The goal of the SECM is to promote a total sportsperson by having him or her to be competent, literate, and enthusiastic the in the sport by following the characteristics of the model which include: 1) seasons, 2) culminating event, 3) affiliation, 4) record keeping, 5) formal competition, and 6) festivity. Game performance has been shown to improve in sixth graders (Hastie, 1998c) and in some high school physical education classes (Ormond, Christie, et al., 2002; Ormond, DeMarco, et al., 1995), but one must be wary of these findings due to the methods that were imposed. Hastie (1998c) only followed six subjects in the sixth grade using the SECM. Ormond, Christie, et al. (2002) investigated two different classes at different age levels which where ninth graders and tenth graders. Ormond, DeMarco, et al. (1995) compared two different classes in which one class was intervened with the SECM and the other class was intervened with the traditional approach taught by one teacher. Differences that were found may have been due to the two classes that were investigated and not the curricular models. These are the only studies investigating how the SECM promotes game play, skill development, and knowledge at the secondary level. Further research is needed at this level since it is the last time teachers can affect the physical activity behaviors of the students. 
Gender is another issue one must be aware of when dealing with physical education. Physical education classes are very intimidating for girls (Griffin, 1989; Hutchinson, 1995; Talbot, 1986; Turvey \& Laws, 1988). By being intimidated, girls may be less likely to achieve the ability to play a sport due to a lack of opportunities to respond. Hastie (1998b) discovered that sixth grade girls did have more opportunities to respond with the SECM. Girls also improved in game play by improving their skill during an ultimate frisbee season (Hastie, 1998c). The girls in both studies were in the sixth grade and there were only two females on the team of six that were followed during the game play study. Other than these two studies, very little has been investigated on how girls may benefit from the SECM when measuring game play, knowledge and skill development especially at the secondary level. 


\section{CHAPTER 3}

\section{METHOD}

The purpose of this investigation was to study the effects of the Sport Education Curricular Model (SECM) and the Extended Multi-Activity Model (EMAM) on skill development, knowledge, and game performance. The methods that are described in this chapter are organized into the following six sections: 1) participants, 2) research design, 3) instrumentation, 4) procedures, 5) hypothesis, and 6) data analysis.

\section{Participants}

The setting of the investigation was two secondary physical education classes consisting of a total of eighty-two students in grade nine. Of the 82 students in the classes, sixty-four (i.e., males and females) received prior consent from a parent or guardian. They were randomly assigned to either the SECM $(n=32)$ or the EMAM $(n=32)$ groups within each class with gender being stratified $($ SECM males $=17$, SECM females $=15$, EMAM males = 17, EMAM females $=15)$. Only forty-seven participants $(N=47$; SECM males $=16$, SECM females $=10$, EMAM males = 11, EMAM females = 10) finished the study with the others not completing the investigation due to missing the testing dates or too many classes (i.e., more than 25\%) by not dressing for class, being absent, or being injured, which did not allow much time for the intervention of the curricular models to work. Prior to data collection, approval was obtained from the Institutional Review Board for the Protection of Human Subjects. A letter concerning the collection of data at a public school was sent to the assistant high school principal for approval (see Appendix A). Consent forms (see Appendix B) were sent to the parents or guardians of the participants to explain the research being conducted, thus granting permission to 
utilize their child as a participant. Assent forms (see Appendix C) were given to participants and collected on the same day.

\section{Research Design}

The research design was a mixed model with three independent variables. Curricular models (i.e., SECM and EMAM) was a between subjects independent variable. Gender (i.e., male and female) was a between subjects independent variable while testing occasion (i.e., pretest, mid-test, and post-test) was a within subjects independent variable. Thus, this research design was a 2 × 2 × 3 format with two between subjects independent variables and one within subjects independent variable. The dependent variables were skill tests (i.e., volleyball serve, volleyball set, and volleyball pass), knowledge test score (i.e., declarative knowledge, procedural knowledge, and total knowledge), game performance (i.e., skill execution, decision made, adjust, game involvement, and game performance), and the answers to the survey depicting the participants' feelings regarding the volleyball unit. The research design of the independent and dependent variables are depicted in Figure 1 (see Figure 1). Participants were administered skill tests, knowledge tests, a physical education survey, and were assessed on their game performance by playing an actual game which was videotaped. Participants were placed into either the SECM or EMAM through a stratified random assignment prior to the intervention phase. The intervention consisted of a 20-lesson unit on the sport of volleyball. Data were collected before the volleyball unit began (pre-test), after the tenth lesson (mid-test), and after the 20-lesson unit ended (post-test). The dependent variable measures indicated which curricular model was more effective in students learning the sport of volleyball along with how students felt after the volleyball unit. 
Teachers collaborated on lesson planning to ensure both models were followed. Each teacher implemented both models to eliminate any teacher differences. During the first class, teacher A used the SECM while teacher B used EMAM. During the second class, teacher A Testing Occasion (Within-Subjects IV) Pre-test Mid-test Post-test

Independent Variables

Curricular Model (Between Subjects IV) Gender (Between Subjects IV) SECM EMAM

\begin{tabular}{|l|l|l|l|l|l|}
\hline $\mathrm{M}$ & $\mathrm{F}$ & $\mathrm{M}$ & $\mathrm{F}$ & $\mathrm{M}$ & $\mathrm{F}$ \\
\hline & & & & & \\
\hline & & & & & \\
\hline
\end{tabular}

Dependent Variables Items Each Score Range Skills Test

Serve

10 Trials

0-4

$0-40$

Set-up

20 Trials

0-1

$0-20$

Pass

10 Trials

0-1

$0-20$

Knowledge Test Declarative

20 Questions

0-1

$0-20$

Procedural

15 Questions

0-1

0-15

Total

35 Questions

0-1

0-35

Game Performance

Skill Execution

Various

0-1

Various

Decision Made

Various

0-1

Various

Adjust

Various

0-1

Various

Total

Various

0-1

Various

Game Involvement Total

Various

0-1

Various

Figure 1. Research design of the independent and dependent variables. 
Note. $\mathrm{M}=$ Males, $\mathrm{F}=$ Females, $\mathrm{IV}=$ Independent variables, $\mathrm{SECM}=$ Sport Education

Curricular Model, and EMAM = Extended Multi-Activity Model

administered EMAM and teacher B administered SECM. Teachers were videotaped and their teaching was analyzed by the researcher to verify that both models were implemented correctly.

\section{Pilot Research}

The purpose for conducting the pilot research was to assess the logistics of the study by evaluating participants $(N=16)$ taking a college volleyball course. Volleyball skill tests (i.e., serve, pass, and set-up), knowledge test (i.e., procedural and declarative knowledge), and game performance were assessed prior to the teacher utilizing the SECM during the course. Skill tests were administered using the American Alliance for Health, Physical Education, Recreation, and Dance (AAHPERD; 1969) serving, passing, and set-up tests for volleyball by the primary investigator and the volleyball teacher. The 35-question knowledge test designed from the McGee and Farrow (1987) test bank was then administered. Game performance was analyzed by placing participants on four teams and videotaping game play. Games were videotaped for 15 minutes then analyzed by the primary investigator using the Game Performance Assessment Instrument (Oslin, Mitchell, \& Griffin, 1998). The instrument was used to assess how participants execute skills, make decisions, and adjust to playing conditions during actual game play. Once pre data had been collected, the instructor taught participants how to play volleyball using the SECM for ten lessons. The intervention time was shorter than a typical SECM season but the lessons lasted for 75 minutes. Post testing occurred at the end of the season to determine any significant improvement in the dependent variables using Multivariate Analysis of Variances (MANOVA) on the skill tests, knowledge (i.e., declarative and procedural), and three of the 
components of game performance (i.e., decision made, skill execution, and adjust). Significant effects were then analyzed via Analysis of Variance (ANOVA).

Mean scores for skill tests are recorded in Table 1.

Table 1.

Pilot Skill Test Scores

\begin{tabular}{lccc}
\hline & Pretest & Posttest & Total \\
\hline Serve & $17.06(5.32)$ & $21.00(5.21)$ & $19.75(1.41)$ \\
Set & $5.63(4.00)$ & $5.88(3.67)$ & $5.75(3.78)$ \\
Pass & $4.25(2.57)$ & $13.44(3.03)$ & $8.84(5.42)$ \\
\hline
\end{tabular}

Note. Mean (SD).

Mean scores for the knowledge tests are reported in Table 2.

Table 2.

Pilot Knowledge Test Scores

Pretest Posttest Total

Declarative

10.50 (2.56)

10.56 (2.22)

$10.53(2.36)$

Procedural

7.69 (1.85)

$7.75(1.23)$

7.72 (1.55)

Knowledge Test

$18.19(3.71)$

$18.31(2.64)$

$18.25(3.17)$

Score

Note. Mean (SD). 
The game performance scores for participants are recorded in Table 3.

Table 3.

Pilot Game Performance Scores

\begin{tabular}{lccc}
\hline & Pretest & Posttest & Total \\
\hline Game Involvement & $30.25(15.63)$ & $32.75(12.67)$ & $31.50(14.05)$ \\
Decision Made & $11.41(7.94)$ & $11.97(6.22)$ & $11.69(7.01)$ \\
Skill Execution & $5.15(4.66)$ & $4.55(5.47)$ & $4.85(5.01)$ \\
Adjust & $3.38(2.70)$ & $5.13(4.25)$ & $4.25(3.35)$ \\
Game Performance & $6.76(3.70)$ & $7.21(3.96)$ & $6.99(3.78)$ \\
\hline
\end{tabular}

Note. Mean (SD).

For the skill tests, the Multivariate Analysis of Variance (MANOVA) revealed a significant main effect for time of test, Wilks’ lambda $=.12, F(3,13)=32.62, p<.05$. Univariate Analysis of Variances (ANOVA) were conducted revealing that the pass skill test had a significant difference, $F(1,15)=111.04, p<.05$ while the serve and the set were not significant although the serve did show some improvement.

For the declarative and procedural sections of the knowledge test, a MANOVA revealed that there was no significant difference for time, Wilks' lambda $=1.0, F(2,14)=.01, p>.05$ (ns). An ANOVA for total knowledge also did not reveal a significant difference for time, $F$ (1, 15) $=.018, p>.05(n s)$.

A MANOVA was conducted on certain game performance variables (i.e., decision made, skill execution, and adjust) which revealed no significant difference, Wilks’ lambda = .72, F (3, 
$13)=1.67, p>.05$ (ns). For total game involvement, a univariate ANOVA revealed that game involvement was not significant for time, $F(1,15)=.446, p>.05(n s)$. Game performance also did not have a significant improvement over time, $F(1,15)=.23, p>.05(n s)$, but did have a trend of improving over time.

In conclusion, the SECM did improve certain skills of volleyball (i.e., serve and pass) while not having much effect on knowledge. The participants did show improvement on game performance over time but overall the group did have fairly high skills in volleyball when playing games. By using a college basic instruction class, it is not a typical population for this age group. Most students who sign up for a volleyball class at the college level usually have experience in the sport. By conducting the research at a high school in a population where there was a lower skill level, the SECM could be more effective.

Instrumentation

\section{Skill Tests}

The American Alliance for Health, Physical Education, Recreation, and Dance (AAHPERD; 1969) serving, passing, and set-up tests for volleyball were conducted by graduate assistants who were trained to administer the skill tests before data collection occurred. The principal investigator provided testing protocols with each skill test and provided a written description of each test to the administrators. The serve test (see Figure 2) measured volleyball serving ability by having a participant to execute 10 trials. The total points accumulated from hitting the zones marked on the court determined the score. 


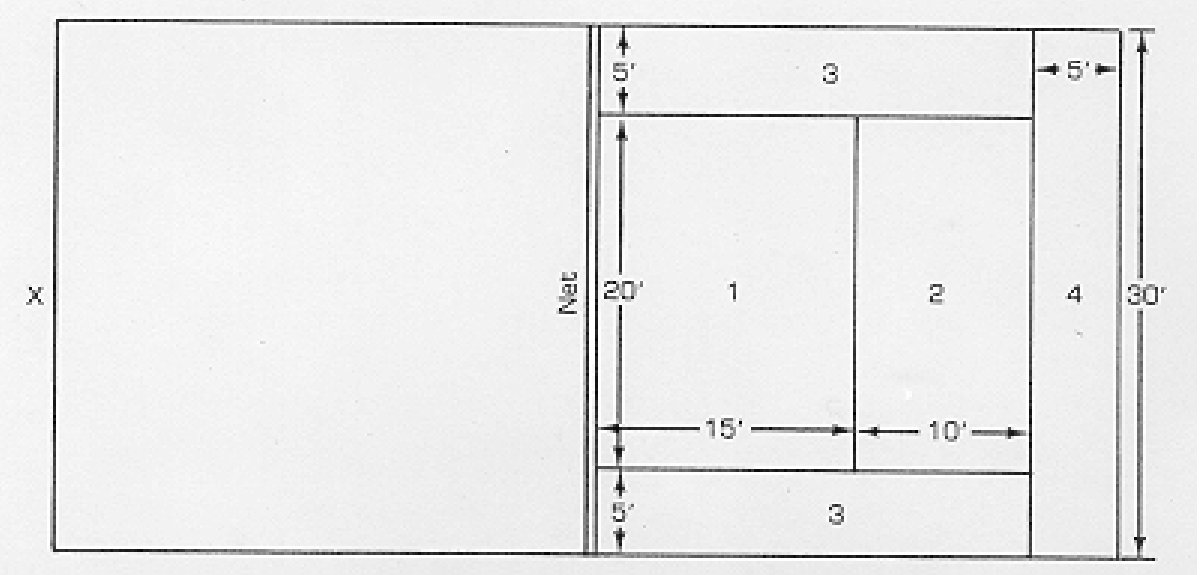

Figure 2. Point zones for the AAHPERD volleyball serving test (Reproduced from AAHPERD Volleyball Skills Test Manual. Reston, VA: AAHPERD, 1969, reprinted with permission).

The set-up test (see Figure 3) required a thrower to toss a high pass to the participant who performs a set-up over the 10-foot rope onto the target area. Ten trials are given to the left and 10 trials to the right. The score was the number of balls that the participant was able to hit in the target areas; thus the highest score attainable was 20 . If the ball hit the rope or any other area of the floor, the participant received a score of zero for that trial. If the toss did not fall into the six by five-foot area then the toss was repeated. 


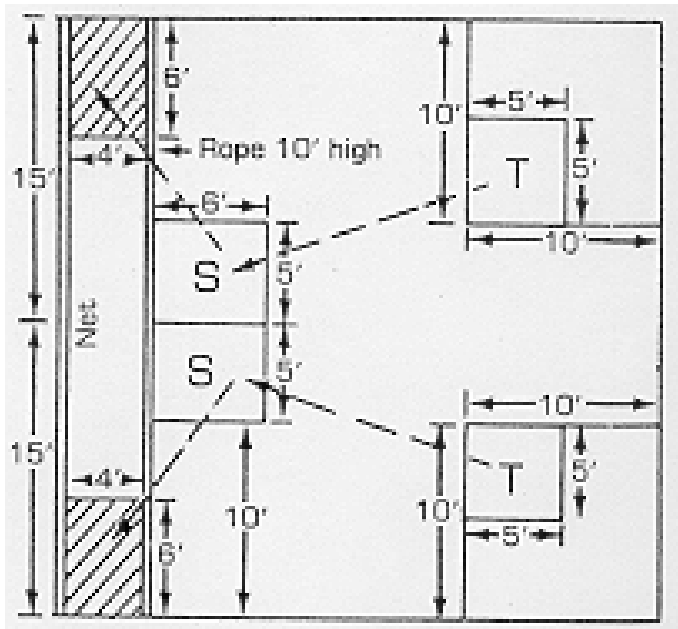

Figure 3. Diagram for the AAHPERD volleyball set-up test. (Reproduced from AAHPERD Volleyball Skills Test Manual. Reston, VA: AAHPERD, 1969, reprinted with permission).

Note. T represents thrower and S represents subject.

The passing test (see Figure 4) required a thrower to toss a high pass to the participant who attempted to perform a legal volleyball pass over the eight-foot high rope into the marked areas of the court. Twenty trials were executed alternating between the right and left marked areas. The score was determined by the number of legal passes that landed in the marked areas; thus a participant may have scored up to 20. 


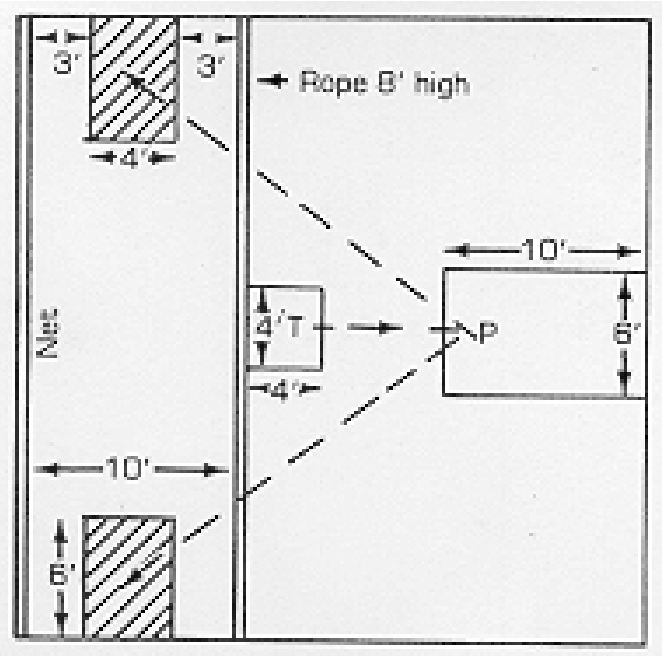

Figure 4. Diagram for the AAHPERD volleyball passing test. (Reproduced from AAHPERD Volleyball Skills Test Manual. Reston, VA: AAHPERD, 1969, reprinted with permission). Note. P represents passer and T represents thrower.

AAHPERD (1969) claims content validity with reliabilities of .70 for tests scored on basis of accuracy for the volleyball skill tests (i.e., serving, set-up, and passing) Knowledge Test

The declarative and procedural knowledge test (see Appendix D) consisted of a total of 35 questions with the first 20 questions being declarative and the last 15 being procedural from the volleyball question bank from McGee and Farrow (1987). The questions were selected from the bank by the principal investigator which best reflected the objectives of the volleyball unit. The questions focused on the techniques, rules and strategies of volleyball.

Although the knowledge test had no data quality coefficients, other researchers have used the test bank in conducting their research (French, Werner, Rink, Taylor, \& Hussey, 1996; French, Werner, Taylor, Hussey, \& Jones, 1996). The test bank of McGee and Farrow has also been recommended by Safrit and Wood (1995) as being “the best source of test items for sport" (p. 421). Content validity was determined by matching the questions with the objectives of the 
volleyball unit. For example, question two was matched up with the lesson dealing with the set skill. Teachers taught students the set along with when and how it should be performed.

Content validity was also strengthened by having an outside researcher who had taught the sport of volleyball for two years and a physical education teacher with 11 years of teaching experience at the public school level and 16 years coaching experience of volleyball also determined if the questions reflected the objectives of the unit.

\section{Game Performance}

Game performance was measured utilizing the Game Performance Assessment Instrument (GPAI) for volleyball (Oslin, Mitchell, \& Griffin, 1998; see Appendix E). According to Oslin, Mitchell, \& Griffin (1998) the instrument was designed to assess game performance by measuring behaviors that demonstrated tactical awareness, as well as the student's ability to solve tactical problems by choosing the appropriate skills. The GPAI allowed the researcher to observe and code game performance as appropriate or inappropriate through a tally sheet when the following behaviors occurred: 1) decisions made, 2) skill execution, and 3) adjust.

There were three levels of the decision made category, which consisted of passing the ball over the net and passing to set up the attack. For example, an appropriate decision made was when a participant decided to pass the ball over the net on the third hit. One rule of volleyball is that a team may only pass the ball on their side of the court twice and hit it over the net on the third hit. If the participant passed the volleyball over the net from the net on the first hit then this would be categorized as inappropriate. The participant needs to set up the attack so an appropriate decision would be to pass the volleyball to a teammate.

The skill execution category was composed of the forearm pass, overhead pass or set, and spike. In the set example, the participant would have a legal contact ball that was passed to a 
teammate or over the net on the third hit or by trying to catch the opposite team off guard. There were times when a player acts like he or she would set to a teammate but hit it over the net to surprise the other team. If the participant set the ball illegally by catching the ball or by hitting it out of bounds this was considered inappropriate.

The last category was adjust (i.e., support) which was defined as the player opening up or was in pursuit of the ball. An example of this criterion would be when the ball was hit down the line and a participant attempted to get to the ball by moving toward it, this would be considered appropriate. If the participant did not attempt to move toward the ball, this was categorized as inappropriate.

A tally mark was placed under one of the categories as the behavior occurred. Once data had been collected, the following equations were utilized to measure game performance and game involvement.

Game involvement = total appropriate decisions + number of inappropriate decisions + number of efficient skill executions + number of inefficient skill executions + number of supporting movements.

Decision-making index $(\mathrm{DMI})=$ number of appropriate decisions made $/$ number of inappropriate decisions made.

Skill execution index $(\mathrm{SEI})=$ number of efficient skill executions / number of inefficient skill executions.

Support index or Adjust (SI) = number of appropriate supporting movements / number of inappropriate supporting movements.

Game performance $=(\mathrm{DMI}+\mathrm{SEI}+\mathrm{SI}) / 3$. 
Oslin, Mitchell, and Griffin (1998) measured content validity of the GPAI by providing a questionnaire to undergraduate physical education majors who used the instrument in assessing a single performer during 10 minutes of game play. The students responded $95 \%$ in favor of the instrument to assess game play. Content validity was strengthened by six physical education teacher/coaches with 10 to 30 years of experience. The definitions and terms were revised until all six experts were in agreement. Construct validity was measured by how the GPAI was able to distinguish between high and low individuals in game performance during basketball, soccer, and volleyball. The GPAI was able to differentiate between high and low game performers for the skill-execution across all three studies and the decisions-made component in the soccer and volleyball studies. Ecological validity was met by selecting the components of the GPAI according to what was to be taught in a particular instructional setting (i.e., basketball, soccer, and volleyball).

Instrument reliability was determined by retesting $30 \%$ of the students in the soccer, basketball, and volleyball studies (Oslin, Mitchell, \& Griffin, 1998). The soccer correlation coefficients were as follows: decisions made $r=.85$, skill execution $r=.97$, and support $r=.87$. The basketball correlation coefficients were decisions made $r=.85$, skill execution $r=.84$, and support $r=.99$. The volleyball correlation coefficients were decisions made $r=.90$, skill execution $r=.85$, and adjust $r=.97$.

\section{Procedures}

Approval was first sought from the assistant principal of the high school where the study was conducted. The Institutional Review Board for the protection of Human Subjects approved the current study, and then the participants and teachers were notified two weeks in advance. Teachers and data collectors were trained during this two-week period. Participants were 
instructed on the purpose and the procedures of the study by the primary investigator. Consent forms were sent home for parent or guardian approval and assent forms were given to participants. Once consent and assent forms were collected, a date for the pretest measurements was selected by individuals involved in the research study (e.g., teachers, principal, etc.).

\section{Teachers and Data Collectors Training}

Two graduate teaching assistants not associated with the high school were selected as the instructors during this study. The teachers have teaching certificates in physical education and had experience using the SECM and multi-activity model. Both teachers had adequate knowledge in volleyball due to their experience teaching the subject either in a public school setting or in a collegiate physical education setting. The teachers took the knowledge test that the students took to confirm declarative knowledge $(M=16, S D=1.41)$, procedural knowledge $(M=13.5, S D=.71)$ and total knowledge $(M=29.5, S D=2.12)$.

The primary investigator went over the characteristics of the models with the two teachers to ensure they knew the differences. To ensure both models were followed, both teachers collaborated on lesson planning with the primary investigator so both models were followed.

The AAHPERD skill tests data collectors were trained in how to administer the tests by the primary investigator. The primary investigator conducted each skill test with instructions and demonstrations. Training included a practice data collection session using 5 college students. Two data collectors administered one skill test and then compared scores. An 80\% agreement between observers on volleyball skill tests was met to ensure competence in test administration. Interobserver scores for the skill tests administrators ranged from $99 \%$ to $100 \%$ with a mean value of $99.6 \%$. 
Prior to data collection, the primary investigator and an outside researcher were trained to analyze data for measuring game performance with the GPAI. They were trained using a 15minute videotape of volleyball games taped during a college general physical education class before the study occurred. The primary investigator and the outside researcher were trained to a minimum standard of $80 \%$ or greater agreement with each other on 3 consecutive 4 -minute segments of the videotape using the following formula: IA = agreements/(agreements + disagreements) x 100 (Kazdin, 1982).

The primary investigator was checked throughout the study for inter-observer agreement for 30 (i.e., 10 for pretest, 10 for mid-test and 10 for posttest) of the 141 game performance observations (i.e., 47 participants times three testing occasions of pretest, mid-test, and posttest). The primary investigator and the trained second observer coded game performance for the same participants during the game play episodes of each testing occasion then interobserver agreement scores were calculated. The range of interobserver agreement ranged from $80 \%$ to $100 \%$ with an average level of $91 \%$. The range met the acceptable level of $80 \%$ that was established before the investigation.

\section{Pretest, Mid-test, and Posttest}

Prior to the intervention, participants were randomly placed into either the SECM group or the EMAM group with gender being stratified. Once groups were established, the SECM group was tested on the dependent variables that consisted of skill development (i.e., serving, set-up, and passing) while the EMAM group was tested on the dependent variables of the knowledge tests (i.e., procedural and declarative knowledge). Graduate assistants and the primary investigator administered skill tests while one of the physical education teachers administered the written knowledge tests consisting of 20 declarative and 15 procedural 
questions. Participants had all the time needed to complete the test. Participants were also asked to answer two questions from the Physical Education Survey (see Appendix F) about what they liked and disliked about the physical education class. These questions provided some background on how the participants felt about their current physical education experience before the intervention. When the groups completed the skill tests or knowledge tests, they switched the next day so the EMAM group was administered the skill tests while the SECM group was administered the knowledge tests.

The third day included testing of game performance. Participants were placed on volleyball teams according to the group in which they were randomly placed (i.e., SECM or EMAM). As a method of team selection described by Siedentop (1994), a student committee worked with the physical education teacher and the primary investigator to select teams. There were six teams per class (Class $1=6$ teams, Class $2=6$ teams) with three teams being in the SECM group and three teams being in the EMAM group for each class. Teams played one game of volleyball for 15 minutes. Games were videotaped and analyzed by the primary investigator for game performance using the GPAI.

After pretesting had been completed, participants received the intervention of the curricular models.

After the tenth lesson of both models had been completed, participants were retested on the dependent variables (i.e., skill tests, knowledge test, and game performance). The same protocol of the pretest was followed during the mid-test. Posttesting of the dependent variables occurred after the $20^{\text {th }}$ lesson of both curricular models. Testing protocol followed during the pretest and mid-test stayed the same. Participants were asked to answer the last two questions of 
the physical education survey, which helped to identify what participants thought of the volleyball unit.

\section{Volleyball Units}

The units of both models were very similar in that they contained the same types of tasks. These tasks included informing, refinement, extension, and application according to the content of that particular lesson. For example, when teachers were instructing on the set, they instructed the class of the critical elements of the set followed by demonstration and checking for understanding. Students were given an informing task of the set so the teacher could observe for correct form and provide any feedback. The next task included an extension by making the task easier or more difficult depending upon the students' performance. The differences in the models were the way these tasks were presented and when the modified game play was implemented.

The 20-lesson unit of SECM contained the seven characteristics described by Siedentop (1994) (i.e., seasons, culminating event, affiliation, record keeping, formal competition, and festivity). Participants were placed on teams in which they remained during the entire unit after pretesting had been completed. Participants were assigned roles that they completed each day (see Appendix G). The teachers led the whole class in instruction after the coaches performed the coaching plan on skill development and tactical development (see Appendix $\mathrm{H}$ for unit plan). After instruction, teams practiced the lesson's focus through informing, refinement, extension and application tasks. Then a contest took place. The next phase of the SECM contained practice and scrimmages against other teams during modified application contests. Practice sessions were led by the coach with the teachers monitoring and giving feedback. Scrimmages allowed teams to compete and allowed students to perform roles (e.g., referee, and statistician). Teachers 
instructed students on how to perform roles and gave feedback to students on skills and game play. The formal competition phase of the unit contained game play with students continuing to perform roles. Teachers managed the competitions and gave feedback to students about performance. The unit ended with the culminating event, which was a tournament. Teams were ranked according to their wins and losses during the formal competition phase. The playoff tournament ended with the last day being the championship game and awards ceremony (i.e., festivity).

During the SECM, teams earned points for their team to win the overall championship. This point system (see Appendix I) was in place to ensure that games were not the main emphasis of the competition but the total sport culture. Teams earned points for wearing team colors, good behavior, executing team roles, good sportsmanship, and winning application contests. Points were also taken away for misbehavior or unsportsmanlike behavior.

The EMAM unit plan (see Appendix J) consisted of lessons of skill development, which were teacher directed followed by modified game play then a tournament with full sided teams. Teachers instructed whole classes on executing skills then gave students tasks (i.e., informing, refinement, extension, and application) to perform. Teachers provided a review of skills then introduced the new skill for that lesson. Once all skills had been taught, teachers provided a lesson of skill review. During the skill development phase of the EMAM, teachers provided feedback to students on performance. After skills were taught, participants engaged in modified game play to allow them to use the skills while learning the tactical aspect of playing volleyball (e.g., setting up the attack). This aspect was different than the traditional multi-activity model due to the length of the unit. By conducting a true multi-activity model, teachers do not have the time to teach tactical situations nor utilize modified game play. Since the EMAM unit was 
longer (i.e., 20 lessons), the extra lessons allowed teachers to work on utilizing modified game play to instruct participants how to utilize the skills learned in real game situations. But to ensure that no affiliation was taking place, participants were not on the same team for each lesson. Participants were placed on different teams until the tournament when they were placed on the teams that the student committee selected before pretesting occurred. Students kept their own scores and called their own games, but no specific roles (e.g., referees or statisticians) were assigned. Teachers monitored games and provided feedback to students about skills and rules if necessary. Lessons 18 through 20 were an end of season tournament with a championship game and consolation games played on the last day.

Intervention Verification

To ensure the curricular models were followed during the intervention phase of the study, a checklist had been developed to measure the characteristics of each curricular model (see Appendix K). An outside investigator not associated with this study was trained by the principal investigator to check the characteristics of the models on the list in which both models were followed. Training entailed the outside investigator watching four taped lessons that showed both models ( $\mathrm{SECM}=2$, EMAM = 2) with inter-observer agreement reaching $100 \%$, which was higher than the $80 \%$ that was set prior to data collection.

All lessons were videotaped, then 20 lessons (Teacher A SECM = 5, Teacher A EMAM $=5$, Teacher B SECM $=5$, Teacher B EMAM $=5$ ) were randomly sampled to ensure both models were being observed by having the outside investigator code the lessons by using the checklist to determine which model was being used. The observer was periodically checked for inter-observer agreement for $20 \%$ of the lessons that were sampled. Inter-observer agreement for 
the four lessons (i.e., 20\% of the 20 lessons sampled) was also 100\%, which was higher than the $80 \%$ that was set prior to data collection.

To ensure that the teachers were consistent when implementing the two models, 20 lessons from both teachers using both curricular models (Teacher A SECM = 5, Teacher A $\mathrm{EMAM}=5$, Teacher B SECM = 5, Teacher B EMAM = 5) were randomly selected and analyzed for teacher and student behaviors. Analysis of the lessons were evaluated using the West Virginia University Teaching Evaluation System (WVUTES), an academic learning time (ALT) based instrument (Hawkins, Wiegand, and Bahneman, 1983). This instrument is a multiple behavior coding system that allows a researcher to collect eleven teacher behaviors and eight student behaviors that occur during a lesson (see Appendix L). The system is widely used in measuring teacher and student behaviors in physical education; thus the system determined if teacher and student behaviors were similar in the lessons of both curricular models. Means and standard deviations of student behaviors are recorded in Table 4 and teacher behaviors are recorded in Table 5. The observer was trained using this system before data collection. Training entailed a series of video clips of a physical education setting in which the observer was required to achieve accuracy and reliability ratings of at least $85 \%$ with another observer for coding the behaviors. The observer was periodically checked for interobserver agreement for four of the 20 lessons (i.e., 20\%). Interobserver agreement ranged from $80 \%$ to $99 \%$ with an average level of 96\%. Interobserver agreement was calculated using the following formula: IA= agreements/(agreements + disagreements) x 100 (Kazdin, 1982). 
Table 4.

\section{Student Behaviors}

Sport Education Curricular Model

\begin{tabular}{|c|c|c|c|c|c|c|}
\hline 3ehavior & Teacher A & Teacher B & Total & Teacher A & Teacher B & Total \\
\hline ippropriate & 37.85 (8.74) & 31.01 (9.63) & 34.43 (9.39) & 31.61 (14.18) & $24.04(6.29)$ & 27.83 (11.08) \\
\hline inappropriate & $0.23(0.26)$ & $0.08(0.08)$ & $0.16(0.20)$ & $0.41 \quad(0.43)$ & $0.42(0.41)$ & $0.41(0.40)$ \\
\hline ve & $5.72(4.90)$ & 10.12 (9.39) & $7.92(7.43)$ & 13.06 (11.69) & 12.67 (9.61) & $12.86(10.09)$ \\
\hline Ipporting & $1.28(1.43)$ & 0.37 (0.71) & $0.83(1.17)$ & 1.07 (1.71) & 3.12 (3.11) & $2.09(2.60)$ \\
\hline lent & $14.08(7.20)$ & $23.96(5.48)$ & 19.02 (7.97) & $15.83(9.08)$ & $18.06(5.65)$ & $16.95(7.23)$ \\
\hline & $0.36(0.75)$ & $1.59(1.80)$ & $0.98(1.45)$ & 2.64 (3.16) & $2.47(1.60)$ & 2.55 (2.36) \\
\hline & $32.67(3.44)$ & $24.94(8.59)$ & 28.81 (7.39) & $23.58(5.91)$ & $23.07(8.46)$ & 23.32 (6.89) \\
\hline & 7.81 (3.68) & $7.93(0.73)$ & $7.87(2.50)$ & $11.80(8.92)$ & $16.15(8.41)$ & 13.98 (8.49) \\
\hline
\end{tabular}

Note. Mean $(S D)$. Expressed as percent duration. 
Table 5.

\section{Teacher Behaviors}

Sport Education Curricular Model

\begin{tabular}{|c|c|c|c|c|c|c|}
\hline \multirow[b]{2}{*}{ Behavior } & \multicolumn{3}{|c|}{ Sport Education Curricular Model } & \multicolumn{3}{|c|}{ Extended Multi-Activity Model } \\
\hline & Teacher A & Teacher B & Total & Teacher A & Teacher B & Total \\
\hline General observation & $27.24(8.20)$ & $36.99(16.61)$ & $32.11(13.37)$ & $35.52(12.39)$ & $41.17(4.92)$ & $38.34(9.37)$ \\
\hline Encouragement & $0.10(0.14)$ & $0.15(0.16)$ & $0.13(0.14)$ & $0.48(0.27)$ & $0.17(0.15)$ & $0.33(0.26)$ \\
\hline Positive Feedback & $2.01(2.11)$ & $1.14(0.74)$ & $1.57(1.56)$ & $3.01(1.03)$ & $0.95(0.69)$ & $1.98(1.37)$ \\
\hline Corrective Feedback & $0.86(2.11)$ & $1.21(0.69)$ & $1.04(0.52)$ & $0.99(0.72)$ & $1.30(0.75)$ & $1.15(0.71)$ \\
\hline Management & $36.70(8.64)$ & $31.02(7.57)$ & $33.86(8.22)$ & $23.21(6.95)$ & $18.08(10.65)$ & $20.65(8.90)$ \\
\hline Verbal instruction & $8.49(9.42)$ & $6.37(5.85)$ & $7.43(7.48)$ & $14.61(8.06)$ & $8.41(9.27)$ & $11.51(8.82)$ \\
\hline Modeling & $3.10(3.24)$ & $0.39(0.47)$ & $1.75(2.61)$ & $2.32(2.50)$ & $4.00(5.40)$ & $3.16(4.06)$ \\
\hline Physical guidance & $0.00(0.00)$ & $0(0.00)$ & $0(0.00)$ & $0(0.00)$ & $0(0.00)$ & $0(0.00)$ \\
\hline Non-task verbal & $0.19(0.22)$ & $0.14(0.19)$ & $0.17(0.19)$ & $0.16(0.19)$ & $0.05(0.12)$ & $0.11(0.16)$ \\
\hline Off task & $0.00(0.00)$ & $0(0.00)$ & $0(0.00)$ & $0(0.00)$ & $0(0.00)$ & $0(0.00)$ \\
\hline Specific observation & $21.53(3.90)$ & $22.37(12.47)$ & $21.95(8.72)$ & $19.96(8.21)$ & $19.37(3.21)$ & $19.67(5.88)$ \\
\hline
\end{tabular}

Note. Mean (SD). Expressed as percent duration but encouragement, positive feedback, and corrective feedback expressed as rate per minute.

Extended Multi-Activity Model 
The lessons of the teachers and the curricular models were analyzed with a Multivariate Analysis of Variance (MANOVA) on the eight student behaviors and a separate MANOVA on the 11 teacher behaviors. The results of student behaviors revealed no significant difference for the main effect of model, Wilks' lambda $=.40, F(8,9)=1.70, p>.05$ (ns), the main effect of teacher, Wilks' lambda $=.35, F(8,9)=2.11, p>.05$ (ns), nor the interaction effect of model $\mathrm{x}$ teacher, Wilks’ lambda $=.44, F(8,9)=1.42, p>.05(n s)$.

The results of the teacher behaviors did reveal a significant main effect for model, Wilks' lambda $=.16, F(10,7)=3.71, p<.05$, but not the main effect of teacher, Wilks' lambda $=.30$, $F(10,7)=1.67, p>.05(n s)$, nor the interaction effect of model $x$ teacher, Wilks' lambda $=.31$, $F(10,7)=1.55, p>.05(n s)$.

A separate univariate Analysis of Variance was conducted on the main effect for model to investigate any significant differences in the teacher behaviors. The only two teacher behaviors that revealed a significant difference was positive feedback, $F(1,16)=5.62, p<.05$, and verbal instruction, $F(1,16)=11.89, p<.01$. The teachers provided more positive feedback for the EMAM than the SECM. The teachers provided more verbal instruction for the SECM than the EMAM. The findings of the teacher and student behaviors reveal that the two teachers were virtually the same when implementing the models thus any changes of the dependent variables for the current investigation could be attributed to the intervention and not the teachers.

\section{Hypothesis}

The following hypotheses were based on the previous empirical and theoretical literature and the intuition of the primary investigator:

1. Participants (i.e., males and females) in the EMAM will score higher on skill tests than the SECM at the middle and end of the 20-lesson unit; 
2. Participants in the SECM model (i.e., males and females) will score higher on knowledge test scores than EMAM;

3. Participants in SECM (i.e., males and females) will have better game performance scores at the middle and end of the 20-lesson unit than the EMAM due to better decision-making and skill execution during game play;

4. Participants in SECM will enjoy the experience of the participating in this model rather than participants in EMAM.

\section{Data Analysis}

The first research question had to do with which model (i.e., SECM or EMAM) would best improve skills when utilizing skill tests. To answer this question, a Multivariate Analysis of Variance (MANOVA) was conducted in which the independent variables consist of $2 \times 2 \times 3$ (curricular model $\mathrm{x}$ gender $\mathrm{x}$ testing occasion) described previously and the dependent variables were the volleyball serve, set, and pass. To the extent that this analysis yielded a significant ( $\mathrm{p}<$ .05) finding, component Analysis of Variance (ANOVA) was calculated. To the extent that any one of these three ANOVAs yielded a significant difference $(p<.05)$, multiple comparisons for significant effects were computed by the Tukey post hoc test. Each of these ANOVAs had three main effects and four interaction effects. The significant main effects and interactions were analyzed using post hoc multiple comparisons. Accordingly, the significant main effects and interactions were parsed to identify areas of skill tests (i.e., serve, set, and pass) that are differentiated by the independent variables of the research design.

The second research question had to do with which model would best improve knowledge (i.e., declarative and procedural) of the sport of volleyball. A MANOVA again was utilized to answer this research question in which the $2 \times 2 \times 3$ research design consisted of the 
independent variables of curricular model, gender, and testing occasion and the dependent variables of the declarative and procedural while an ANOVA was utilized for total score. If the analysis yielded a significant difference for procedural and/or declarative $(\mathrm{p}<.05)$, ANOVAs were calculated for the MANOVA. If one of the three ANOVAs yielded a significant finding ( $\mathrm{p}$ $<.05$ ), a Tukey post hoc test was conducted to investigate the multiple comparisons. Each of these ANOVAs had three main effects and four interaction effects.

The third research question had to do with which model would best improve game involvement, game performance and the subscales of game performance (i.e., decision made, skill execution, and adjust). One ANOVA was utilized to answer if game involvement was affected while a separate ANOVA was conducted on game performance. A MANOVA was utilized to answer the research question consisting of the independent variables of the $2 \times 2 \times 3$ research design (i.e., curricular model $\mathrm{x}$ gender $\mathrm{x}$ testing occasion) and the dependent variables of skill execution, decision made, and adjust. If there was a significant difference ( $\mathrm{p}<.05$ ), three ANOVAs were conducted on skill execution, decision making, and adjust. If one of the five ANOVAs (i.e., game involvement, game performance, skill execution, decision making, and adjust) yielded a significant difference, a Tukey post-hoc test was utilized to investigate the multiple comparisons. The ANOVAs had three main effects and four interaction effects.

The fourth research question had to do with how participants would feel about the two models after the intervention. The primary investigator documented answers to these questions by analyzing the physical education survey. Analysis of the participants' answers was investigated for any emerging themes by groups. 


\section{CHAPTER 4}

\section{RESULTS}

The purpose of this chapter is to provide the results of the investigation dealing with the four research questions.

Research Question One

The first research question had to do with which model (i.e., SECM or EMAM) would best improve skills when utilizing skill tests. Mean scores of the volleyball skill tests are reported in Table 6.

Table 6.

Skill Test Scores

\begin{tabular}{llcccc}
\hline Group & & Pretest & Mid-test & Posttest & Total \\
\hline \multirow{2}{*}{ SECM } & Serve & $11.46(5.43)$ & $12.54(6.77)$ & $12.69(6.93)$ & $12.23(6.35)$ \\
& Set & $4.38(3.29)$ & $4.46(2.64)$ & $5.35(2.48)$ & $4.73(2.82)$ \\
& Pass & $2.19(2.17)$ & $2.73(2.09)$ & $3.23(1.70)$ & $2.72(2.02)$ \\
& Serve & $12.63(5.25)$ & $14.81(5.99)$ & $16.00(4.95)$ & $14.48(5.48)$ \\
& Set & $4.63(2.96)$ & $4.94(2.64)$ & $5.75(2.72)$ & $5.10(2.76)$ \\
& Pass & $2.38(1.86)$ & $3.19(2.26)$ & $3.13(1.71)$ & $2.90(1.95)$ \\
& Serve & $9.60(5.44)$ & $8.90(6.59)$ & $7.40(6.47)$ & $8.63(6.04)$ \\
& Set & $4.00(3.89)$ & $3.70(2.58)$ & $4.70(2.00)$ & $4.13(2.86)$ \\
& Pass & $1.90(2.69)$ & $2.00(1.63)$ & $3.40(1.78)$ & $2.43(2.13)$ \\
& Serve & $8.05(6.95)$ & $8.38(5.88)$ & $10.76(5.54)$ & $9.06(6.17)$ \\
& Set & $4.62(2.56)$ & $3.90(2.59)$ & $4.19(2.42)$ & $4.24(2.50)$
\end{tabular}


Curricular Models 58

\begin{tabular}{|c|c|c|c|c|c|}
\hline & Pass & $2.10(2.30)$ & $2.76(2.10)$ & 3.95 (3.47) & $2.94(2.76)$ \\
\hline \multirow[t]{3}{*}{ Males } & Serve & 11.73 (6.63) & 10.45 (5.35) & $14.18(4.87)$ & $12.12(5.71)$ \\
\hline & Set & $5.09(2.91)$ & $4.82(2.92)$ & 4.55 (2.73) & $4.82(2.78)$ \\
\hline & Pass & $2.55(2.54)$ & $2.73(2.15)$ & $2.64(2.25)$ & $2.64(2.25)$ \\
\hline \multirow[t]{3}{*}{ Females } & Serve & $4.00(4.88)$ & $6.10(5.82)$ & $7.00(3.43)$ & $5.70(4.81)$ \\
\hline & Set & $4.10(2.13)$ & 2.90 (1.79) & $3.80(2.10)$ & $3.60(2.01)$ \\
\hline & Pass & $1.60(2.01)$ & $2.80(2.15)$ & $5.40(4.09)$ & 3.27 (3.24) \\
\hline \multirow[t]{3}{*}{ Total } & Serve & $9.94(6.32)$ & 10.68 (6.65) & $11.83(6.35)$ & $10.82(6.45)$ \\
\hline & Set & $4.49(2.96)$ & $4.21(2.60)$ & $4.83(2.50)$ & $4.51(2.68)$ \\
\hline & Pass & $2.15(2.21)$ & 2.74 (2.07) & 3.55 (2.64) & $2.82(2.37)$ \\
\hline \multirow[t]{3}{*}{ Males } & Serve & 12.26 (5.75) & 13.04 (6.04) & $15.26(4.91)$ & $13.52(5.66)$ \\
\hline & Set & $4.81(2.90)$ & 4.89 (2.71) & $5.26(2.74)$ & $4.99(2.75)$ \\
\hline & Pass & $2.44(2.12)$ & 3.00 (2.18) & $2.93(1.92)$ & $2.79(2.07)$ \\
\hline \multirow[t]{3}{*}{ Females } & Serve & $6.80(5.79)$ & $7.50(6.22)$ & $7.20(5.04)$ & 7.17 (5.62) \\
\hline & Set & 4.05 (3.05) & $3.30(2.20)$ & $4.25(2.05)$ & 3.87 (2.47) \\
\hline & Pass & $1.75(2.31)$ & 2.40 (1.90) & $4.40(3.23)$ & $2.85(2.75)$ \\
\hline
\end{tabular}

Note. Mean $(S D)$. Participants $(N=47)$ were grouped into one of two groups, which were SECM = Sport Education Curricular Model $(n=26$; males $=16$, females $=10)$ and EMAM = Extended Multi-Activity Model $(n=21$; males $=11$, females $=10)$.

The scores for the dependent variables of the volleyball serve, pass, and set tests were analyzed with a 2 x 2 x 3 (curricular model x gender x testing occasion) Multivariate Analysis of 
Variance (MANOVA). Significant main effects were found for gender, Wilks' lambda $=.55, F$ $(3,41)=11.28, p<.01$, and time, Wilks' lambda $=.75, F(6,168)=4.25, p<.01$, but no significant main effect for group, Wilks' lambda $=.83, F(3,41)=2.83, p>.05(n s)$. There was a significant interaction for gender $\mathrm{x}$ time, Wilks' lambda $=.85, F(6,168)=2.34, p<.05$, but no significant interaction for group x gender, Wilks' lambda $=.95, F(3,41)=.75, p>.05(n s)$, group $\mathrm{x}$ time, Wilks' lambda $=.92, F(6,168)=1.16, p>.05(n s)$, or group $\mathrm{x}$ gender $\mathrm{x}$ time, Wilks' lambda $=.89, F(6,168)=1.71, p>.05(n s)$.

The significant multivariate tests were followed up with univariate Analysis of Variance (ANOVA) for each dependent variable. A gender effect was found for the serve, $F(1,43)=$ 21.15, $p<.01$ (see Figure 5), but not for the set, $F(1,43)=.42, p>.05$ (ns) nor the pass, $F(1$, 43) $=.29, p>.05(n s)$.

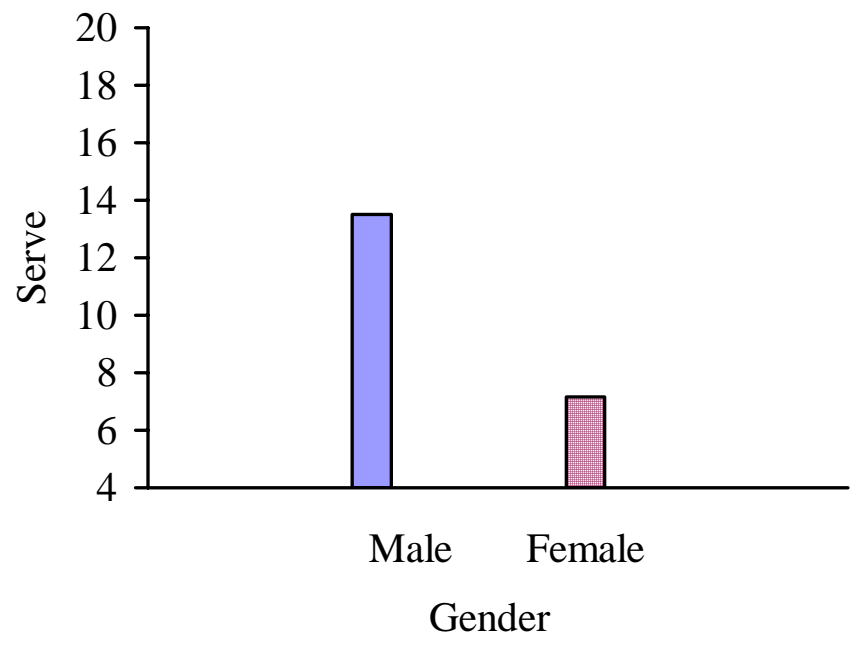

Figure 5. Serve skill test for gender, $F(1,43)=21.15, p<.01$. 
The time effect was only found for the pass, $F(2,86)=8.33, p<.01$ with a steady increase in the pass test over time (see Figure 6). A Tukey post hoc test revealed the only significant difference for time was between the pretest score and the posttest score. There was no time effect for the serve, $F(2,86)=2.08, p>.05(n s)$ or the set, $F(2,86)=1.04, p>.05(n s)$.

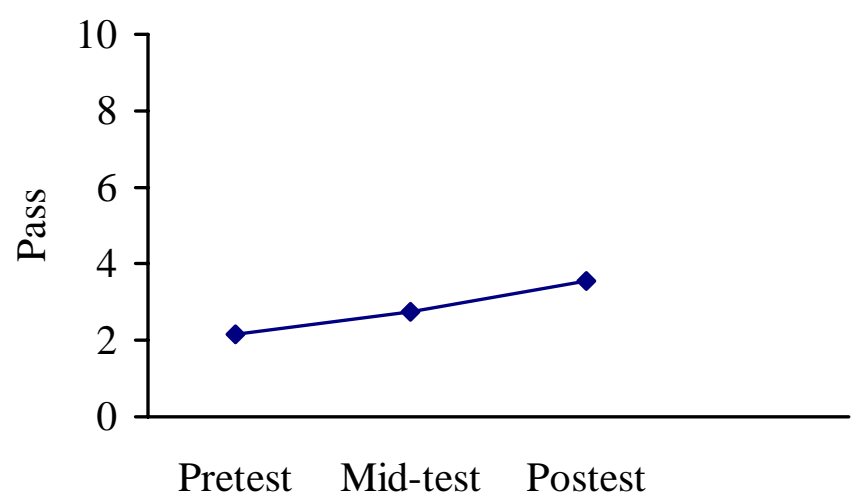

Time

Figure 6. Pass skill test for time, $F(2,86)=8.33, p<.01$.

The gender $\mathrm{x}$ time interaction effect was only found for the pass, $F(2,86)=5.27, p<.01$ (see Figure 7) and not the serve, $F(2,86)=1.61, p>.05(n s)$ or the set, $F(2,86)=1.37, p>.05$ (ns). 


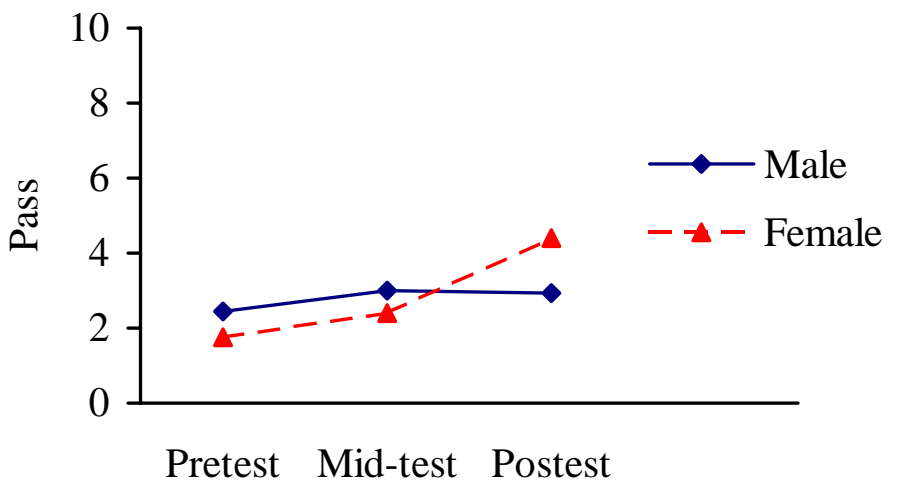

Time

Figure 7. Pass skill test for gender $\mathrm{x}$ time, $F(2,86)=5.27, p<.01$.

The gender $\mathrm{x}$ time interaction for the pass was broken down for multiple comparisons using the Tukey post hoc test. The multiple comparisons revealed a significant difference for the females from the mid-test and posttest comparison along with a significant difference from the pretest and posttest comparison. There was also a significant difference in the posttest scores of males to females of the pass skill test with the females outperforming the males on the pass skill test. Other multiple comparisons did not reveal any significant differences.

Although there were main effects (i.e., gender and time) and an interaction effect (i.e., gender $\mathrm{x}$ time), one must be aware that the interaction of group $\mathrm{x}$ time and group $\mathrm{x}$ gender $\mathrm{x}$ time are the effects that this investigation was most interested in due to the research question. There was no group $\mathrm{x}$ time interaction effect, which suggests that one group (i.e., SECM and EMAM) did not statistically outperform the other. However, the data is conceptually interesting in light 
of the research question but it was not statistically meaningful. The SECM group $(n=26)$ and the EMAM group $(n=21)$ did show a slight improvement in the serve skill tests across time (see Figure 8) along with a slight improvement in the set (see Figure 9) and the pass (see Figure 10).

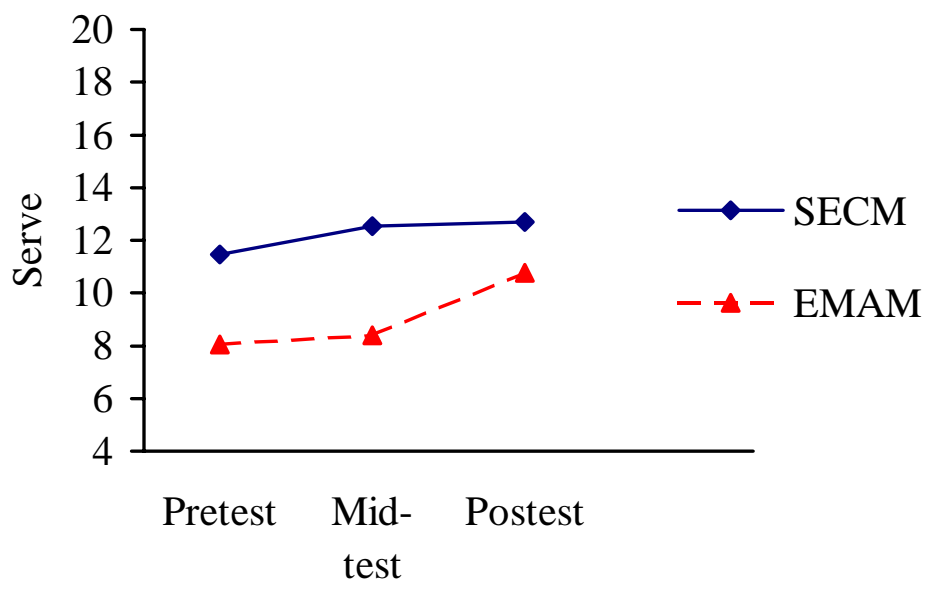

Time

Figure 8. Serve skill test for group x time, Wilks' lambda $=.92, F(6,168)=1.16, p>.05(n s)$.

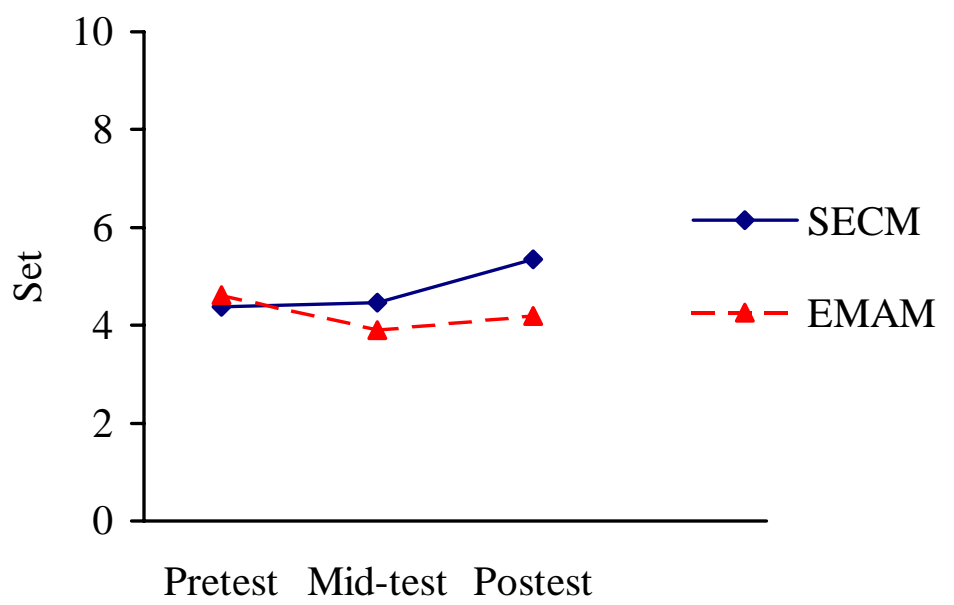

Time

Figure 9. Set skill test for group x time, Wilks’ lambda $=.92, F(6,168)=1.16, p>.05$ (ns). 


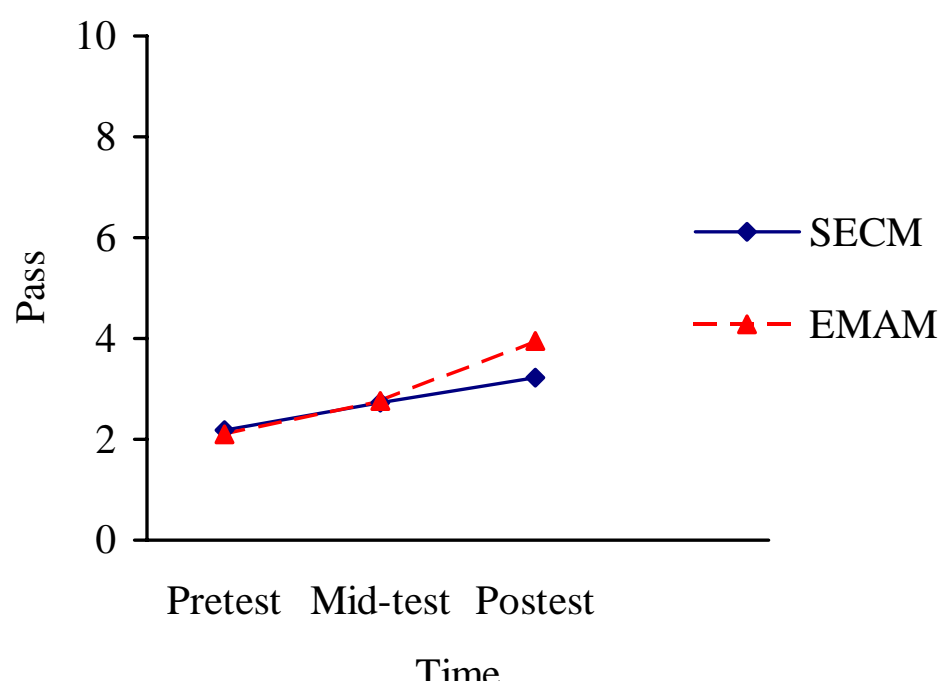

Figure 10. Pass skill test for group $\mathrm{x}$ time, Wilks' lambda $=.92, F(6,168)=1.16, p>.05$ (ns).

There was also no interaction effect for group $\mathrm{x}$ gender $\mathrm{x}$ time possibly due to the small sample size in each of the cells. The SECM males $(n=16)$ showed some improvement over time while the EMAM males $(n=11)$ had a decrease from pretest to mid-test but rebounded with an increase during the posttest of the serve skill test. As for the females, the SECM females ( $n=$ 10) did worse on the serve test over time while the EMAM females $(n=10)$ slightly improved over time (see Figure 11). 


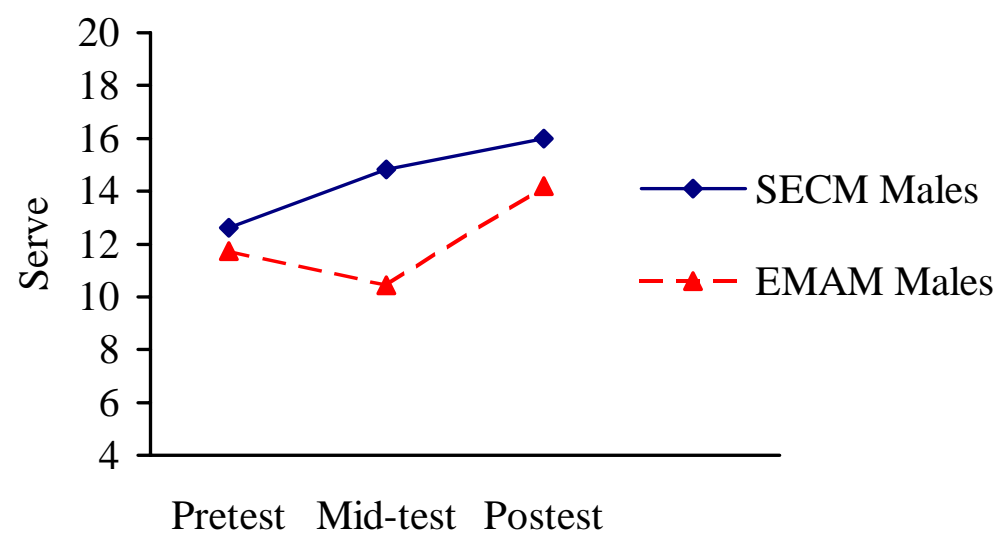

Time

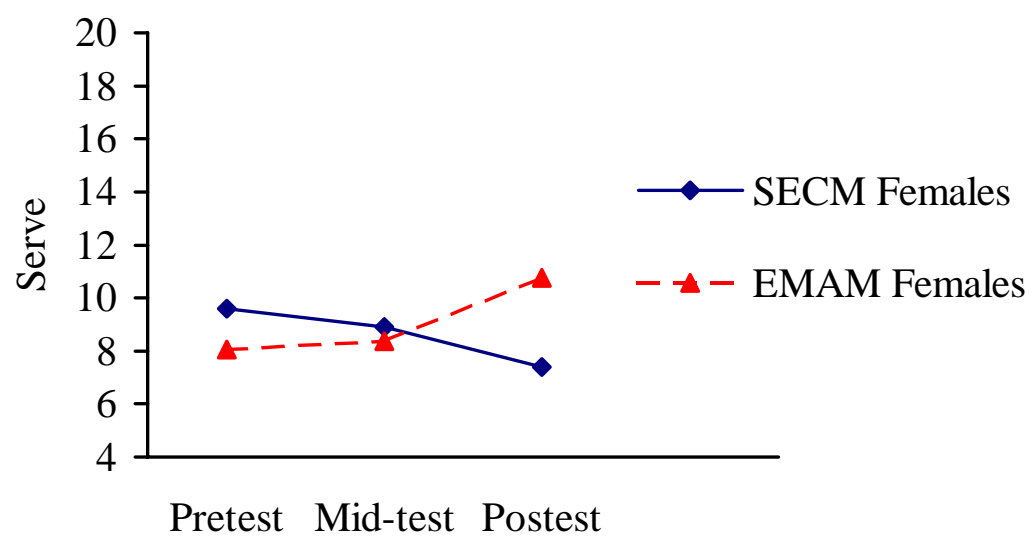

Time

Figure 11. Serve test for group x gender $\mathrm{x}$ time, Wilks' lambda $=.89, F(6,168)=1.71, p>.05$ (ns).

The SECM males showed a steady increase in the set skill test while the EMAM males showed a steady decline in the set skill test over time. The SECM females had a slight improvement from the pretest to the posttest while the EMAM females actually decreased from the pretest to posttest (see Figure 12). 
Curricular Models 65

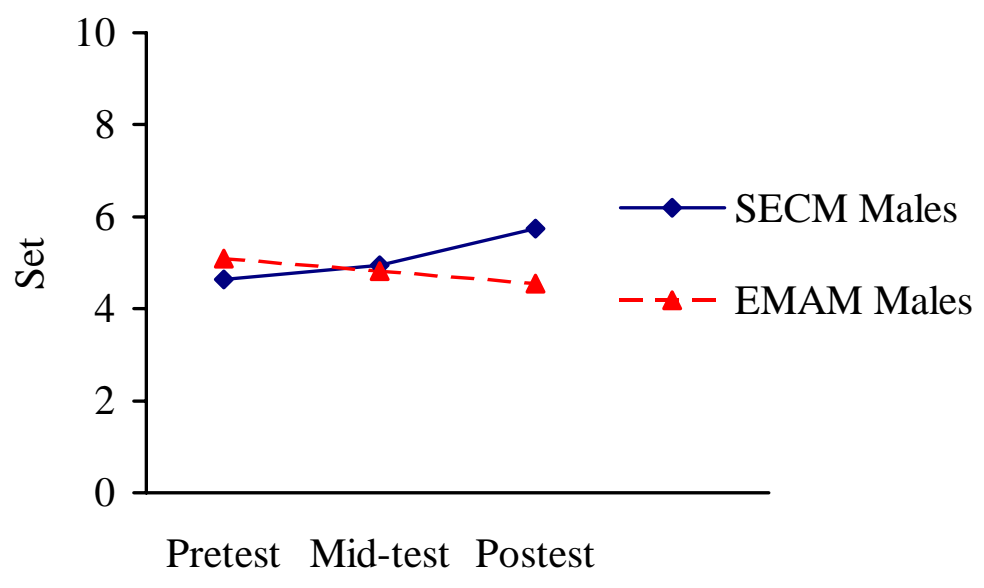

Time

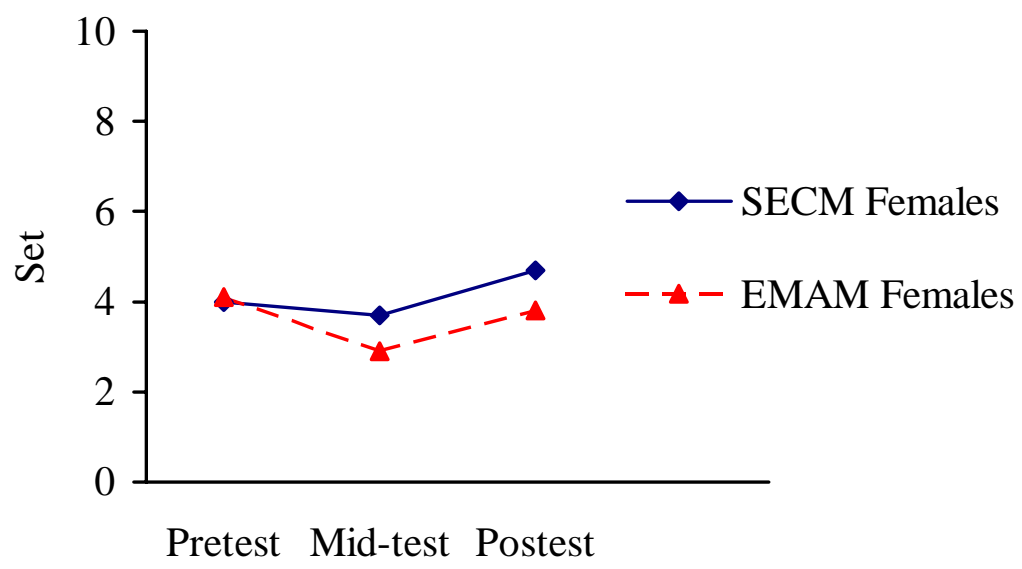

Time

Figure 12. Set skill test for group $\mathrm{x}$ gender $\mathrm{x}$ time, Wilks' lambda $=.89, F(6,168)=1.71, p>$ $.05(n s)$.

When measuring the pass skill test, both groups of males only slightly improved over time while the females showed a steady increase although non-significant (see Figure 13). 


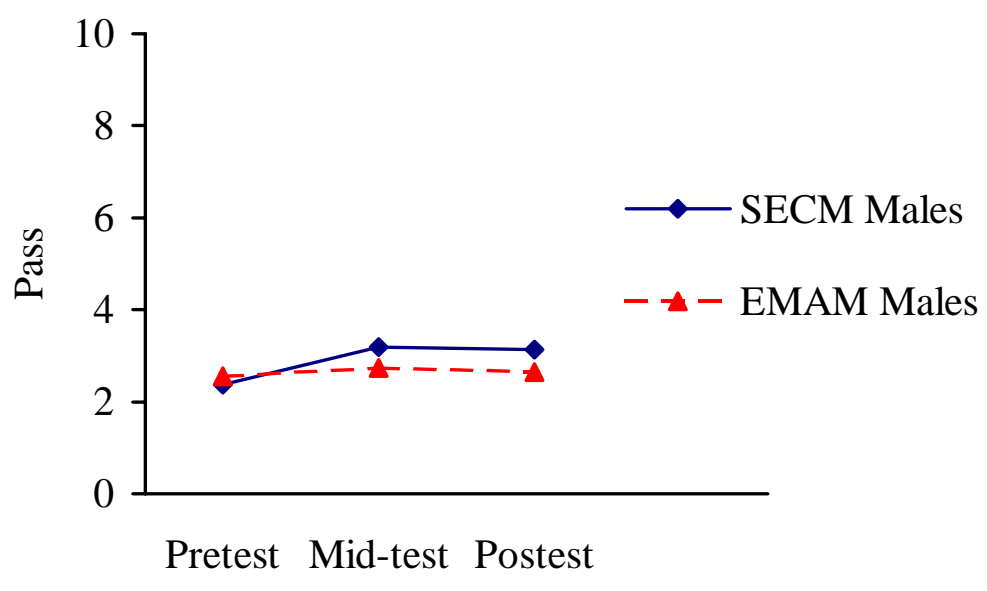

Time

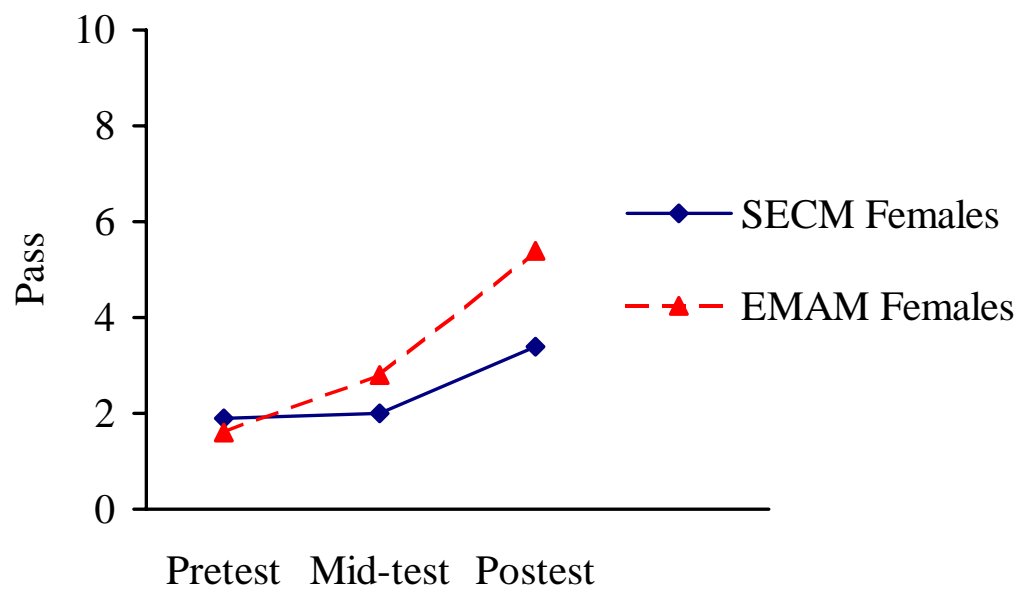

Time

Figure 13. Pass skill test for group $\mathrm{x}$ gender $\mathrm{x}$ time, Wilks' lambda $=.89, F(6,168)=1.71, p>$ $.05(n s)$.

As for the research question, both models did have some skill improvement over time but one must be aware that there was no significance for the group $\mathrm{x}$ time interaction or the group $\mathrm{x}$ gender $\mathrm{x}$ time interaction. If one would want to promote significant skill improvement when 
utilizing skill tests, neither model provided sufficient evidence that one of them was superior to the other.

\section{Research Question Two}

The second research question had to do with which model would best improve knowledge (i.e., declarative and procedural) of the sport of volleyball. The knowledge test consisted of 35 multiple-choice questions that were subdivided into declarative knowledge questions (i.e., first 20 questions) and procedural knowledge questions (i.e., last 15 questions). Mean scores of the knowledge test scores (i.e., declarative, procedural, and total knowledge test) are located in Table 7.

Table 7.

Knowledge Test Scores

\begin{tabular}{llcccc}
\hline \multirow{2}{*}{ Group } & & Pretest & Mid-test & Posttest & Total \\
\hline \multirow{2}{*}{ SECM } & Declarative & $6.35(1.90)$ & $8.04(3.32)$ & $7.23(2.76)$ & $7.21(2.77)$ \\
& Procedural & $4.96(2.01)$ & $5.08(1.98)$ & $5.50(2.23)$ & $5.18(2.06)$ \\
& $\begin{array}{l}\text { Knowledge } \\
\text { Males }\end{array}$ & $11.31(3.04)$ & $13.11(4.49)$ & $12.73(4.38)$ & $12.38(4.05)$ \\
& Test Score & & & & \\
& Declarative & $6.63(2.00)$ & $7.94(3.66)$ & $7.19(2.97)$ & $7.25(2.94)$ \\
& Procedural & $4.69(1.92)$ & $4.38(1.89)$ & $5.44(1.93)$ & $4.83(1.93)$ \\
& $\begin{array}{l}\text { Knowledge } \\
\text { Test Score }\end{array}$ & $11.31(3.38)$ & $12.31(5.08)$ & $12.63(4.44)$ & $12.08(4.30)$ \\
& & & & & \\
Females & Declarative & $5.90(1.73)$ & $8.20(2.86)$ & $7.30(2.54)$ & $7.13(2.53)$ \\
& Procedural & $5.40(2.17)$ & $6.20(1.62)$ & $5.60(2.76)$ & $5.73(2.18)$
\end{tabular}




\begin{tabular}{|c|c|c|c|c|c|}
\hline & $\begin{array}{l}\text { Knowledge } \\
\text { Test Score }\end{array}$ & $11.30(2.58)$ & 14.40 (3.17) & $12.90(4.51)$ & 12.87 (3.63) \\
\hline \multirow[t]{3}{*}{ EMAM } & Declarative & 6.57 (2.91) & $7.52(2.86)$ & 7.90 (3.16) & 7.33 (2.98) \\
\hline & Procedural & 3.90 (1.92) & $4.62(1.56)$ & 4.52 (1.75) & 4.35 (1.75) \\
\hline & $\begin{array}{l}\text { Knowledge } \\
\text { Test Score }\end{array}$ & $10.48(4.08)$ & $12.14(3.24)$ & $12.43(4.27)$ & 11.68 (3.93) \\
\hline \multirow[t]{3}{*}{ Males } & Declarative & $6.55(1.86)$ & $6.91(2.34)$ & 6.82 (3.09) & $6.76(2.41)$ \\
\hline & Procedural & $3.36(1.80)$ & $4.27(1.42)$ & $3.64(1.86)$ & $3.76(1.70)$ \\
\hline & $\begin{array}{l}\text { Knowledge } \\
\text { Test Score }\end{array}$ & $9.91(2.55)$ & 11.18 (1.83) & 10.45 (4.08) & $10.52(2.93)$ \\
\hline \multirow[t]{3}{*}{ Females } & Declarative & $6.60(3.86)$ & $8.20(3.33)$ & $9.10(2.92)$ & $7.97(3.44)$ \\
\hline & Procedural & $4.50(1.96)$ & $5.00(1.70)$ & $5.50(0.97)$ & $5.00(1.60)$ \\
\hline & $\begin{array}{l}\text { Knowledge } \\
\text { Test Score }\end{array}$ & 11.10 (5.38) & $13.20(4.16)$ & $14.60(3.47)$ & $12.97(4.50)$ \\
\hline \multirow[t]{3}{*}{ Total } & Declarative & $6.45(2.38)$ & $7.81(3.10)$ & 7.53 (2.93) & $7.26(2.86)$ \\
\hline & Procedural & $4.49(2.02)$ & $4.87(1.80)$ & $5.06(2.07)$ & $4.81(1.97)$ \\
\hline & $\begin{array}{l}\text { Knowledge } \\
\text { Test Score }\end{array}$ & 10.94 (3.53) & 12.68 (3.97) & $12.60(4.29)$ & $12.07(4.00)$ \\
\hline \multirow[t]{3}{*}{ Males } & Declarative & 6.59 (1.91) & 7.52 (3.18) & 7.04 (2.97) & 7.05 (2.73) \\
\hline & Procedural & 4.15 (1.96) & 4.33 (1.69) & $4.70(2.07)$ & 4.40 (1.90) \\
\hline & $\begin{array}{l}\text { Knowledge } \\
\text { Test Score }\end{array}$ & $10.74(3.10)$ & $11.85(4.06)$ & $11.74(4.36)$ & $11.44(3.86)$ \\
\hline \multirow[t]{2}{*}{ Females } & Declarative & 6.25 (2.94) & 8.20 (3.02) & $8.20(2.82)$ & 7.55 (3.02) \\
\hline & Procedural & 4.95 (2.06) & $5.60(1.73)$ & $5.55(2.01)$ & 5.37 (1.93) \\
\hline
\end{tabular}


Knowledge

$11.20(4.11)$

$13.80(3.65)$

$13.75(4.01)$

$12.92(4.05)$

Test Score

Note. Mean $(S D)$. Participants $(N=47)$ were grouped into one of two groups, which were SECM = Sport Education Curricular Model $(n=26)$ and EMAM = Extended Multi-Activity Model $(n=21)$.

A 2 x 2 x 3 (curricular model $\times$ gender $\mathrm{x}$ testing occasion) MANOVA was utilized to investigate any differences in the dependent variables of the declarative and procedural scores. Significant main effects were found for group, Wilks' lambda $=.78, F(2,42)=5.90, p<.01$, gender, Wilks' lambda $=.80, F(2,42)=5.33, p<.01$, and time, Wilks' lambda $=.88, F(4,170)$ $=2.92, p<.05$. There were no interaction effects for group $\mathrm{x}$ gender, Wilks' lambda $=.98, F(2$, $42)=.52, p>.05(n s)$, group $x$ time, Wilks' lambda $=.97, F(4,170)=.57, p>.05(n s)$, gender $\mathrm{x}$ time, Wilks' lambda $=.97, F(4,170)=.75, p>.05(n s)$, or group $\mathrm{x}$ gender $\mathrm{x}$ time, Wilks' lambda $=.96, F(4,170)=.98, p>.05(n s)$ of the dependent variables of declarative and procedural scores.

Significant multivariate tests were followed up with univariate ANOVAs for each dependent variable of declarative and procedural scores. Procedural scores were significant for the group main effect, $F(1,43)=6.56, p<.05$ with the SECM group performing better than the EMAM group (see to Figure 14) but no main effect was found for declarative scores, $F(1,43)=$ $.06, p>.05(n s)$. 


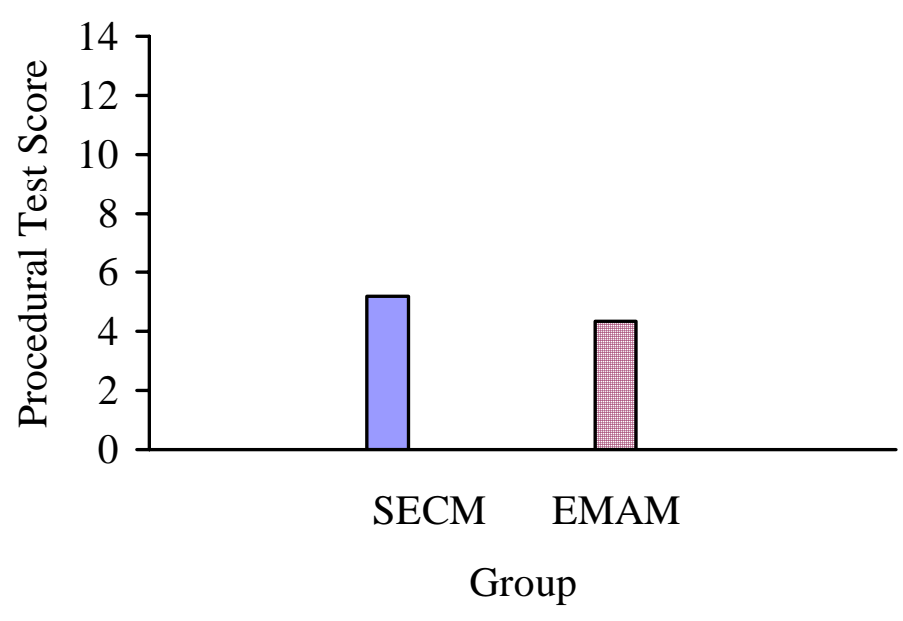

Figure 14. Procedural test scores for group, $F(1,43)=6.56, p<.05$.

Procedural scores were also significant for the gender main effect, $F(1,43)=9.13, p<$ .01 with females performing better than males (see Figure 15), but no gender effect on declarative scores, $F(1,43)=.69, p>.05(n s)$. 


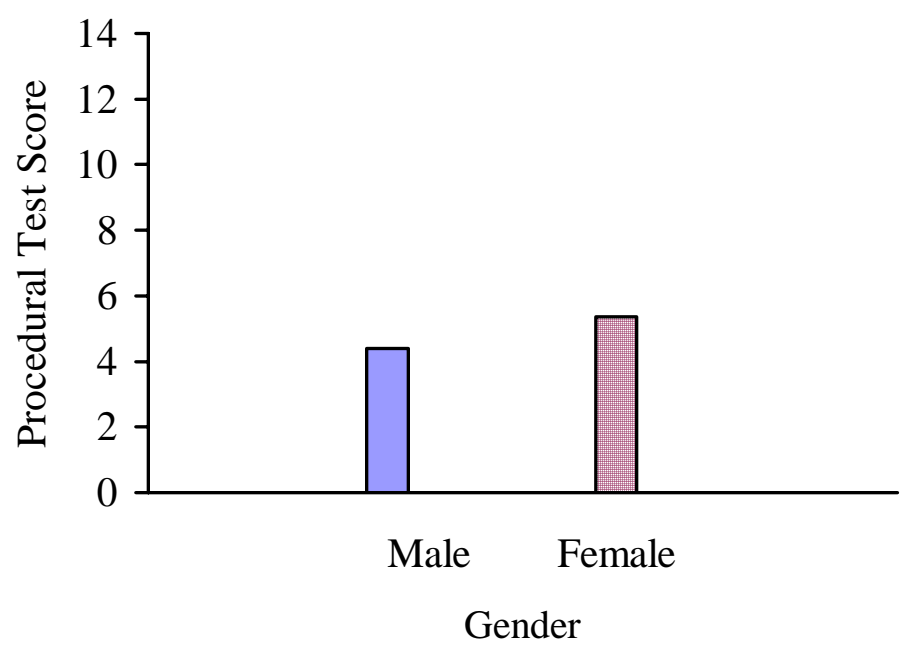

Figure 15. Procedural test scores for gender, $F(1,43)=9.13, p<.01$.

Time effect was found to be significant on the declarative scores, $F(2,86)=5.18, p<.01$ (see Figure 16) but not procedural scores, $F(2,86)=1.29, p>.05$ (ns). A Tukey post hoc analysis revealed a significant difference between the pretest and mid-test scores but no other significant differences for the other multiple comparisons.

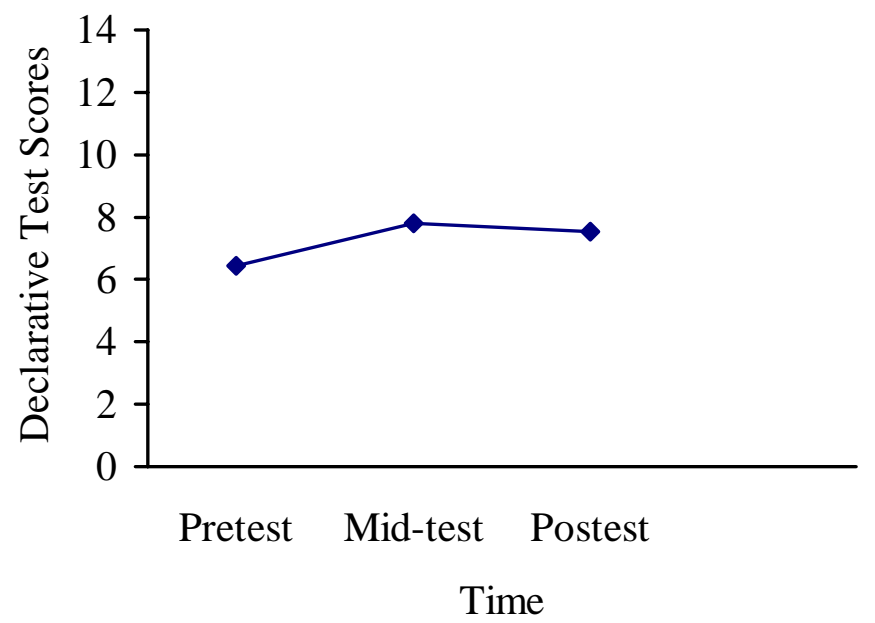

Figure 16. Declarative test scores for time, $F(2,86)=4.93, p<.01$. 
A 2 × 2 × 3 (curricular model x gender x testing occasion) ANOVA was calculated for the total knowledge test score. The only significant main effect was for time, $F(2,86)=5.20, p$ $<.01$ (see Figure 17). A Tukey post hoc test revealed a significant difference between the pretest and mid-test along with a difference in the pretest and posttest scores.

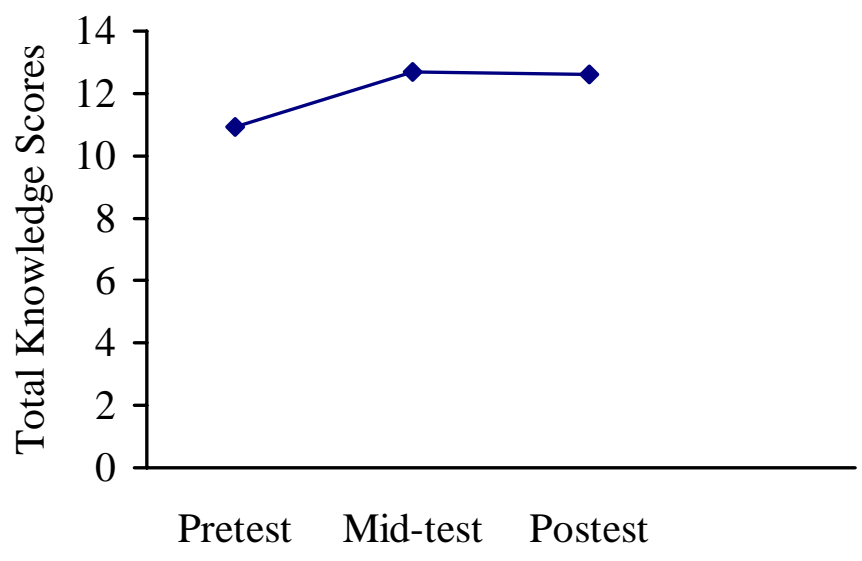

Time

Figure 17. Total knowledge test scores for time, $F(2,86)=5.20, p<.01$.

There were no significant differences in total knowledge scores for the main effects of group, $F(1,43)=.66, p>.05(n s)$ and gender, $F(1,43)=3.10, p>.05(n s)$. There were no significant interactions effects for group x gender, $F(1,43)=.83, p>.05(n s)$, group $\mathrm{x}$ time, $F$ $(2,86)=.27, p>.05(n s)$, gender $x$ time, $F(2,86)=1.03, p>.05(n s)$, or group $x$ gender $x$ time, $F(2,86)=1.31, p>.05(n s)$.

Although there were no group $\mathrm{x}$ time or group $\mathrm{x}$ gender $\mathrm{x}$ time interactions for any of the dependent variables of the knowledge test, it is conceptually interesting when dealing with the research question. As for the declarative knowledge, both groups had slight improvements over time (see Figure 18). 
Curricular Models 73

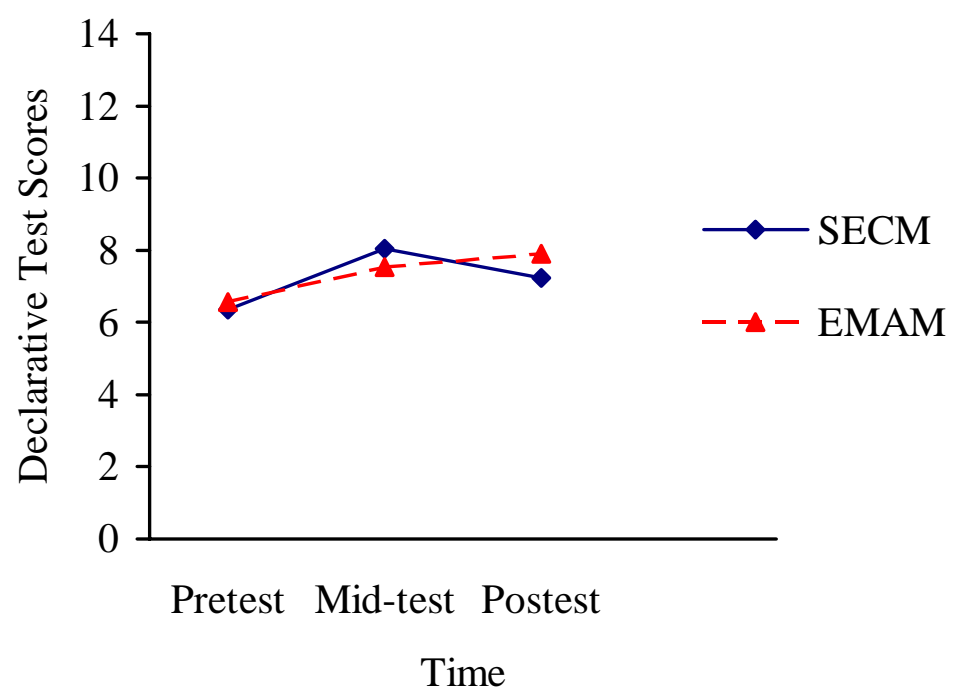

Figure 18. Declarative test scores for group $\mathrm{x}$ time, Wilks' lambda $=.97, F(4,170)=.57, p>$ $.05(n s)$.

As for the procedural test scores for both groups, the SECM only had a slight improvement from the pretest $(M=4.96, S D=2.01)$ to the posttest $(M=5.50, S D=2.23)$ while the EMAM group had their highest mean score on the mid-test $(M=4.62, S D=1.56)$ compared to the mean score of the pretest $(M=3.90, S D=1.92$; see Figure 19$)$. 


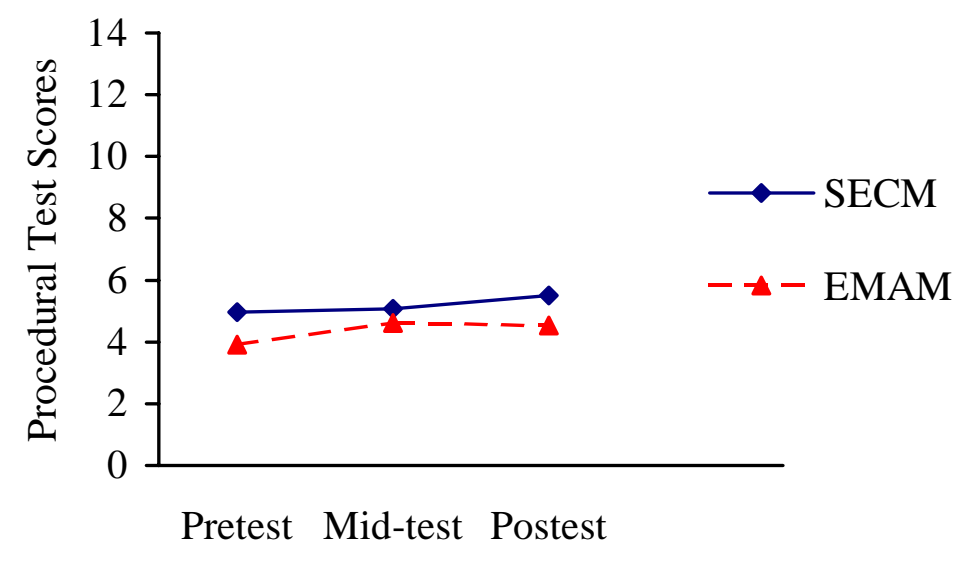

Time

Figure 19. Procedural test scores for group x time, Wilks’ lambda $=.97, F(4,170)=.57, p>$ .05 (ns).

The total score for the SECM group and EMAM group revealed that both groups had slight improvements over time with the EMAM group actually gaining near the SECM group on the posttest (see Figure 20).

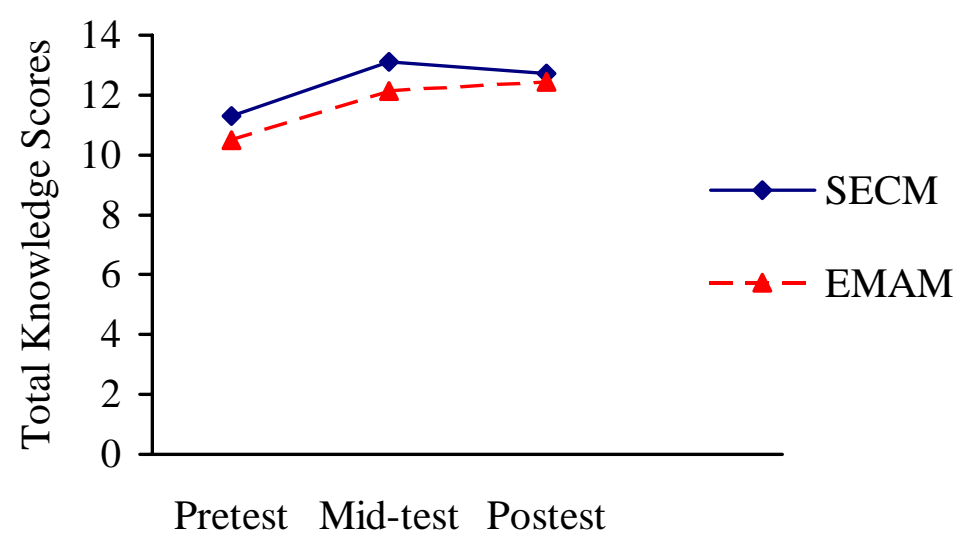

Time

Figure 20. Total knowledge test scores for group x time, $F(2,86)=.27, p>.05(n s)$. 
When the groups are sorted by gender, both groups of males (i.e., SECM males and EMAM males) had very little improvement for the declarative test scores. The EMAM females did better across time on the declarative test while the SECM females performed just as well on the mid-test but had a decline on the posttest (see Figure 21).

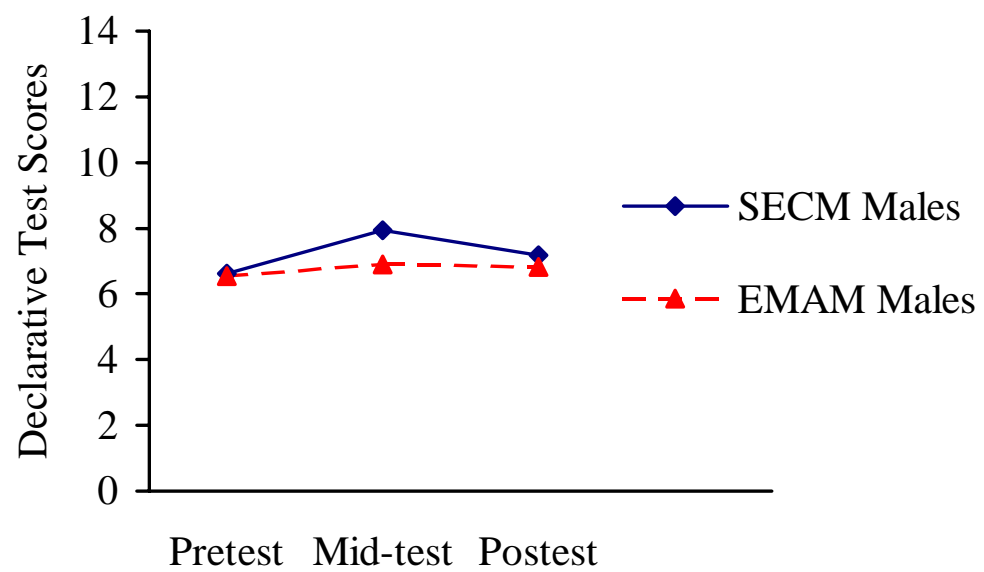

Time

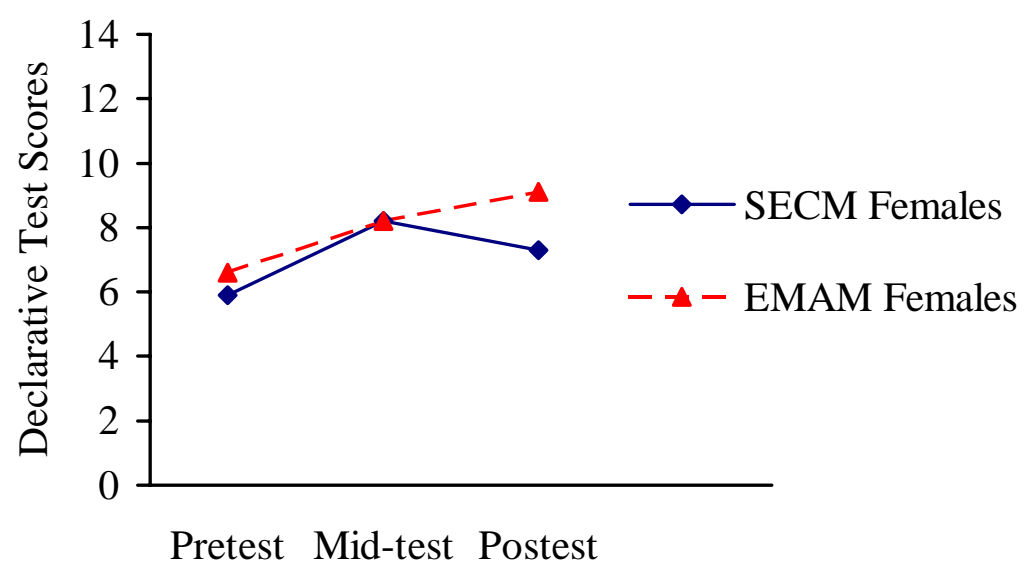

Time

Figure 21. Declarative test scores for group $\mathrm{x}$ gender $\mathrm{x}$ time, Wilks' lambda $=.96, F(4,170)=$ $.98, p>.05(n s)$. 
For the procedural test scores, the SECM males had a slight decrease in scores for the mid-test but they were able to improve their procedural score on the posttest. The EMAM males improved on the mid-test but faltered on the posttest. For the females, both groups had a steady increase in procedural test scores at the mid-test but the SECM females declined on the posttest while the EMAM females were able to increase their scores (see Figure 22).

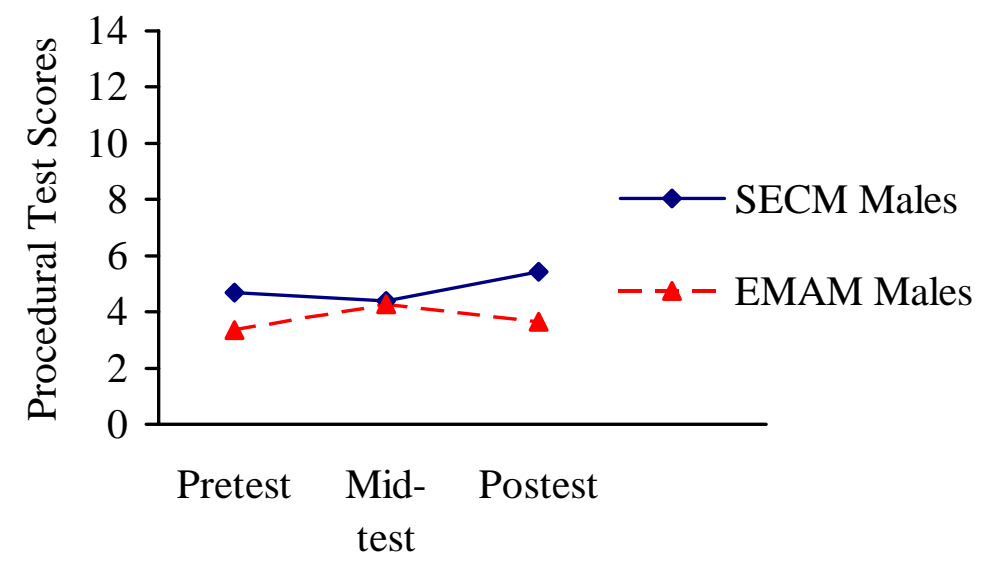

Time

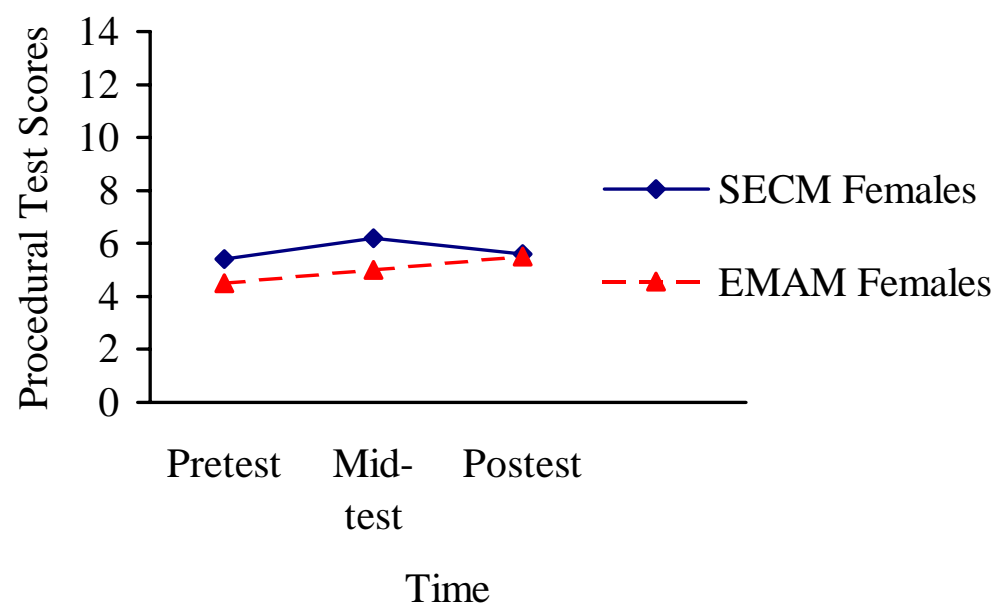

Figure 22. Procedural test scores for group $\mathrm{x}$ gender $\mathrm{x}$ time, Wilks' lambda $=.96, F(4,170)=$ $.98, p>.05(n s)$. 
The total knowledge score revealed that the SECM males had a slight increase in scores while the EMAM males had an increase that paralleled SECM at the mid-test but there was a decrease in the posttest. The SECM females improved only at the mid-test followed by a decline in total scores while the EMAM females had a steady increase in the total score across time (see Figure 23).

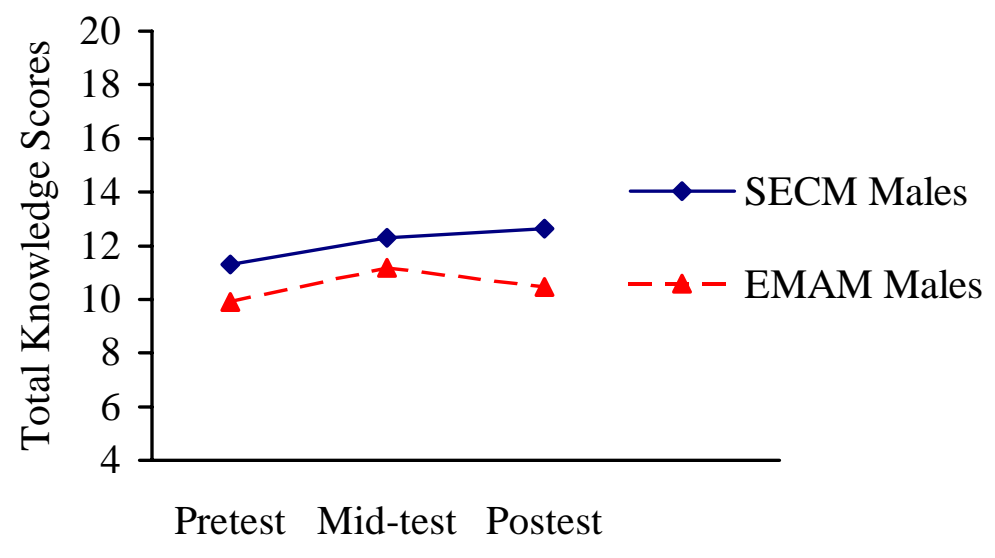

Time

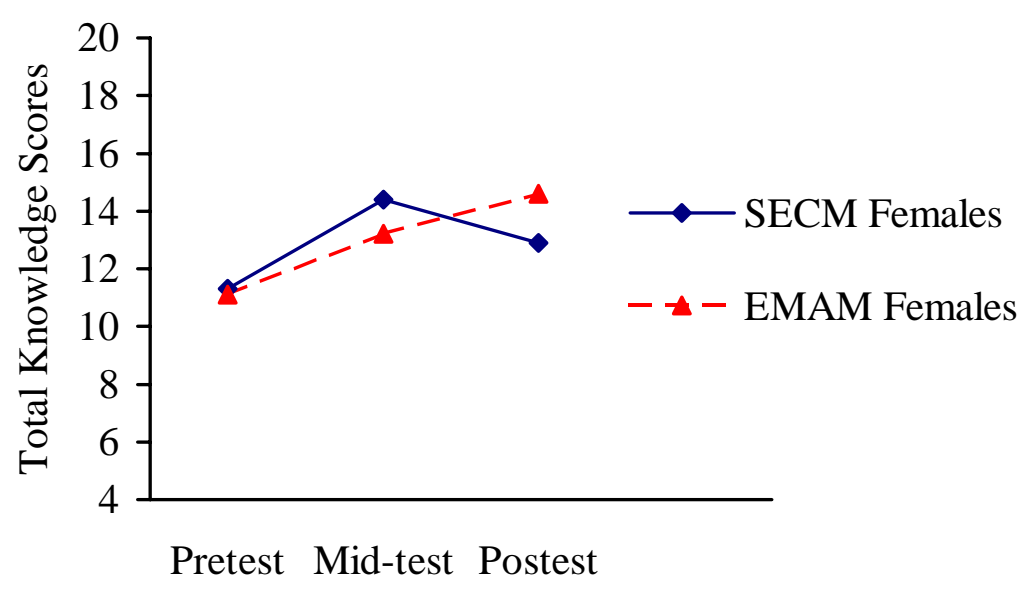

Time

Figure 23. Total knowledge test scores for group $\mathrm{x}$ gender $\mathrm{x}$ time, $F(2,86)=1.31, p>.05(n s)$. 
The research question asked which curricular model would best improve volleyball knowledge. Both groups improved some knowledge, but the scores were not large enough to find a significant interaction of group $\mathrm{x}$ time or group $\mathrm{x}$ gender $\mathrm{x}$ time so neither model was able to promote volleyball knowledge to a significant level.

\section{Research Question Three}

The third research question had to do with which model would best improve game involvement, game performance and the subscales of game performance (i.e., decision made, skill execution, and adjust). Game performance was measured via videotapes using the Game Performance Assessment Instrument. Means and standard deviations of the dependent variables of game involvement, decision made, skill execution, adjust, and game performance are reported in Table 8.

The scores of the dependent variables of decision made, skill execution, and adjust were analyzed utilizing a 2 x 2 x 3 (curricular model x gender x testing occasion) MANOVA. Significant main effects were found for the group, Wilks' lambda $=.81, F(3,41)=3.25, p<.05$, gender, Wilks' lambda $=.81, F(3,41)=3.29, p<.05$, and time, Wilks’ lambda $=.80, F(6,168)$ $=3.27, p<.01$. There was also an interaction effect for group $\mathrm{x}$ time, Wilks' lambda $=.81, F(6$, $168)=3.08, p<.01$. There were no interaction effects for group $\mathrm{x}$ gender, Wilks' lambda $=.84$, $F(3,41)=2.69, p>.05(n s)$, gender $x$ time, Wilks’ lambda $=.91, F(6,168)=1.35, p>.05(n s)$, or group x gender $\mathrm{x}$ time, Wilks’ lambda $=.88, F(6,168)=1.79, p>.05(n s)$.

Significant multivariate tests were followed up with univariate ANOVAs for each dependent variable of decision made, skill execution, and adjust. There was a significant 
Table 8.

Game Performance Scores

\begin{tabular}{|c|c|c|c|c|c|}
\hline Group & & Pretest & Mid-test & Posttest & Total \\
\hline \multirow[t]{5}{*}{ SECM } & $\begin{array}{l}\text { Game } \\
\text { Involvement }\end{array}$ & $18.77(15.21)$ & $21.46(15.64)$ & 19.27 (12.97) & 19.83 (14.51) \\
\hline & Decision Made & $2.09(2.07)$ & 4.65 (3.63) & $4.09(4.48)$ & 3.61 (3.66) \\
\hline & Skill Execution & $0.89(0.79)$ & $2.38(2.61)$ & $2.53(2.26)$ & $1.93(2.15)$ \\
\hline & Adjust & $2.60(2.13)$ & $3.50(1.94)$ & $3.50(1.82)$ & 3.20 (1.99) \\
\hline & $\begin{array}{l}\text { Game } \\
\text { Performance }\end{array}$ & $1.86(1.14)$ & 3.51 (1.67) & 3.33 (1.87) & $2.90(1.74)$ \\
\hline \multirow[t]{5}{*}{ Males } & $\begin{array}{l}\text { Game } \\
\text { Involvement }\end{array}$ & $24.63(16.42)$ & $27.13(17.44)$ & $24.50(13.25)$ & $25.42(15.51)$ \\
\hline & Decision Made & 1.97 (1.97) & $5.42(4.10)$ & $5.03(5.40)$ & 4.14 (4.28) \\
\hline & Skill Execution & $0.98(0.65)$ & $3.22(3.00)$ & $3.44(2.24)$ & $2.55(2.42)$ \\
\hline & Adjust & $3.44(2.19)$ & $4.13(2.03)$ & $3.88(2.13)$ & 3.81 (2.09) \\
\hline & $\begin{array}{l}\text { Game } \\
\text { Performance }\end{array}$ & $2.13(1.12)$ & $4.25(1.65)$ & $4.05(1.90)$ & $3.48(1.83)$ \\
\hline \multirow[t]{5}{*}{ Females } & $\begin{array}{l}\text { Game } \\
\text { Involvement }\end{array}$ & $9.40(5.85)$ & $12.40(4.95)$ & $10.90(6.97)$ & $10.90(5.90)$ \\
\hline & Decision Made & $2.28(2.32)$ & $3.42(2.41)$ & $2.60(1.78)$ & 2.77 (2.16) \\
\hline & Skill Execution & $0.75(1.00)$ & $1.05(0.82)$ & $1.07(1.42)$ & 0.95 (1.08) \\
\hline & Adjust & $1.25(1.14)$ & $2.50(1.35)$ & $2.90(0.99)$ & $2.22(1.34)$ \\
\hline & $\begin{array}{l}\text { Game } \\
\text { Performance }\end{array}$ & $1.43(1.09)$ & $2.32(0.80)$ & $2.19(1.15)$ & 1.98 (1.07) \\
\hline
\end{tabular}




\begin{tabular}{|c|c|c|c|c|c|}
\hline \multirow[t]{5}{*}{ EMAM } & $\begin{array}{l}\text { Game } \\
\text { Involvement }\end{array}$ & 15.38 (11.43) & 21.76 (17.54) & 15.62 (13.14) & 17.59 (14.36) \\
\hline & Decision Made & $2.18(2.36)$ & $2.99(1.61)$ & $2.46(2.46)$ & $2.54(2.17)$ \\
\hline & Skill Execution & $0.92(1.17)$ & 1.04 (1.19) & $1.09(0.88)$ & $1.02(1.07)$ \\
\hline & Adjust & 2.50 (1.94) & 2.02 (1.89) & $1.48(1.58)$ & $2.00(1.83)$ \\
\hline & $\begin{array}{l}\text { Game } \\
\text { Performance }\end{array}$ & $1.87(1.14)$ & $2.02(0.94)$ & 1.68 (1.39) & $1.85(1.16)$ \\
\hline \multirow[t]{5}{*}{ Males } & $\begin{array}{l}\text { Game } \\
\text { Involvement }\end{array}$ & 19.64 (13.65) & 27.45 (18.73) & 20.55 (15.37) & 22.55 (15.95) \\
\hline & Decision Made & $1.25(0.78)$ & $3.11(1.44)$ & $1.75(1.74)$ & $2.04(1.56)$ \\
\hline & Skill Execution & $1.28(1.28)$ & $1.05(0.88)$ & $1.03(0.85)$ & $1.12(1.00)$ \\
\hline & Adjust & $2.82(2.36)$ & $2.31(1.65)$ & $1.55(1.35)$ & $2.22(1.86)$ \\
\hline & $\begin{array}{l}\text { Game } \\
\text { Performance }\end{array}$ & $1.78(1.02)$ & $2.16(0.66)$ & 1.44 (1.13) & $1.79(0.98)$ \\
\hline \multirow[t]{5}{*}{ Females } & $\begin{array}{l}\text { Game } \\
\text { Involvement }\end{array}$ & 10.70 (6.07) & $15.50(14.54)$ & 10.20 (7.67) & $12.13(10.06)$ \\
\hline & Decision Made & $3.20(3.08)$ & $2.85(4.16)$ & 3.23 (2.97) & $3.09(2.61)$ \\
\hline & Skill Execution & $0.52(0.92)$ & $1.03(1.50)$ & $1.17(0.96)$ & $0.91(1.15)$ \\
\hline & Adjust & $2.15(1.38)$ & $1.70(2.16)$ & $1.42(1.87)$ & $1.76(1.80)$ \\
\hline & $\begin{array}{l}\text { Game } \\
\text { Performance }\end{array}$ & $1.96(1.30)$ & $1.86(1.20)$ & $1.94(1.64)$ & $1.92(1.35)$ \\
\hline
\end{tabular}

Total

$\begin{array}{lcccc}\text { Game } & 17.26(13.62) & 21.60(16.34) & 17.64(13.03) & 18.83(14.43) \\ \text { Involvement } & & & & \\ \text { Decision Made } & 2.13(2.18) & 3.91(3.00) & 3.36(3.77) & 3.13(3.12) \\ \text { Skill Execution } & 0.90(0.97) & 1.78(2.18) & 1.89(1.91) & 1.52(1.81) \\ \text { Adjust } & 2.55(2.02 & 2.84(2.04) & 2.60(1.98) & 2.66(2.00)\end{array}$


Game $\quad 1.86(1.13) \quad 2.84(1.57) \quad 2.59(1.85) \quad 2.43(1.59)$

Performance

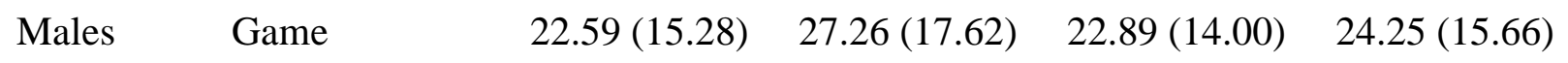

Involvement

Decision Made $\quad 1.67(1.61) \quad 4.48(3.44) \quad 3.69(4.54) \quad 3.28(3.58)$

$\begin{array}{llll}\text { Skill Execution } \quad 1.10(0.95) & 2.34(2.58) \quad 2.46(2.15) \quad 1.97(2.08)\end{array}$

$\begin{array}{llll}\text { Adjust } & 3.19(2.24) & 3.39(2.06) & 2.93(2.16)\end{array} 3.17(2.14)$

Game $\quad 1.99(1.07) \quad 3.40(1.69) \quad 2.99(2.07) \quad 2.79(1.75)$

Performance

Females

$\begin{array}{lcccc}\text { Game } & 10.05(5.84) & 13.95(10.69) & 10.55(7.14) & 11.52(8.20) \\ \text { Involvement } & & & & \\ \text { Decision Made } & 2.74(2.70) & 3.13(2.11) & 2.92(2.41) & 2.93(2.38) \\ \text { Skill Execution } & 0.63(0.95) & 1.04(1.18) & 1.12(1.18) & 0.93(1.11) \\ \text { Adjust } & 1.70(1.31) & 2.10(1.80) & 2.16(1.65) & 1.99(1.59) \\ \text { Game } & 1.69(1.20) & 2.09(1.02) & 2.06(1.38) & 1.95(1.20) \\ \text { Performance } & & & & \end{array}$

Note. Mean $(S D)$. Participants $(N=47)$ were grouped into one of two groups, which were SECM = Sport Education Curricular Model $(n=26)$ and EMAM = Extended Multi-Activity Model $(n=21)$. 
difference in the main effect for group favoring SECM for the dependent variables of skill execution, $F(1,43)=4.75, p<.05$ (see Figure 24 ) and adjust, $F(1,43)=7.48, p<.01$ (see Figure 25), but not decision made, $F(1,43)=2.18, p>.05$ (ns).

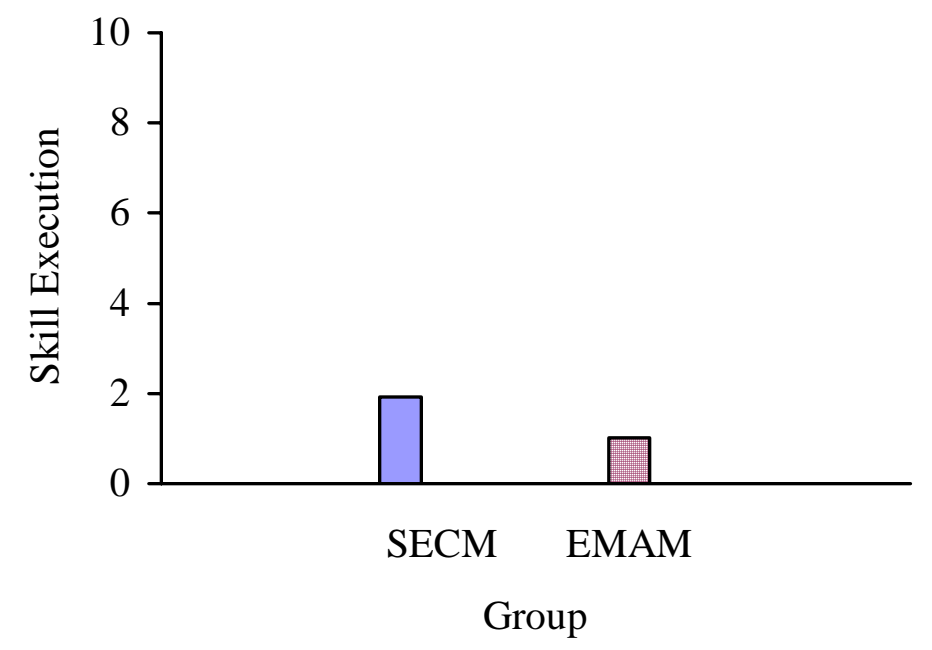

Figure 24. Skill execution for group, $F(1,43)=4.75, p<.05$.

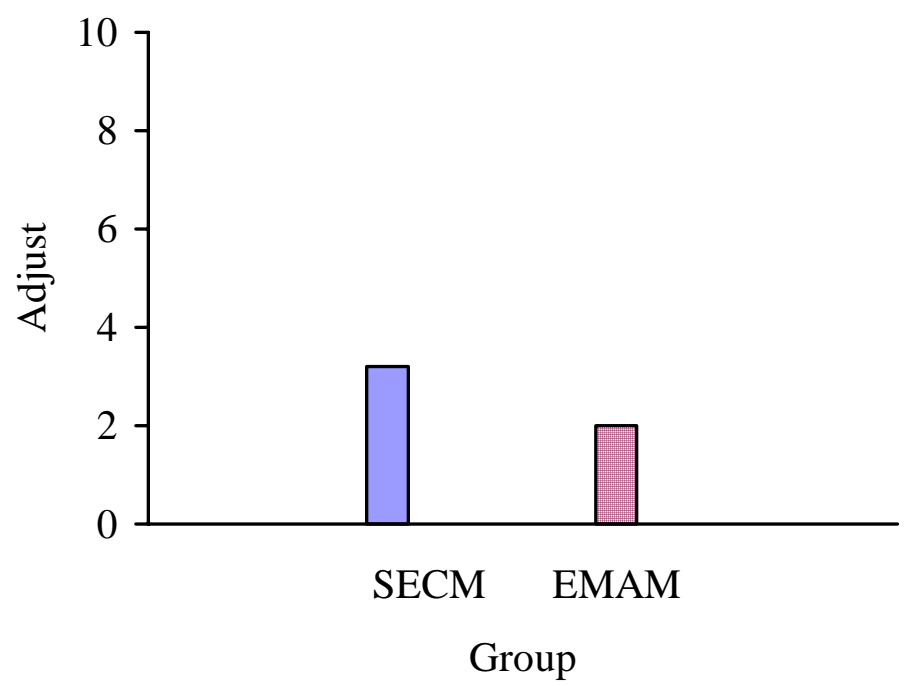

Figure 25. Adjust for group, $F(1,43)=7.48, p<.01$. 
The SECM group had higher scores for both skill execution and adjust than the EMAM group. The decision made dependent variable did not have a significant main effect for group but the SECM group did have a higher score than EMAM group although it was not large enough to be significant.

The gender main effect also found a significant difference for skill execution, $F(1,43)=$ 7.10, $p<.05$ (see Figure 26) and adjust, $F(1,43)=7.54, p<.01$ (see Figure 27).

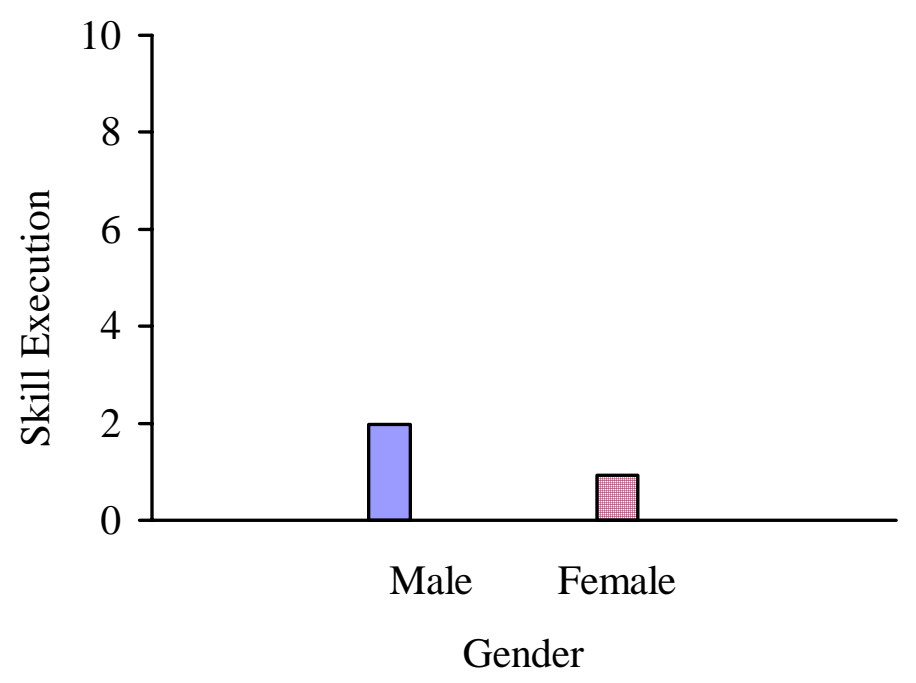

Figure 26. Skill execution for gender, $F(1,43)=7.10, p<.05$. 


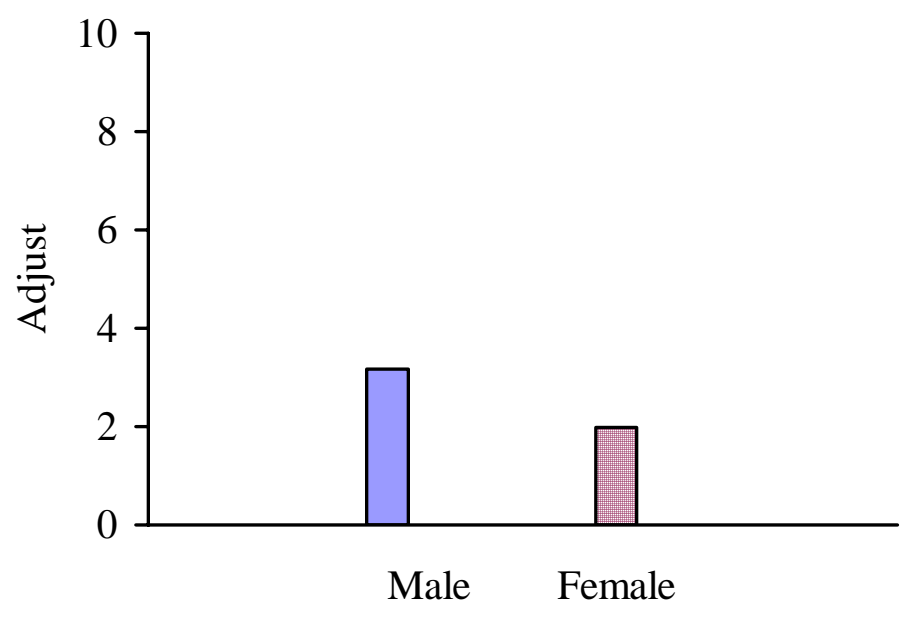

Gender

Figure 27. Adjust for gender, $F(1,43)=7.54, p<.01$.

The males had higher scores than the females for these two dependent variables but there was no main effect for decision made, $F(1,43)=.07, p>.05(n s)$.

Time main effect was significant for decision made, $F(2,86)=4.00, p<.05$ (see Figure 28 ) and skill execution, $F(2,86)=5.09, p<.01$ (see Figure 29) but not for adjust, $F(2,86)=$ $.32, p>.05$ (ns). A Tukey post hoc revealed that there was a significant difference between the pretest and mid-test of decision made but no other significant differences for the other multiple comparisons. A Tukey post hoc for skill execution was significant for the pretest to mid-test along with pretest to posttest. Other multiple comparisons were not significant. At least one group or a combination of both groups made better decisions during game play from pretest to mid-test but had a slight decrease from mid-test to posttest. There was also an improvement on skill execution across time. These results reveal that at least one group or the combination of both groups improved on what decisions were being made and how they executed the skills during game play. 


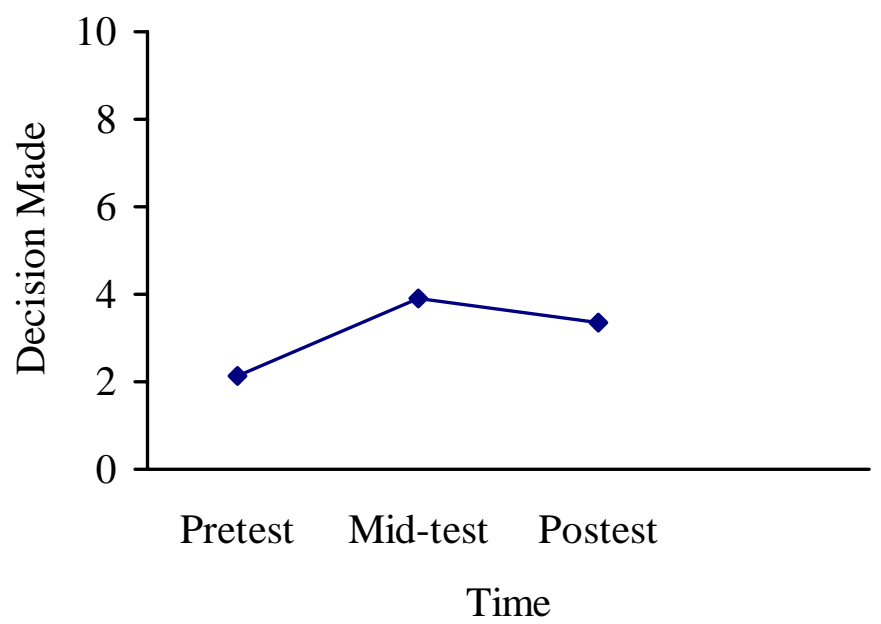

Figure 28. Decision made for time, $F(2,86)=4.00, p<.05$.

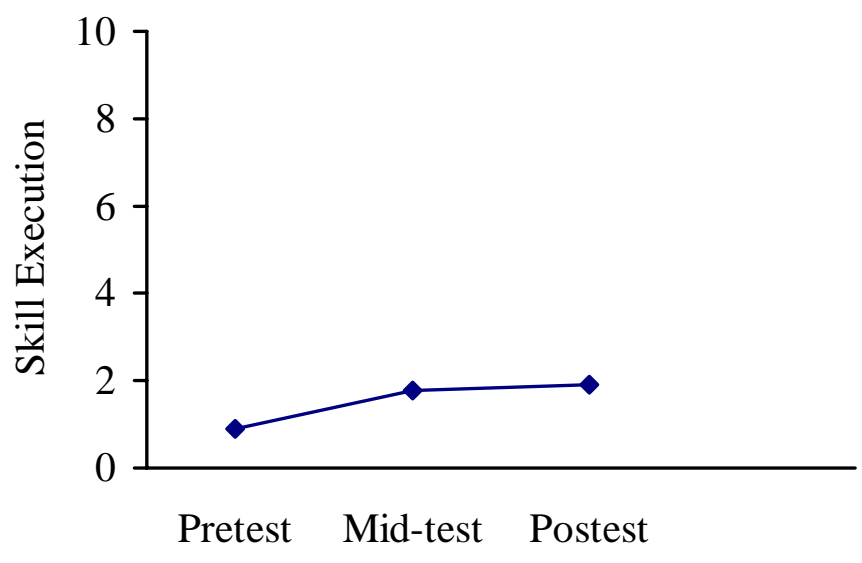

Time

Figure 29. Skill execution for time, $F(2,86)=5.09, p<.01$.

The two interaction effects that are of interest to answering the research question are the group $\mathrm{x}$ time and group $\mathrm{x}$ gender $\mathrm{x}$ time interactions. The group $\mathrm{x}$ time interaction was only 
significant for the dependent variable adjust, $F(2,86)=4.84, p<.05$ (see Figure 30).

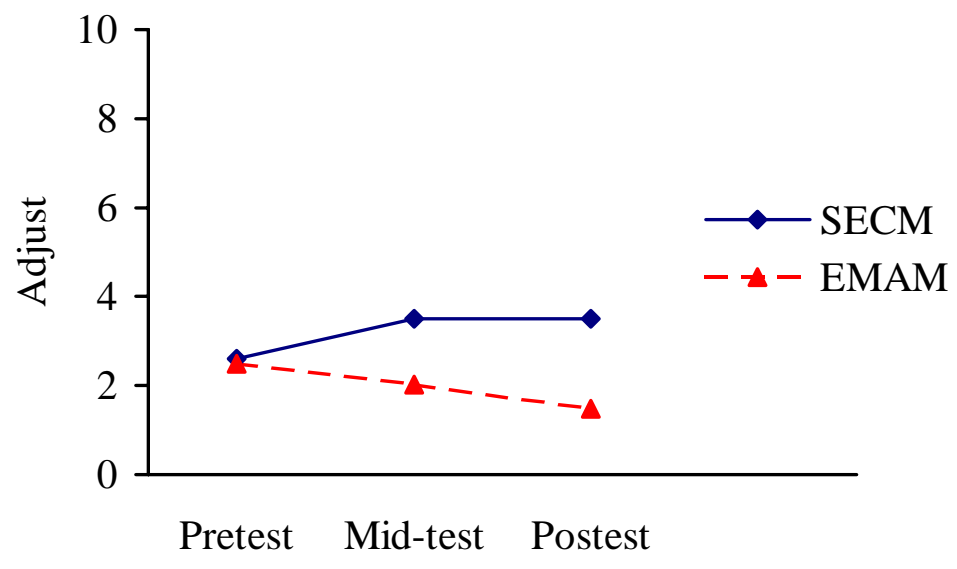

Time

Figure 30. Adjust for group $\mathrm{x}$ time, $F(2,86)=4.84, p<.05$.

A Tukey post hoc test was conducted for multiple comparisons of the group $\mathrm{x}$ time interaction for adjust. The test revealed that the SECM mid-test score was significantly different than the EMAM mid-test score. There was also a significant difference between the SECM posttest score to the EMAM posttest score. Other multiple comparisons were not significantly different.

There was no significant group $\mathrm{x}$ time interaction for decision made, $F(2,86)=1.72, p>$ .05 (ns) or skill execution, $F(2,86)=3.06, p>.05(n s)$. Although there was no significant interaction for decision made and skill execution, it was of interest to investigate further to answer the research question. The SECM group had a slight improvement on decision made across time (see Figure 31). 


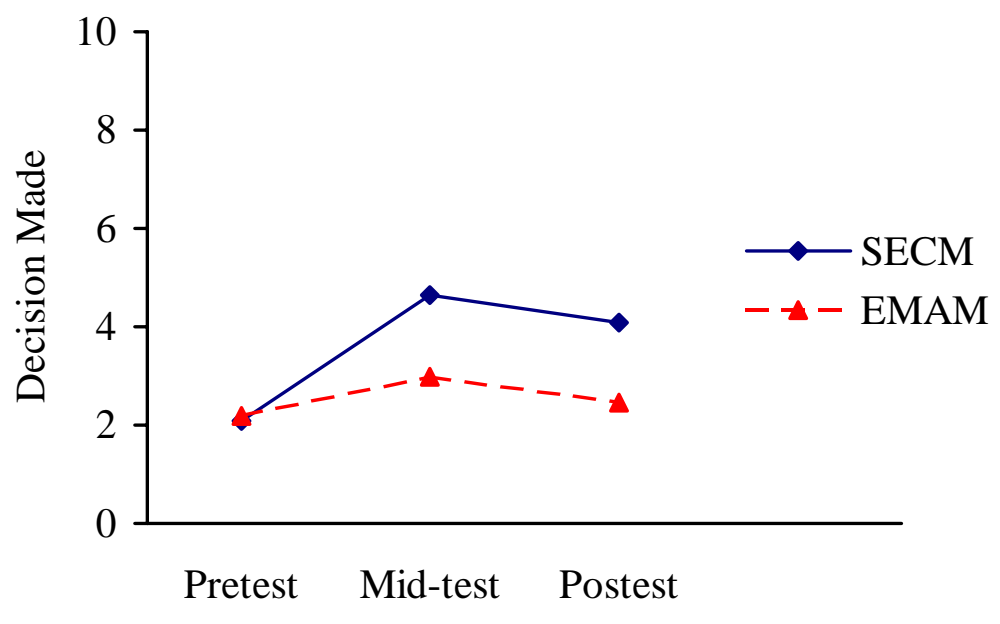

Time

Figure 31. Decision made for group x time, $F(2,86)=1.72, p>.05(n s)$.

Although the group $\mathrm{x}$ time interaction for skill execution was not significant, the SECM group did execute skill correctly over time while the EMAM group did not show very much improvement (see Figure 32).

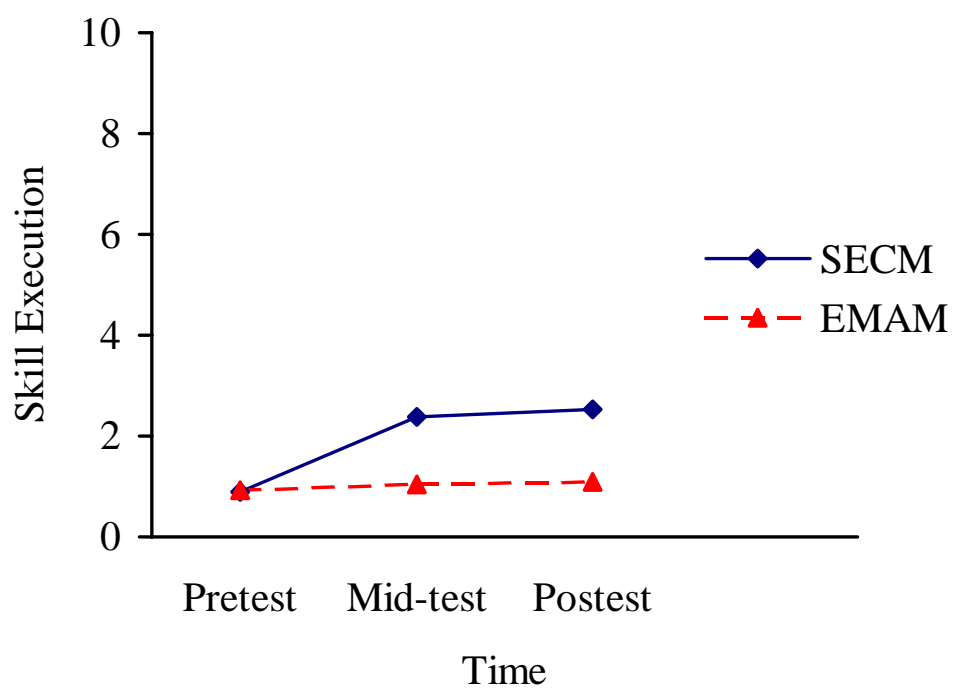

Figure 32. Skill execution for group x time, $F(2,86)=3.06, p>.05$ (ns). 
There also was no group $\mathrm{x}$ gender $\mathrm{x}$ time interaction for the three dependent variables (i.e., decision made, skill execution and adjust), Wilks' lambda $=.88, F(6,168)=1.79, p>.05$ (ns). When the groups were further broken down into gender, the SECM males had better decisions over time while the SECM females and the EMAM females did not have much of a change (see Figure 33).

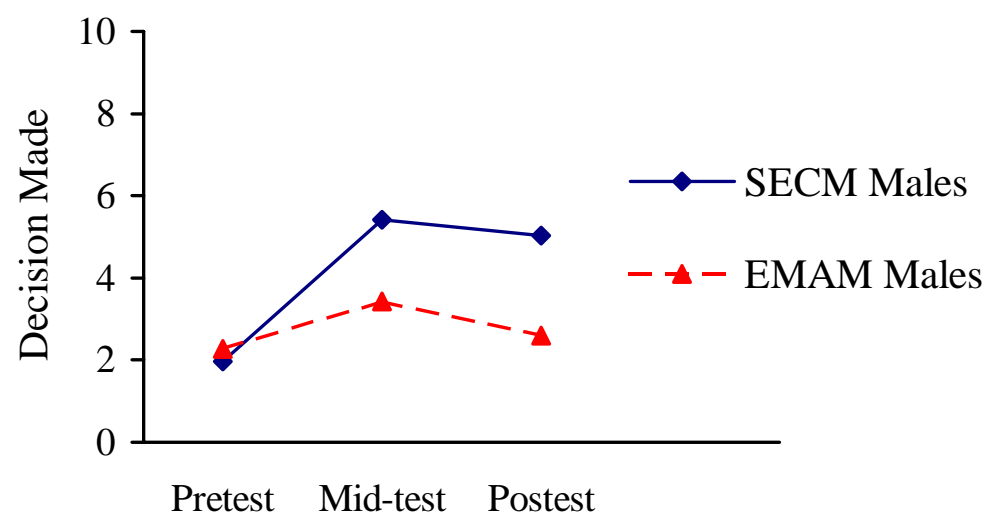

Time

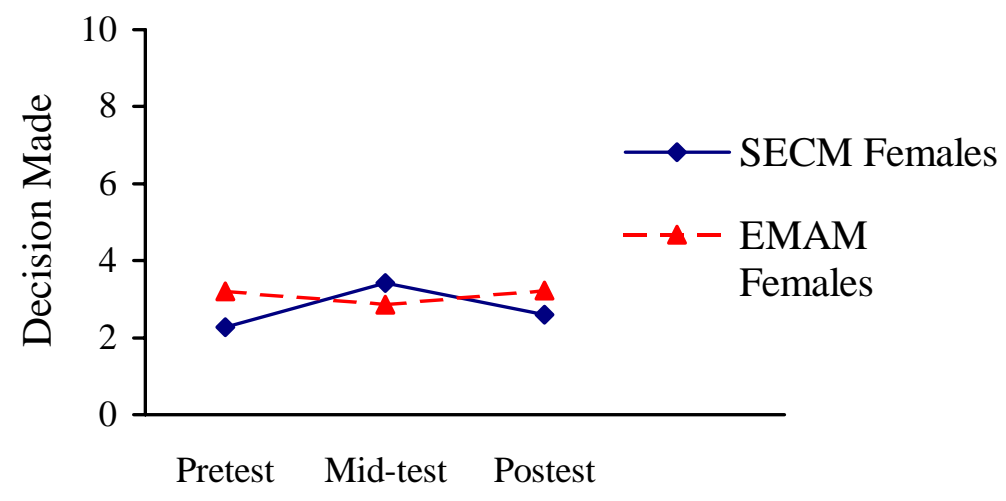

Time

Figure 33. Decision made for group $\mathrm{x}$ gender $\mathrm{x}$ time, Wilks' lambda $=.88, F(6,168)=1.79, p$ $>.05(n s)$. 
As for skill execution, the SECM males did have an increase in skill execution on the mid-test $(M=3.22, S D=3.00)$ and posttest $(M=3.44, S D=2.24)$ compared to the pretest $(M=$ $.98, S D=.65$ ) while the EMAM males, EMAM females, and SECM females did not show any type of improvement in skill execution (see Figure 34).
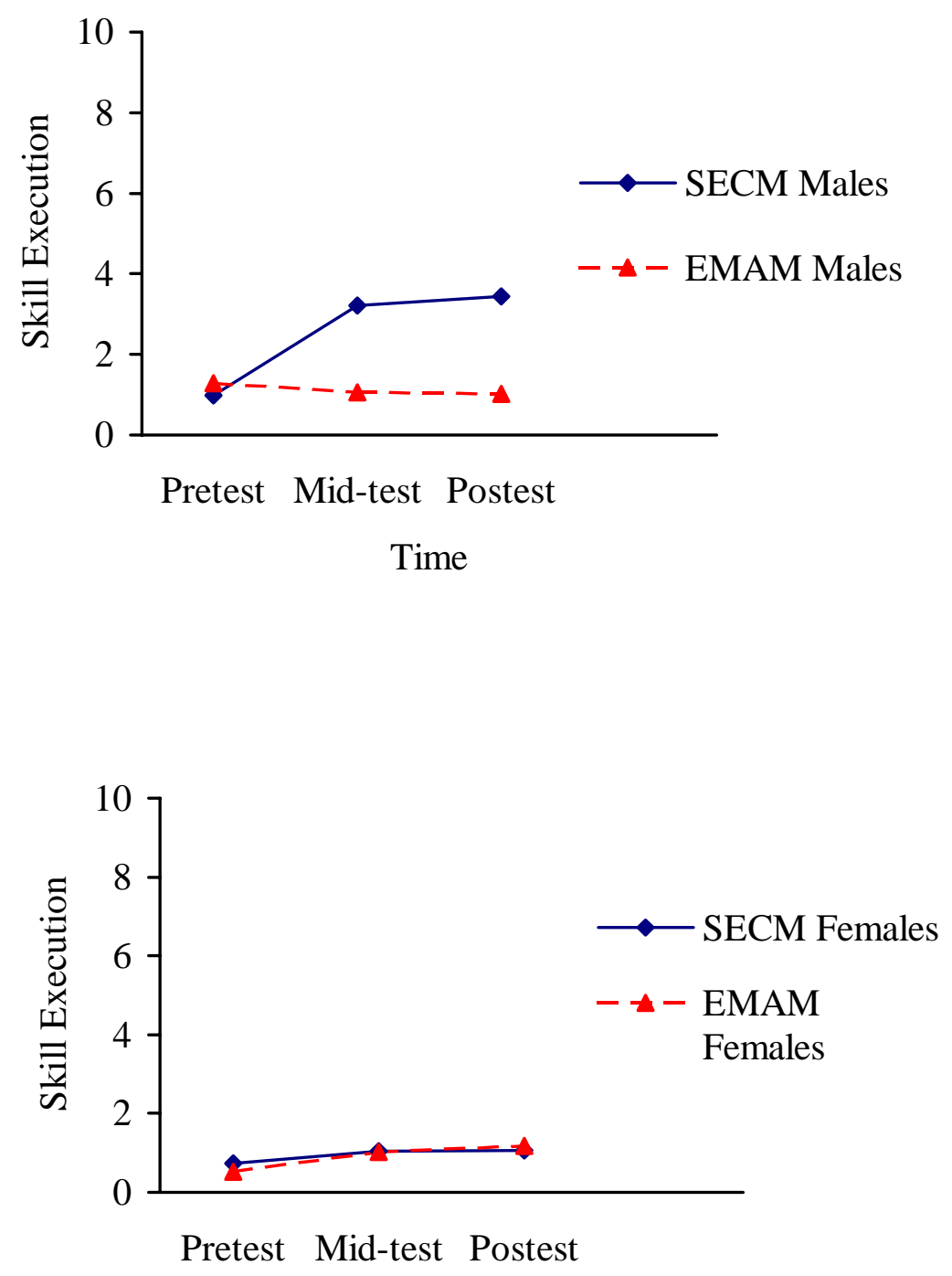

Time

Figure 34. Skill execution for group $\mathrm{x}$ gender $\mathrm{x}$ time, Wilks' lambda $=.88, F(6,168)=1.79, p$ $>.05(n s)$. 
For the adjust dependent variable, the SECM males only slightly improved while the EMAM males had a decrease in the adjust scores. The SECM females did have some improvement across time while the EMAM females did not have any type of improvement (see Figure 35).

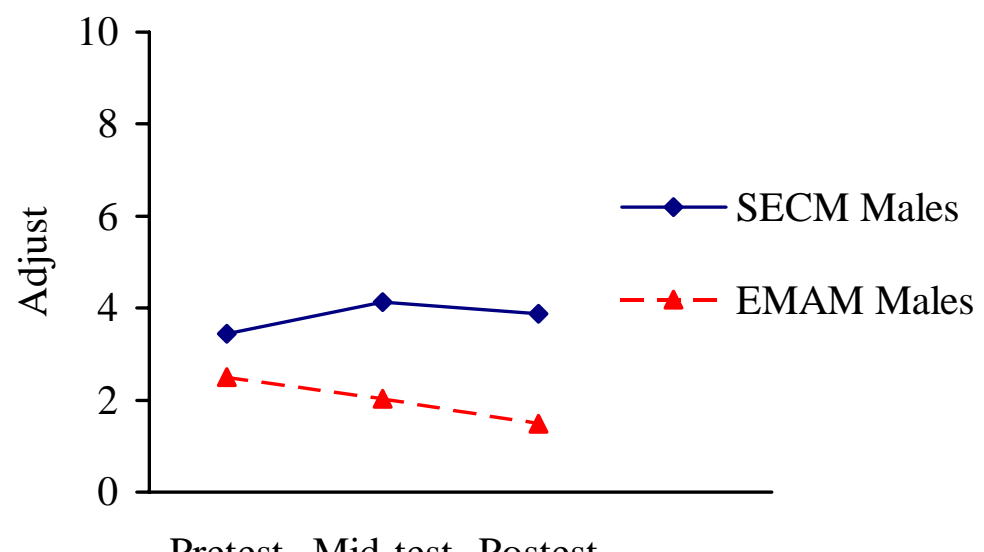

Time

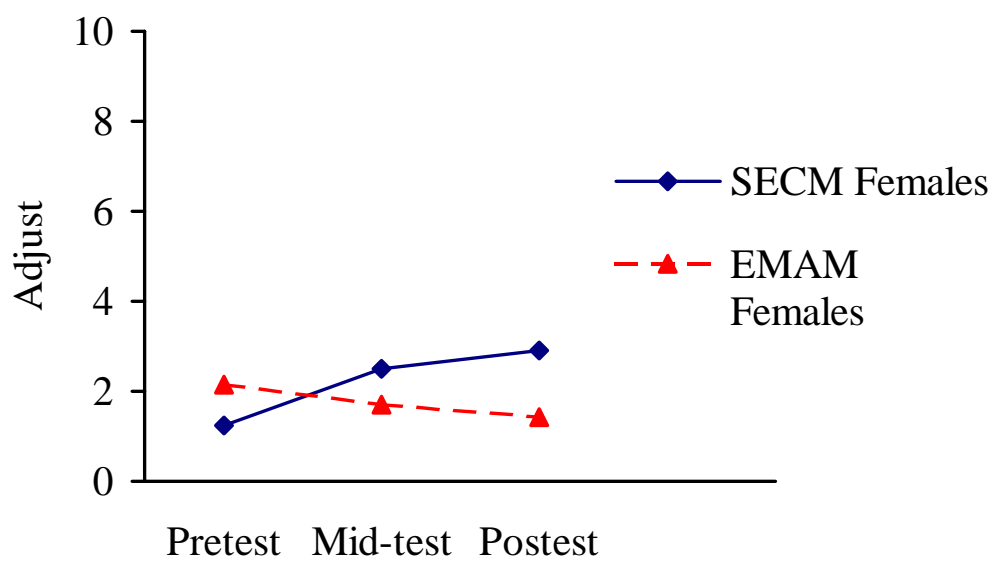

Time

Figure 35. Adjust for group $\mathrm{x}$ gender $\mathrm{x}$ time, Wilks' lambda $=.88, F(6,168)=1.79, p>.05$ (ns). 
Game involvement was measured with a univariate ANOVA to investigate if participants increased involvement over time. Game involvement measures how active participants were during the volleyball game by utilizing the following equation:

Game involvement $=$ total appropriate decisions + number of inappropriate decisions + number of efficient skill executions + number of inefficient skill executions + number of supporting movements.

There were main effects for gender, $F(1,43)=13.65, p<.01$ (see Figure 36) and time, $F(2,86)$ $=4.02, p<.05$ (see Figure 37). Tukey post hoc test revealed a significant difference only between pretest and mid-test with other comparisons not being significantly different.

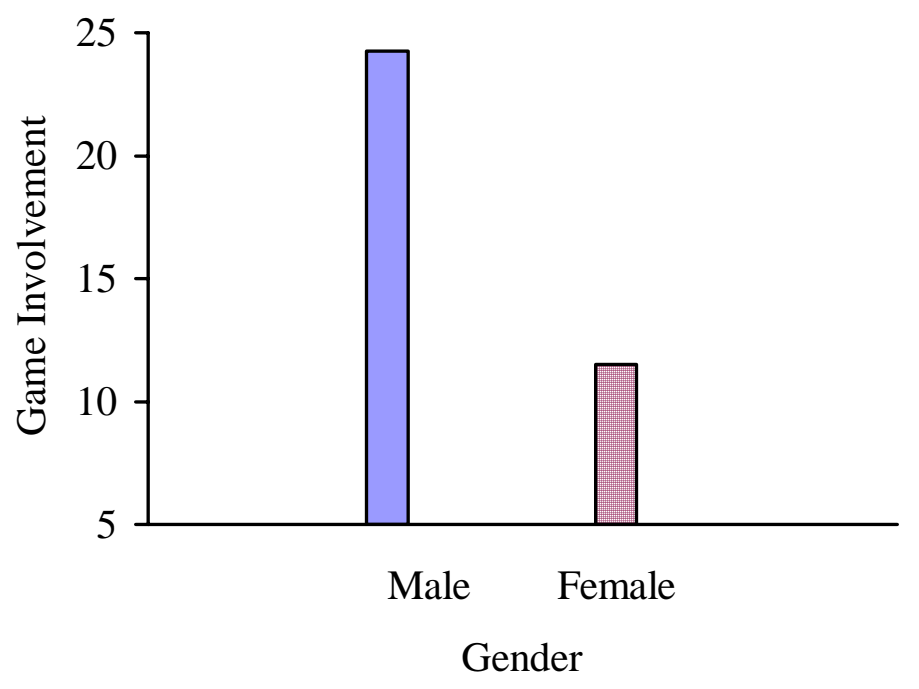

Figure 36. Game involvement for gender, $F(1,43)=13.65, p<.01$. 


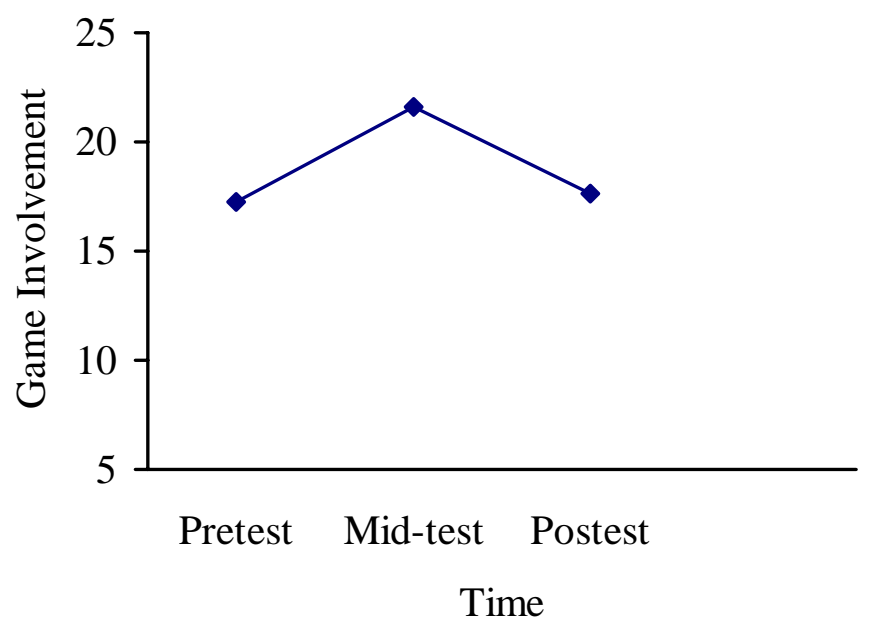

Figure 37. Game involvement for time, $F(2,86)=4.02, p<.05$.

There were no main effect for group, $F(1,43)=.06, p>.05$ (ns) or any interaction effects for group $\mathrm{x}$ gender, $F(1,43)=.37, p>.05(n s)$, group $\mathrm{x}$ time, $F(2,86)=.79, p>.05(n s)$, gender $\mathrm{x}$ time, $F(2,86)=.09, p>.05(n s)$, or group $\mathrm{x}$ time $\mathrm{x}$ gender, $F(2,86)=.15, p>.05(n s)$.

Although there was no significant group x time interaction, the SECM group tended to be more involved at the pretest and posttest than the EMAM group (see Figure 38). 


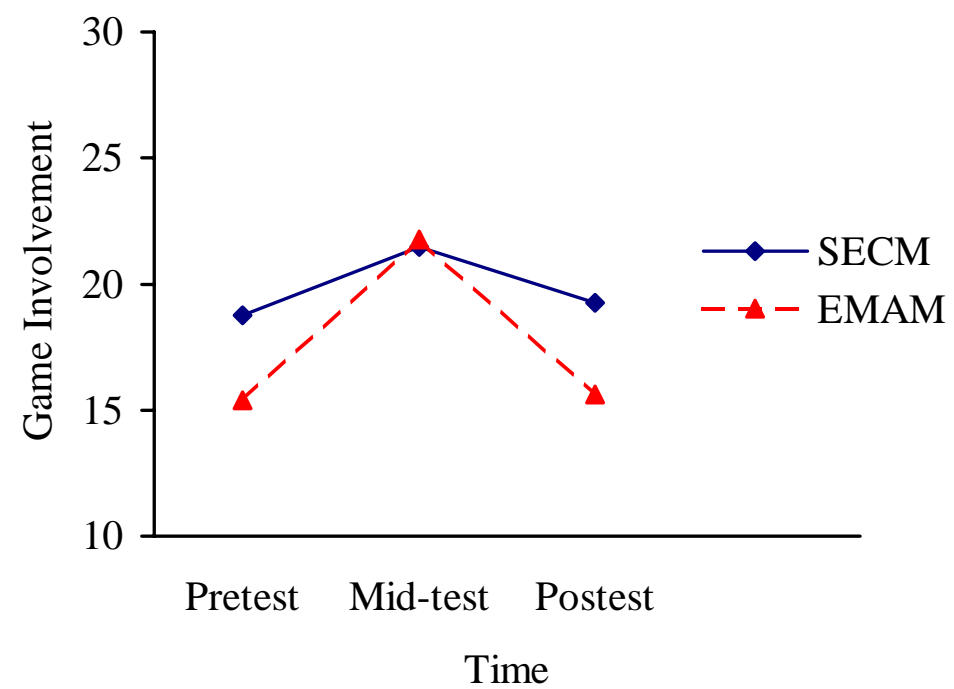

Figure 38. Game involvement for group x time, $F(2,86)=.79, p>.05(n s)$.

When investigating the group $\mathrm{x}$ gender $\mathrm{x}$ time interaction, there was no statistical significance although the SECM males seemed to have been more involved at pretest and posttest while the female game involvement scores were very similar except for the mid-test where the EMAM females were more involved in game play (see Figure 39). 


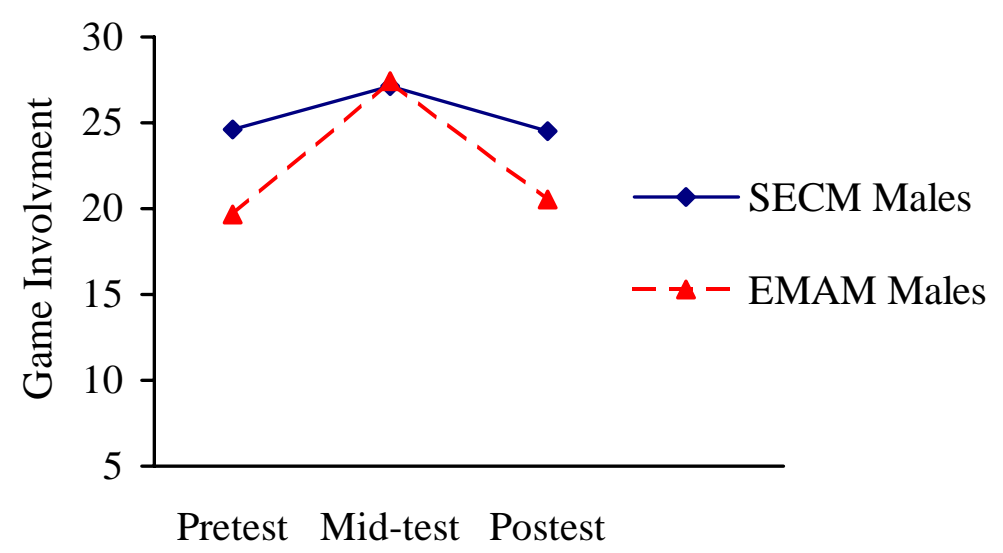

Time

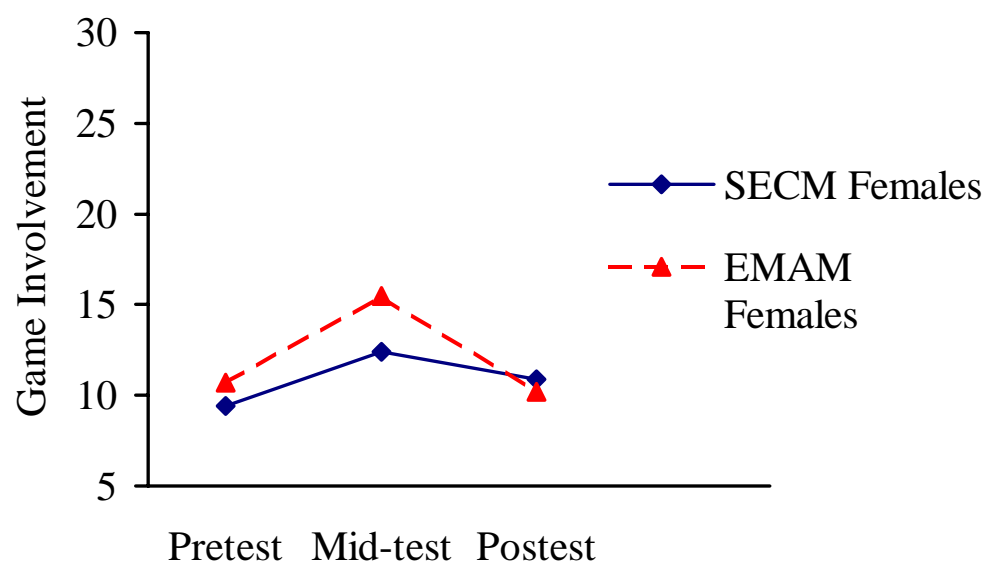

Time

Figure 39. Game involvement for group $\mathrm{x}$ gender $\mathrm{x}$ time, $F(2,86)=.15, p>.05(n s)$.

Game performance was calculated by summing the scores of decision made, skill execution, and adjusts then dividing the sum by three. A univariate ANOVA was utilized to measure any significant differences for the dependent variable of game performance. The results revealed a significant main effect for group, $F(1,43)=9.02, p<.01$ (see Figure 40), gender, $F$ $(1,43)=5.58, p<.05$ (see Figure 41), and time, $F(2,86)=7.31, p<.01$ (see Figure 42). 
Curricular Models 95

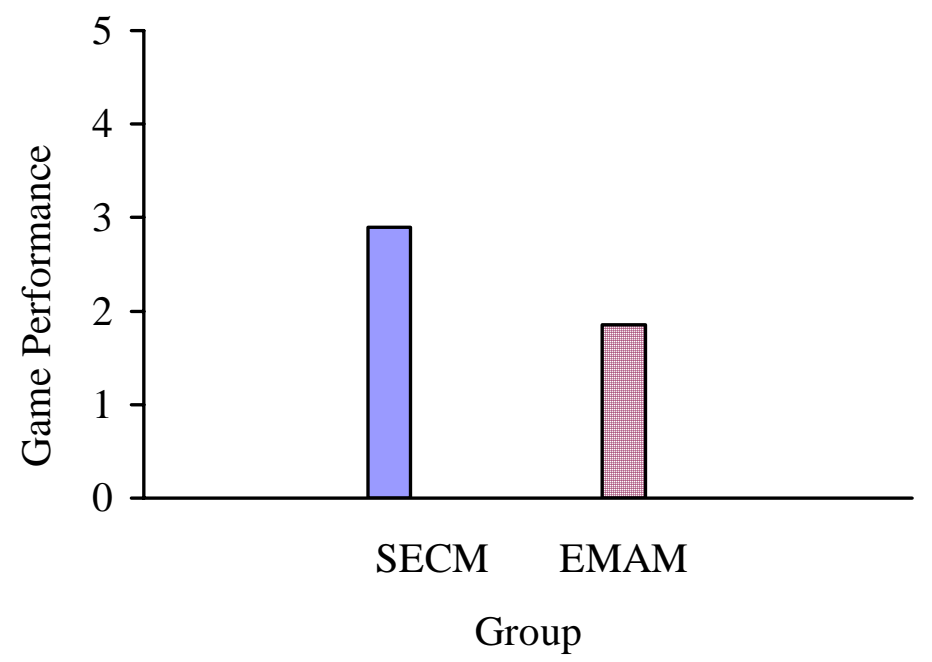

Figure 40. Game performance for group, $F(1,43)=9.02, p<.01$.

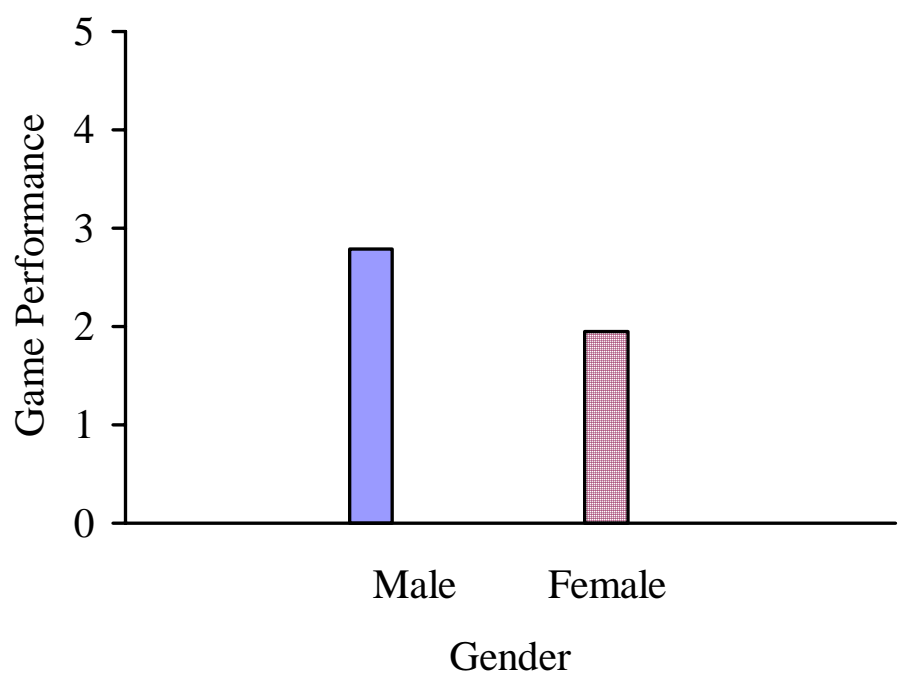

Figure 41. Game performance for gender, $F(1,43)=5.58, p<.05$. 


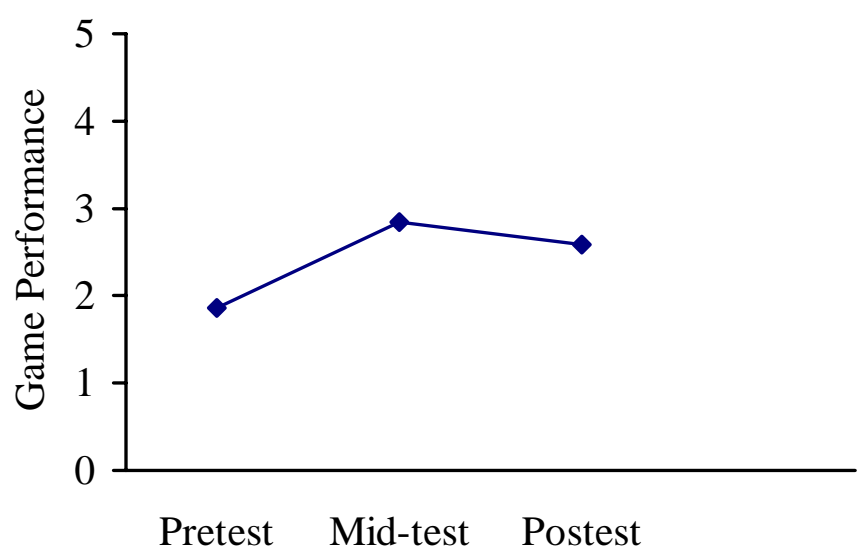

Time

Figure 42. Game performance for time, $F(2,86)=7.31, p<.01$.

A Tukey post hoc test revealed that the multiple comparisons of pretest to mid-test, and pretest to posttest were significantly different, but not mid-test to posttest. There was an interaction effect for group x gender, $F(1,43)=7.65, p<.01$ (see Figure 43) with a Tukey post hoc test revealing significant differences between SECM males and EMAM males plus SECM males and SECM females. Other multiple comparisons were not significant.

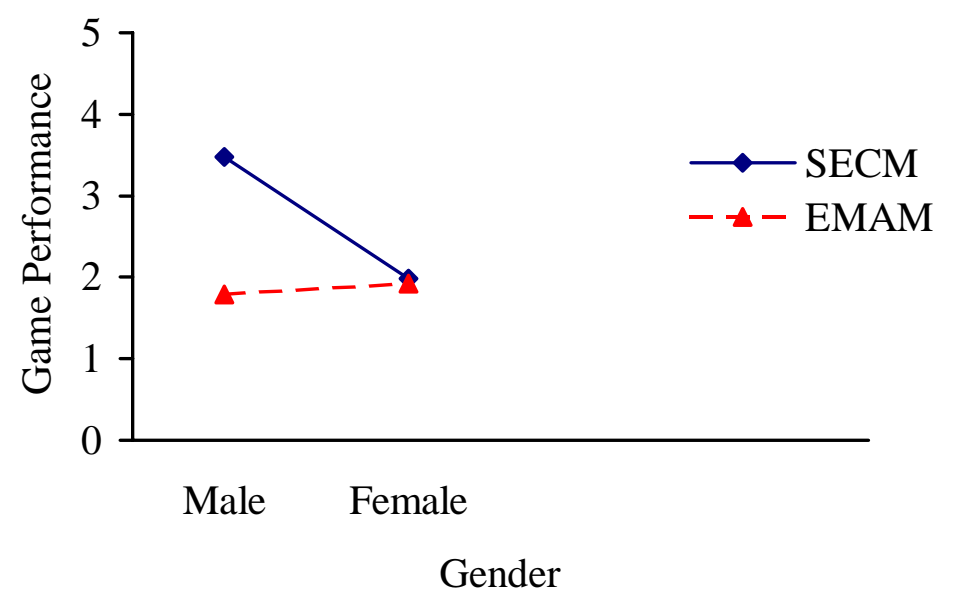

Figure 43. Game performance for group $\mathrm{x}$ gender, $F(1,43)=7.65, p<.01$. 
The most revealing statistical significance in answering the research question for which model would improve game performance was the statistical interaction effect for group $\mathrm{x}$ time, $F$ $(2,86)=8.06, p<.01$ (see Figure 44$)$.

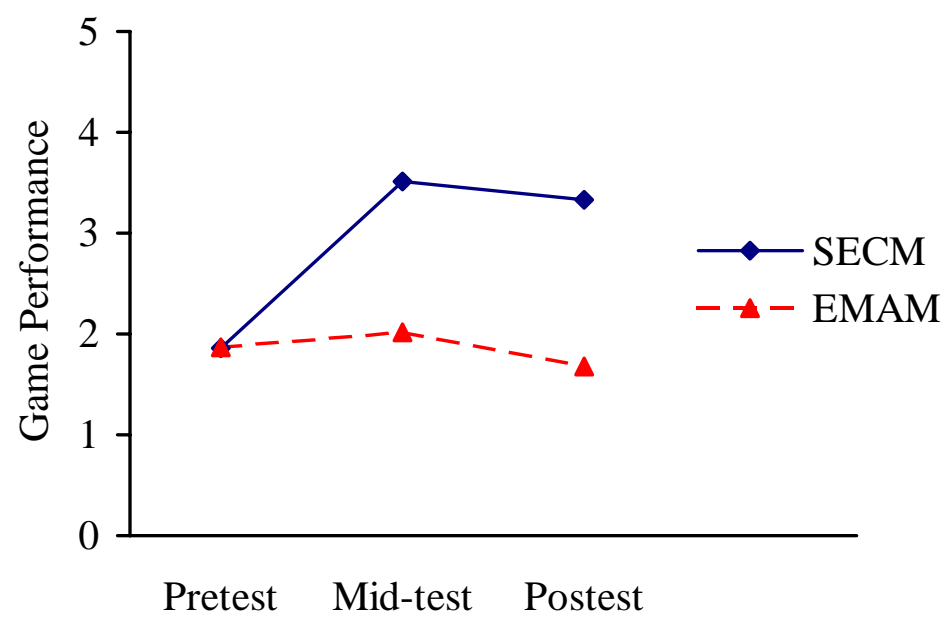

Time

Figure 44. Game performance for group x time, $F(2,86)=8.06, p<.01$.

A Tukey post hoc revealed a significant difference between the SECM pretest and SECM midtest along with a difference in the SECM pretest and SECM posttest. When comparing the groups, the SECM mid-test and EMAM mid-test were significantly different. The posttest scores were also significantly different of the SECM and EMAM. The SECM group had a larger improvement in game performance than the EMAM group from the pretest to the mid-test. There was a slight decline for both groups from the mid-test to the posttest with the SECM group still outperforming the EMAM group. By improving the decisions made, skill execution, and adjust during game play, the SECM group was able to improve overall game performance scores. The SECM group was making better decisions such as trying to pass the ball to a teammate with 
the appropriate skill like the set. The skill execution was also better because the ball would be passed to a teammate rather than accidentally being hit over the net.

There were no interaction effects for gender $\mathrm{x}$ time, $F(2,86)=1.83, p>.05(n s)$ or group $\mathrm{x}$ gender $\mathrm{x}$ time, $F(2,86)=1.39, p>.05(n s)$.

The group $\mathrm{x}$ gender $\mathrm{x}$ time interaction was not statistically significant but the data were conceptually interesting in light of the research question. The SECM males did improve from the pretest $(M=2.13, S D=1.12)$ to the mid-test $(M=4.25, S D=1.65)$ and posttest $(M=4.05$, $S D=3.48)$ while the EMAM males only had a slight improvement from pretest $(M=1.78, S D=$ $1.02)$ to mid-test $(M=2.16, S D=.66)$. There was very little improvement for the female groups (see Figure 45). 


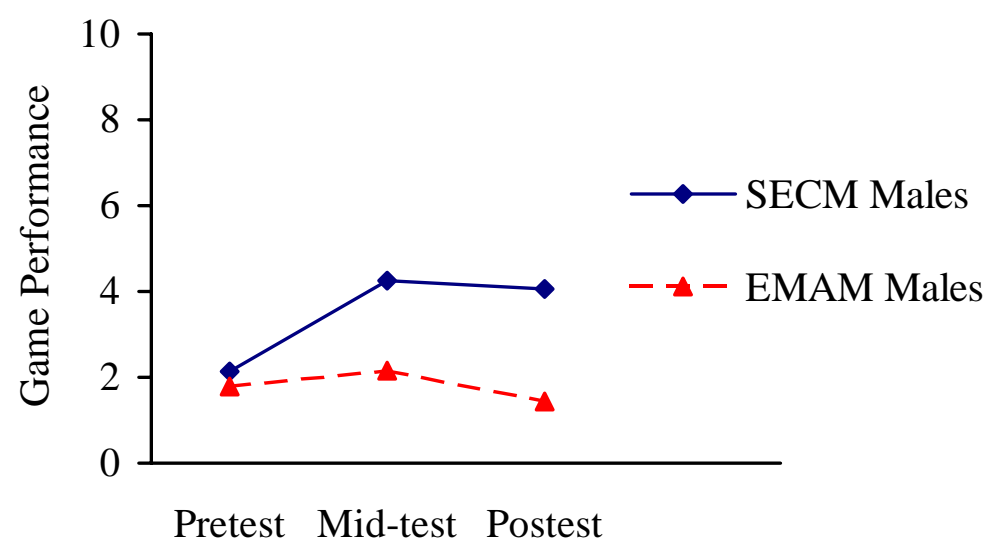

Time

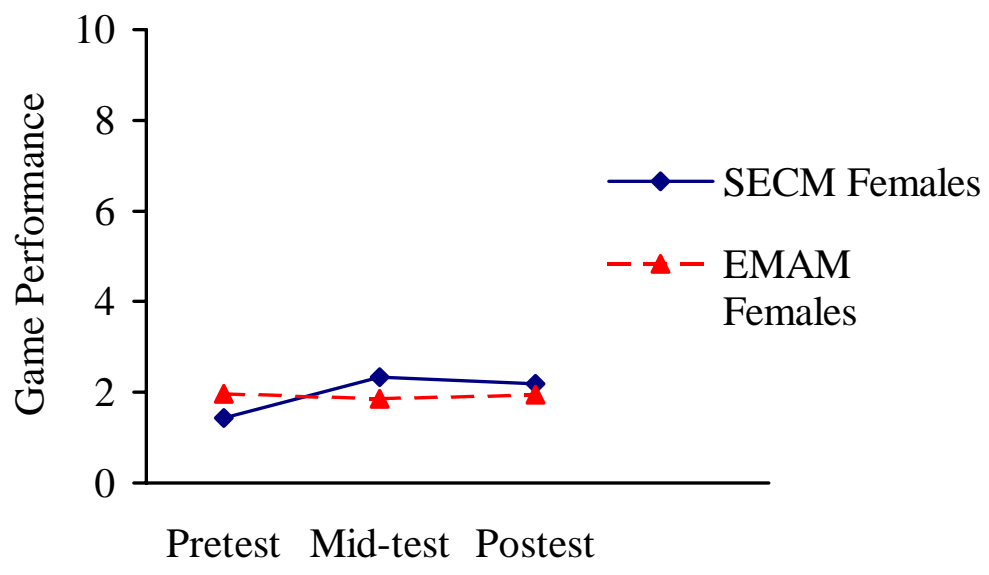

Time

Figure 45. Game performance for group $\mathrm{x}$ gender $\mathrm{x}$ time, $F(2,86)=1.39, p>.05(n s)$.

As for answering the research questions of which model would promote overall game performance, the SECM group statistically improved game performance scores compared to the EMAM group. The SECM group was able to make better decisions during the game play along with more appropriate skill execution. The SECM group also increased the adjust dependent variable across time, which allows for the conclusion that the SECM did promote higher game performance scores than the EMAM. 


\section{Research Question Four}

The fourth research question had to do with how participants would feel about the two models after the intervention. The physical education survey was given prior to the intervention to establish any emerging themes. Participants answered the first two questions of the physical education survey which were: 1) Describe what you like about your physical education class. Give at least 3 examples. 2) Describe what you don’t like about your physical education class. Give at least 3 examples.

Once data were collected and analyzed by the primary investigator, an outside investigator analyzed the same surveys looking for common themes to ensure that a consensus was met about the common themes emerging from the physical education survey. A theme that emerged from the first physical education question was that a majority of students did enjoy playing certain sports (e.g., basketball, team hand ball) and activities that are associated with physical education. Another theme was that they enjoyed their regular physical education teachers along with the social environment of being with friends. The participants' answers to question two can be categorized into two emerging themes. The first emerging theme was that there are some activities in which participants did not like to participate (e.g., wiffle ball). The second emerging theme was that the females did not like to participate with the males. Some of the males felt the same way toward the females. This particular high school does not have coeducational physical education classes the majority of the school year except for a few sports (e.g., kickball, volleyball). Another theme was that participants did not like to dress for class along with having to take tests.

After the intervention of the two models was completed, the last two questions of the survey were given. The first question asked for participants to describe what they liked about the 
volleyball class by providing at least 3 examples. One theme was that both groups enjoyed the games along with learning the skills to play volleyball as well as with how they liked their teachers. A SECM participant stated, “The last thing that I liked was learning how to be better at the sport of volleyball.” The SECM group also liked how they were on teams and were able to work as a team. One female participant stated, "Sportsmanship improved among the teams.” The SECM group also described how they liked to perform some of the roles that are associated with the SECM such as referee and coach.

When the participants were asked what they disliked about the volleyball class, the EMAM group stated that the unit was too long. The unit lasted 20 days not counting the days for testing (i.e., pretest, mid-test, and posttest). The EMAM group also did not like the fitness routine that was performed at the beginning of class. Unlike the SECM group, the EMAM participants had to follow the fitness routine that was teacher directed while the SECM participants followed a fitness task card. The SECM group stated that they did not like the drills associated with the skills that were taught at the beginning of the unit. The role of statistician was also not very popular with the SECM group which is a role associated with the SECM. Both groups stated their dismay with having to take the multiple-choice test three times. Although it was not stated on the survey, the teachers did hear from the EMAM group that they were curious about why the SECM group was allowed to have team names and colors. The SECM group was put on teams on day two of the unit and allowed to pick team names along with the other affiliation aspects of the SECM (e.g., team color, mascot, cheer) while the EMAM group were not put on teams until lesson 16 of the unit. The EMAM also stated to the teachers through informal conversations that they were tired of performing skills and not allowed to play. This format of not playing early in the unit is a characteristic of the multi-activity model. 
Overall, the SECM group seemed to enjoy the sport of volleyball and how the class was executed compared to the EMAM group. The statements did not say anything about not liking to play with the opposite sex, which was mentioned in the physical education survey before the intervention. 


\section{CHAPTER 5}

\section{DISCUSSION and CONCLUSION}

\section{Discussion}

The purpose of this chapter is to discuss the results of the current investigation by describing how the curricular models influenced the dependent variables of volleyball skills, knowledge, and game performance, and by relating the results to the related literature.

\section{Skill Tests}

It was hypothesized that the participants of the Extended Multi-Activity Model (EMAM) would have higher scores on the skill tests (i.e., serve, set, and pass) than the participants of the Sport Education Curricular Model (SECM). This hypothesis was not supported because the interaction effect of group x time did not reveal any significant difference for the skill tests. Participants of both models did show some improvement in the skill tests across time but there was no significant difference except the pass for the main effect of time. Although there was a significance for time, the main effect was unable to state which model was more influential in achieving the difference.

Very little research has been conducted dealing with the SECM and skill tests. Townsend et al. (2004) did report significant gains in skill tests when measuring basketball skills for middle school students following an 18-lesson Sport Education unit. These findings contradict the results of the current investigation but both studies dealt with two types of sports (i.e., invasion game and net/wall game), which could be the reason for the differences. Other researchers have measured skill development as it pertains only to game play, which is discussed later in the chapter. 
As for the EMAM, similar results were reported in field hockey (Turner \& Martinek, 1992, 1999), badminton (Lawton, 1989), soccer (Mitchell, Oslin, \& Griffin 1995), and volleyball (Griffin, Oslin, \& Mitchell, 1995) in that there were no significant differences between groups (i.e., traditional vs. tactical approach) but did have some skill improvement for the traditional style of teaching (i.e., multi-activity). French, Werner, Rink, et al. (1996) reported significant skill gains for three out of four skill tests during a three week intervention for the sport of badminton using the traditional style of teaching. A six week follow up study by French, Werner, Taylor, et al. (1996) found that the traditional group improved significantly on the skill tests of the clear and smash but not the serve or drop from week three to week six of the investigation. These findings contradict the results of the current investigation in that French, Werner, Taylor, et al. found that a longer intervention helped to improve skills of badminton significantly. The current investigation did not find significant gains in the three skill tests of volleyball for the SECM or the EMAM. One possible explanation could be that the two sports are different in that one is an individual sport (i.e., badminton) while the other is a team sport (i.e., volleyball). A participant may not have the same opportunities to respond during lessons as much with a team sport than with an individual sport. The extra practice for the individual sport may have contributed to the significant gain in skills. The other investigations that only revealed slight improvement but no significant gains were team sports except for Lawton (1989). Lawton investigated the sport of badminton but this study used only six one-hour sessions. The current investigation lasted 20 lessons, which has been one of the longer studies dealing with the traditional style of teaching. Although the intervention was longer, the participants were still unable to improve on the skill tests significantly over time, which suggests that there can only be slight improvement in skill tests due to time. 
There was also no significant interaction effect for group $\mathrm{x}$ gender $\mathrm{x}$ time, which reveals that the SECM males and the EMAM males were not statistically significant. The EMAM females did have higher scores on the serve and pass tests but they were still not statistically significant from the SECM females. The findings suggest that the EMAM males and the EMAM females did not improve as well even though they had isolated skill practice that targeted improvement in skills. The current investigation can only report slight improvement on skill tests for SECM males but not significant differences possibly due to the small cell sizes. As for the EMAM females, statistical improvement in skills was expected but was not observed. These results are supported by the findings of Allison and Thorpe (1997). Females in that study also did not improve on the shooting skill test of field hockey possibly due to the intervention time that included only six one hour lessons. By increasing the intervention time of the current study, females had more chances to practice the skills associated with volleyball. The isolated practice at the beginning of the unit did help in slightly improving skills of the females for the serve and the pass. By having isolated practice, the males did not dominate which allowed the females to choose their own partners thus possibly having more opportunities to respond. The earlymodified games may have been detrimental for the SECM females in that they did not have the extra isolated practice that the EMAM females received. Another reason could also be that the SECM females had to perform roles during game play activities such as referee or statistician unlike the EMAM females who had more time to practice.

\section{Volleyball Knowledge}

It was hypothesized that the SECM would perform better than the EMAM on the knowledge test by having higher scores on the declarative and procedural portions of the test. Declarative knowledge has been described as the rules, goals, and subgoals of a sport (French \& 
Thomas, 1987) while procedural knowledge is described as a selection of an appropriate action within the context of the game (McPherson \& French, 1991). This hypothesis was not supported by the results of the study. There was a significant difference for the declarative portion of the knowledge test and the total score over time but it was due to the combination scores of both models. There was no group $\mathrm{x}$ time interaction effect for the total knowledge, declarative knowledge or procedural knowledge suggesting that neither model improved knowledge scores significantly over time although there was some improvement with both models. The results of the current investigation supports the findings of Ormond, DeMarco, et al. (1995) who also reported no significant difference but did have a slight improvement in knowledge after a 12lesson unit of basketball using the SECM and a traditional model of instruction. Ormond, Christie, et al. (2002) also reported an improvement in cognitive scores with the SECM having a greater gain in scores. Other researchers have also found that the traditional model had improvement in knowledge (Allison \& Thorpe, 1997; Lawton, 1989; Turner \& Martinek, 1999; French, Werner, Taylor, et al., 1996).

As for measuring declarative knowledge, one would expect scores to increase in both models because participants must learn the rules of volleyball to play the game but that was not the case. There was only slight improvement in declarative knowledge for both groups. The SECM group performed their best at the mid-test while the EMAM group consistently improved over time. When the groups were separated by gender, there were similar results with the SECM males and SECM females scoring higher on the mid-test then regressing on the posttest. The EMAM males saw very little improvement while the EMAM females had a consistent increase over time but not a significant increase. The slight increase in the mid-test scores could be attributed to when the information was taught to the participants. The majority of declarative 
knowledge was given near the beginning of the unit for both models. Teachers instructed participants on the rules of volleyball while going over skills. For example, while teaching the serve skill, teachers would instruct participants that one of the volleyball rules is that a server has five seconds to serve the volleyball after the official blows the whistle and waves for the server to begin. This type of information was essential at the beginning of a unit especially for the SECM because they began modified game play very early in the unit while the EMAM group was taught the rules then reinforced later during game play.

As described by Turner and Martinek (1999), procedural knowledge should increase with game play. Both groups showed very little improvement in the procedural knowledge scores. The SECM males improved on the posttest compared to the pretest. The EMAM males scored higher on the mid-test. There was an increase in procedural knowledge for the EMAM females with a slight steady increase over time while the SECM females improved on the mid-test but regressed on the posttest. One would have expected the SECM group to perform better than the EMAM group on the procedural section of the knowledge test if this type of knowledge is to increase with game play. The SECM group had consistent game play throughout the intervention while the EMAM only began game play after lesson eight. The EMAM group should have scored higher on the posttest because they started game play later in the unit but their best score was on the mid-test. The SECM group did score higher on the posttest than the other two times but it was only a slight improvement, which suggests that game play did not improve procedural knowledge.

The findings of the knowledge test were disappointing. The teachers gave the knowledge of the sport of volleyball to the participants of both models. Knowledge was given during instruction then reinforced during the closure of the lesson. Procedural knowledge was given 
during the modified game play (i.e., application task) or during full sided games. Although the knowledge was provided, participants did not improve as much as anticipated. This lack of improvement may be attributed to the effort of the participants when taking the test. The teachers of the volleyball unit commented to the primary researcher that some of the participants stated that they did not give an all out effort. The test was composed of 35 questions that should have taken at least thirty minutes but a portion of participants finished under thirty minutes especially during the mid-test and the posttest. The researcher realized that some type of accountability could have made the participants take the test more seriously. Some of the participants even commented on the survey that they disliked taking the volleyball test. This lack of effort could be the reason why there was not as much improvement as the researcher had anticipated.

\section{Game Performance}

It was hypothesized that the SECM group (i.e., males and females) would have better game performance scores at the mid-test and posttest than the EMAM group. This hypothesis was true in that the SECM group was able to increase game performance significantly over time thus outperforming the EMAM participants. Both models in the current study followed the suggestions by Rink, French, and Graham (1996) in that students had time to play, skills were taught to transfer to the game, and there was time to develop skillful players. The intervention time for both models was 20 lessons and there was improvement for both models but the SECM still outperformed the EMAM.

A couple of reasons why these results occurred could be due to the modified games that were offered early in the unit of the SECM and the affiliation aspect of the model. By having early-modified game play (e.g., two vs. two) that incorporated the skills that had been learned, 
participants were able to practice the skills in a real situation instead of the isolated skill practice that is associated with the multi-activity model. By increasing the intervention time of the multiactivity model, EMAM participants were allowed to play modified games during the middle of the unit followed by full-sided games. This is not a characteristic of a true multi-activity model. Siedentop and Tannehill (2000) described the multi-activity model as being a short unit with skills taught in isolation followed by full-sided games. The EMAM allowed for modified game play with the increased time of intervention in the hopes of allowing participants to become more competent in game performance. There should have been an increase in the posttest but there was actually a decline in game performance. This suggests that time was not a factor in improving game performance when following a format of skill development at the beginning of a unit followed by modified game play leading up to full-sided games.

This finding is supported by Turner and Martinek (1999), who also found that a technique group (i.e., multi-activity) did not improve in field hockey skills after an intervention of 15 lessons for 45 minutes each lesson. They concluded that the technique group did not improve in game play because the lessons were not game like enough to transfer to game situations. The current study did have isolated skill practice at the beginning but added a combination of skills to resemble a game like situation. For example, one lesson had the EMAM group work on the forearm pass so a participant would toss the ball to a partner who performed a forearm pass back to his or her partner. This was considered an isolation task because during the game of volleyball, nobody tosses the ball to an opponent. One must learn to execute a forearm pass when the ball is hit to him or her. To work on a game like situation, a task was designed dealing with returning a serve and setting up the attack using the same skill. A participant would serve to the receiver who would perform a forearm pass to the setter. The setter would set the 
ball to a spot on the floor pretending there was a hitter. This task did simulate a game like situation but it did not involve playing against an opponent. These types of tasks were allowed during the EMAM unit to prepare participants for game play.

Although, the EMAM group was allowed to practice a combination of skills, there still was no significant increase in game performance. Mitchell, Oslin, and Griffin (1995) also report no significance in game performance improvement for a traditional model using the Game Performance Assessment Instrument (GPAI). The investigation only used eight lessons with no difference between the pretest and the posttest. They allowed game play for each lesson after skill instruction while the current investigation had a warm up followed by skill practice for the first eight lessons. After lesson eight, the EMAM group was allowed to play modified games building up to full-sided games. Although the current study did have modified games for EMAM, it was not enough to improve game performance.

The SECM group (i.e., males and females) did improve significantly over time from the pretest to the mid-test with a slight decline in the posttest although the posttest was still significantly different than the pretest. Hastie (1998c) also found that game performance increased for six participants of an ultimate Frisbee unit using the SECM. The six-member team improved in efficiency scores from the early stages (1.33) to the later stages (2.68) in addition to an increase in team catching competency. One could believe that the early-modified games associated with the SECM contributed to the significant change, which is supported by other investigations that had modified games early in a unit for a traditional model (French, Werner, Rink, et al., 1996; French, Werner, Taylor, et al., 1996).

Another reason why the SECM performed better than the EMAM could be due to the affiliation aspect of the models. For the SECM group, participants were placed on teams very 
early in the unit (i.e., lesson one) while the participants in the EMAM were put on teams later in the unit (i.e., lesson 16). This method of selecting teams at two different times of the models was due to the characteristics associated with the curricular models. Sport Education requires participants to be on the same team for the entire unit. Teams were not selected for the EMAM until full-sided games occurred. By having affiliation early in a unit, participants would practice and play as a team, which allowed the SECM group to work together as a team.

For example, during the set lesson, teachers instructed participants of both models on the set skill and how the setter is the quarterback of the team. One particular SECM team had "try outs" to find out which teammates were the more competent setters. The team placed the setters in the 4-2 offense with one in the middle of the front row and the other in the middle of the back row. Other teams of the SECM also decided whom the best setters were thus placing them in the appropriate positions, which allowed them to work as a team. Informal observations of game play revealed that the SECM teams would work together in trying to execute the "perfect play" of bump, set, spike. During pretest measurements, participants were hitting the volleyball over the net on the first hit instead of trying to set up a teammate, which is a tactic in volleyball. One teacher commented, “the SECM group would tell their teammates ‘set me up’ during game play while the EMAM group was more interested in hitting the volleyball over the net as fast as possible.”

By playing modified games early in the season with teammates gradually building up to full-sided games helped the SECM group increase game performance. The EMAM group also was taught the same information of why a team would want to set up the attack. They played the same modified rules during the middle part of the unit but participants were not affiliated during this period of the unit. Participants were allowed to choose their own team for that lesson but 
they had to select different teammates for the next lesson. This type of team selection was conducted so there was no affiliation. Participants of the EMAM were allowed to be affiliated later in the unit (i.e., lesson 16). Even though EMAM participants were on a permanent team at this point, they did not work well as a team compared to the SECM group. The EMAM group was still attempting to hit the ball over the net on the first hit instead of setting up the attack by passing to a teammate. The teachers did realize what was happening so they modified the rule so that EMAM teams had to pass to a teammate before the tournament began. When the tournament began, the teachers played regular full-sided games but unfortunately the EMAM teams regressed to trying to hit the volleyball over the net without setting up the attack while the SECM teams were trying to set up a teammate.

This affiliation of teams was supported by Ormond, DeMarco, et al. (1995). Ormond et al. investigated the effects of the SECM and a traditional model for basketball. The SECM group was more concerned with strategy and team unity while the traditional group was more concerned with having fun. Ormond, Christie, et al. (2002) also found that a SECM group was more organized in playing basketball while the traditional group looked more like "street ball." By using affiliation early in a unit, students can be a part of a team thus working on a goal together instead of being selected for teams late in a unit thus not allowing students to learn to play together.

Investigating how gender may be a factor for both models, the results revealed that the SECM males and SECM females did have improvement but was not statistically significant compared to the EMAM males and EMAM females. Hastie (1998b) reports that males and females had the same opportunities to respond during a 20-lesson season of floor hockey. Although the males did dominate during the competition phase, the females still had higher 
success rates at the end of the season compared to the beginning of the season. The SECM allowed the males and females of the current investigation to play and practice together as a team. By allowing participants to practice as a team, the males and females seemed to feel more comfortable playing as a team.

When breaking down game performance into the three levels of decision made, skill execution, and adjust, the SECM group did make better decisions of using the right type of shot and passing to a teammate correctly thus improving skill execution. The SECM group made better decisions during game play at the mid-test and posttest than the pretest according to the criteria of the GPAI. By improving these two dependent variables along with the adjust dependent variable, the SECM group was able to significantly improve game performance over time. By working as a team for the entire unit, participants of the SECM made more quality decisions along with more competent skill execution.

As for the adjust aspect of the GPAI, the SECM group displayed significant improvement than the EMAM. The SECM group seemed to be more involved so when they were on the front line, they would open up when the ball went over their head in anticipation that their teammate would pass the volleyball to them. They were able to adjust in trying to save the ball even though they may not have a chance to save it. Although there may not have been an actual play, the SECM participants were more alert and attempted to save the ball according to the adjust segment of the GPAI. The EMAM participants did not adjust as well to the ball for both males and females. From informal observations, the EMAM group had more standing around not attempting to adjust. They seemed to not give an all out effort even during the tournament.

Overall, the EMAM teams did not have as high an effort level as the SECM teams. This lack of effort was probably due to the lack of competition that was present during the unit. By 
not having any type of competition until later in the EMAM unit, participants were not engrossed in the competition aspect that was present during the SECM unit. The SECM unit had a competition contest starting on lesson two of the unit. Unlike the EMAM unit where the winners of the tournament were recognized, the SECM unit had an overall point championship. Teams earned points not only for the tournament but they were awarded points throughout the unit (e.g., wearing team colors, performing daily roles, team hustle). Teams would earn points for "hustling” when the teacher wanted the class to come in for instructions. Teachers would blow the whistle twice then teams would run to the teacher with the first team earning bonus points. The SECM teams would sprint to the teacher while the EMAM participants would walk because they were not earning points for their team. By implementing a point championship system very early in the unit, teachers were able to utilize it as a management tool.

Game involvement was also measured with no significant interaction effect for group x time or group x gender x time. Game involvement allows one to judge how participants were engaged during game play. It is difficult to measure overall due to there being only 15-minute games that were video taped. There are so many variables that could determine how active a participant is during game play. For example, the time it takes to get the ball and deliver it to the next server can waste time. If there was a long rally, game involvement can be higher but what the researcher was interested in was how the participants would react to those opportunities to respond.

When investigating the mid-test game involvement, both groups were very similar $(\mathrm{SECM} ; M=21.46, S D=15.64 ; \mathrm{EMAM} ; M=21.76, S D=17.54)$ but the SECM group performed better on the decision made, skill execution, adjust, thus overall game performance than the EMAM group. Even when both groups had the same amount of game involvement, the 
SECM scored higher on those dependent variables (i.e., decision made, skill execution, adjust, and game performance). One could think that it really does not matter what amount of game involvement a participant has but it is what that participant does with the opportunity. The participant could make an inappropriate response during game play just as easily as making the appropriate response.

\section{Affective Domain}

It was hypothesized that the SECM group (i.e., males and females) would enjoy the volleyball unit more than the EMAM group. The SECM participants' surveys seemed to reflect that they enjoyed the unit of volleyball. They enjoyed having team names, playing against other teams along with how the competition was set up that included the overall point championship. By having a competition that was not only concerned with winning and losing, the gymnasium environment seemed to run more smoothly than the EMAM. Participants of the EMAM would discover that the SECM group had team and team names along with colors thus ask the teacher why they were not allowed to have those affiliation aspects. Unlike the SECM, the EMAM followed the suggestions by Siedentop and Tannehill (2002) in that there was no affiliation for the EMAM until full-sided games were implemented.

The SECM group liked how they had to do some of the roles such as referee but some of the participants did not like being the statistician. Hastie (1998c) reported that 35 sixth grade girls enjoyed how they were engaged with the unit by performing roles associated with the SECM (e.g., referee, statistician) along with how they were a part of the team, and competing against other teams. Carlson (1995) also reported how lower skilled participants believed they could contribute to the team. 
The findings of Carlson and Hastie support how the participants of the current investigation enjoyed the competition along with how some of the girls enjoyed being on a team. This was not present before the intervention with both genders stating how they did not enjoy playing with members of the opposite sex. The physical education program used in the current study only allows co-educational classes for certain sports (e.g., volleyball). But most of the school year, the physical education class is not co-educational which was apparent in the physical education survey. Members of both sexes stated that they did not like to play with participants of the opposite sex. When the intervention was over and the last two questions of the physical education survey were given, statements about how they did not like to play with members of the opposite sex were absent. Either participants did not want to state this again or the intervention of the models benefited the students in learning how to play together.

\section{Conclusions}

Within the scope of the current study and having analyzed the results, the following conclusions are drawn:

1) When measuring volleyball skills utilizing skill tests (i.e., pass, set, and serve), both curricular models only improved skill development slightly with neither model improving skills significantly.

2) When measuring volleyball total knowledge, declarative knowledge, and procedural knowledge by using 35 multiple choice questions, both curricular models improved knowledge but there were no significant differences over time. There should have been a larger increase but this lack of increase could be attributed to the lack of effort by the participants. 
3) When measuring game performance with the Game Performance Assessment Instrument, both models improved in game performance. The SECM group was more proficient in game performance at the mid-test and posttest compared to the EMAM group. The participants of the SECM were making better decisions, executing skills more effectively, and supporting their teammates (i.e., adjust) compared to the EMAM, which accounted for the higher game performance scores. If the goal for a physical educator is to have students improve game performance, the SECM would be more effective than the EMAM.

4) When measuring how the participants felt about the curricular models, the SECM participants enjoyed their experience more than the EMAM participants. The SECM group was more enthusiastic about the set up of the volleyball unit compared to the EMAM due to how the competition was set up with the championship point system and the affiliation aspect of the SECM.

\section{Practical Recommendations}

Based on the results of this investigation, this section will discuss the ramifications for using the curricular models in a physical education setting. If the goal of a physical education teacher were to improve isolated skill so that students can pass skill tests, either the SECM or the EMAM would not provide sufficient learning for students to pass the volleyball skill tests. Both models were able to provide improvement in skills that were measured via skill tests but not statistical improvement.

If the goal of the physical education teacher were to provide cognitive knowledge of sport (i.e., declarative and procedural), either the SECM or EMAM would provide the necessary knowledge for students to learn the rules and tactical knowledge of a sport. Both models did 
provide cognitive learning for the sport of volleyball and could have provided even more if participants would have been held accountable.

If the goal of the physical education teacher is to provide students the ability to play a game, then the SECM was superior to the EMAM. Being able to play the sport should be the goal of any physical educator. If students were able to play the sport and enjoy the sport then the likelihood of future participation would increase. The SECM provided participants with the skills needed to play the sport of volleyball. Game play should be the top priority of any physical education setting at the secondary level. If students are able to play the sport at a competent level, they are more likely to participate in that sport in the future. The SECM group not only became more competent in playing volleyball; there was more enjoyment in playing. The SECM is set up so that all students are involved during the unit through daily roles, team affiliation, and practicing with their team. There is a sense of belonging for students due to the affiliation aspect of the SECM in that they want to improve so their team can improve. This sense of belonging was lacking in the EMAM. The EMAM group did not work as a team while the SECM group did work as one unit with having a common goal of winning the championship. Physical educators would benefit more from using the SECM than the EMAM due to the creation of a gymnasium climate that enhances game performance, a sense of belonging to a team, and improvement in knowledge.

\section{Research Recommendations}

Based on the results of the current investigation, the researcher proposes the following recommendations for future research: 
1) Extend the research into other populations such as middle school, urban areas, and other suburban settings. The diverse populations will increase the ability to generalize the results across populations.

2) Study how the affiliation component of the Sport Education Curricular Model may be the causal factor for improved game performance. The research would be conducted with one group having affiliation while another group does not receive affiliation. By having the same content for both groups, a researcher could establish how the affiliation would affect game performance along with how participants felt about the affiliation aspect of the SECM.

3) Research should be conducted on different sports and how the SECM would affect the learning of participants through the three domains (i.e., psychomotor, cognitive, and affective). One could investigate if one would get the same results for an individual sport (e.g., badminton) rather than a team sport (e.g., volleyball). There is a dearth of research in how effective the SECM would be for individual sports.

4) Research should be performed on how effective the SECM would be in changing overall physical activity levels. A longitudinal study would be conducted by following participants throughout their middle and high schools then measuring how physically active they are when they no longer have physical education class. As we age, physical activity levels decrease with a concomitant increase in weight gain. The SECM may increase physical activity levels due to reaching the goals of the SECM which are to make participants more competent, literate, and enthusiastic toward sports. 
5) Research should be conducted on how the SECM affects teacher and student behaviors using the West Virginia University Teaching Evaluation System. Measuring teacher and student behaviors would enable researchers to investigate how the model affects the environment of the gymnasium.

6) Research should be conducted on how high and low skilled students are affected by the two models in regards to skill development by testing via skill tests.

7) Research should be conducted on how students feel about physical education by utilizing a Likert scale survey ranging from like to dislike and how the two models (i.e., SECM and EMAM) could affect those students with different dispositions. 


\section{References}

Allison, S., \& Thorpe, R. (1997). A comparison of the effectiveness of two approaches to teaching games within physical education. A skills approach versus a games for understanding approach. The British Journal of Physical Education, 28(3), 9-13.

American Alliance for Health, Physical Education, Recreation, and Dance (1969). AAHPERD Volleyball Skill Test Manual. Reston, VA: AAHPERD.

Bulger, S., Mohr, D., Carson, L., \& Wiegand, R. (2001). Infusing health-related physical fitness in physical education teacher education. Quest, 53, 403-417.

Bunker, D., \& Thorpe, R. (1982). A model for the teaching of games in secondary schools. Bulletin of Physical Education, 18(1), 5-8.

Carlson, T. (1995). “Now I think I can:” The reaction of eight low-skilled students to sport education. ACPHER Healthy Lifestyles Journal, 42(4), 6-8.

Darst, R., \& Pangrazi, P. (2001). Dynamic physical education for secondary school students ( $^{\text {th }}$ ed.). San Francisco, CA: Benjamin Cummings.

French, K., \& Thomas, J. (1987). The relation of knowledge development of children’s basketball performance. Journal of Sport Psychology, 9, 15-32.

French, K., Werner, P., Rink, J., Taylor, K., \& Hussey, K. (1996). The effects of a 3-week unit of tactical, skill, or combined tactical and skill instruction on badminton performance of ninth-grade students. Journal of Teaching in Physical Education, 15, 418-438.

French, K., Werner, P., Taylor, K., Hussey, K., \& Jones, J. (1996). The effects of a 6-week unit of tactical, skill, or combined tactical and skill instruction on badminton performance of ninth-grade students. Journal of Teaching in Physical Education, 15, 439-463.

Grehaigne, J-F., Godbout, P., \& Bouthier, D. (1997). Performance assessment in team sports. 
Journal of Teaching in Physical Education, 16, 500-516.

Griffin, L., Mitchell, S., \& Oslin, J. (1997). Teaching sport concepts and skills: A tactical games approach. Champaign, IL: Human Kinetics.

Griffin, L., Oslin, J., \& Mitchell, S. (1995). An analysis of two instructional approaches to teaching net games [Abstract]. Research Quarterly for Exercise and Sport, 66 (Suppl.), A-64.

Griffin, P. (1989). Equity in the gym: What are the hurdles? Canadian Association of Health, Physical Education, Recreation Journal, 55, 23-26.

Hastie, P. (1996). Student role involvement during a unit of sport education. Journal of Teaching in Physical Education, 16, 88-103.

Hastie, P. (1998a). Applied benefits of the sport education model. Journal of Physical Education, Recreation, and Dance, 69(4), 24-26.

Hastie, P. (1998b). The participation and perceptions of girls during a unit of sport education. Journal of Teaching in Physical Education, 17, 157-171.

Hastie, P. (1998c). Skill and tactical development during sport education season. Research Quarterly for Exercise and Sport, 69, 368-379.

Hastie, P. (2000). An ecological analysis of a sport education season. Journal of Teaching in Physical Education, 19, 355-373.

Hastie, P., \& Sharpe, T. (1999). Effects of a sport education curriculum on the positive social behavior of at-risk rural adolescent boys. Journal of Education for Students Placed at Risk, 4, 417-430.

Hastie, P., \& Trost, S. (2002). Student physical activity levels during a season of sport education. Pediatric Exercise Science, 14, 64-74. 
Hawkins, A., Wiegand, R., \& Bahneman, C. (1983). The conceptual nature of ALT-PE and its use in an undergraduate teacher preparation program. Journal of Teaching in Physical Education, Monograph 1, 11-16.

Hutchinson, G. (1995). Gender-fair teaching in physical education. Journal of Physical Education, Recreation, and Dance, 66(1), 42-47.

Kazdin, A. (1982). Single case research designs. New York: Oxford University Press.

Lawton, J. (1989). Comparison of two teaching methods in games. Bulletin of Physical Education, 25(1), 35-38.

Locke, L. (1992). Changing secondary school physical education. Quest, 44(3), 361-372.

McGee, R., \& Farrow, A. (1987). Test questions for physical education activities. Champaign, IL: Human Kinetics.

McPherson, S., \& French, K. (1991). Changes in cognitive strategy and motor skill in tennis. Journal of Sport and Exercise Psychology, 13, 26-41.

Mitchell, S., Oslin, J., \& Griffin, L. (1995). The effects of two instructional approaches of game performance. Pedagogy in Practice: Teaching and Coaching in Physical Education and Sport,1, 36-48.

Mohr, D., Townsend, J., \& Bulger, S. (2001a). Maintaining the PASE: A day in the life of sport education. Journal of Physical Education, Recreation, and Dance, 72(9), 3746.

Mohr, D., Townsend, J., \& Bulger, S. (2001b). A pedagogical approach to sport education season planning. Journal of Physical Education, Recreation, and Dance, 72(9), 37-46.

National Association for Sport and Physical Education [NASPE]. (1995). Moving into the 
future: National standards for physical education. St. Louis: Mosby.

Ormond, T., Christie, B., Barbieri, D., \& Schell, B. (2002). A comparison of sport education and the traditional unit approach: Game play, activity levels, and knowledge. Research Quarterly for Exercise and Sport, 73 (Suppl.), A-77.

Ormond, T., DeMarco, G., Smith, R., \& Fisher, K. (1995). Comparison of the sport education model and the traditional unit approach to teaching secondary school basketball. Research Quarterly for Exercise and Sport, 66 (Suppl.), A-66.

Oslin, J., Mitchell, S., Griffin, L. (1998). The Game Performance Assessment Instrument (GPAI): Development and preliminary validation. Journal of Teaching in Physical Education, 17, 231-243.

Rink, J. (Ed.). (1996). Tactical and skill approaches to teaching sport and games [Monograph]. Journal of Teaching in Physical Education, 15, 397-516.

Rink, J. (2002). Teaching physical education for learning ( $4^{\text {th }}$ ed.). New York, NY: McGraw Hill.

Rink, J., French, K., \& Graham, K. (1996). Implications for practice and research. Journal of Teaching in Physical Education, 15, 490-502.

Rink, J., French, K., \& Tjeerdsma, B. (1996). Foundations for learning and instruction of sport and games. Journal of Teaching in Physical Education, 15, 399-417.

Safrit, M., \& Wood, T. (1995). Introduction to measurement in physical education and exercise science. St. Louis: Mosby.

Siedentop, D. (1968). A theory for programs of physical education in schools. Dissertation Abstracts International, 30(03), 1006A. (University Microfilms No. AAT6913888).

Siedentop, D. (1987a). High school physical education: Still an endangered species. Journal of 
Physical Education, Recreation, and Dance, 58(2), 24-25.

Siedentop, D. (1987b). The theory and practice of sport education. In G. Barrette, R. Feingold, R. Rees, \& M. Pieron (Eds.), Myths, models, and methods in sport pedagogy (pp. 79-86). Champaign, IL: Human Kinetics.

Siedentop, D. (1994). Sport education: Quality PE through positive sport experiences. Champaign, IL: Human Kinetics.

Siedentop, D. (1996). Physical education and education reform: The case of sport education. In S. Silverman, \& C. Ennis (Eds.), Student learning in physical education: Applying research to enhance instruction (pp. 247-267). Champaign, IL: Human Kinetics.

Siedentop, D. (2002). Sport education: A retrospective. Journal of Teaching in Physical Education, 21, 409-418.

Siedentop, D., Doutis, P., Tsangaridou, N., Ward, P., \& Rauschenbach, J. (1994). Don't sweat gym! An analysis of curriculum and instruction. In M. O'Sullivan (Ed.), High school physical educators: Their world of work [Monograph]. Journal of Teaching in Physical Education, 13, 375-395.

Siedentop, D., \& Tannehill, D. (2000). Developing teaching skills in physical education (4 ${ }^{\text {th }}$ ed.), Mountain View, CA: Mayfield.

Talbot, M. (1986). Gender and physical education. British Journal of Physical Education, 17, $120-122$.

Tinning, R., \& Fitzclarence, L. (1992). Postmodern youth culture and the crisis in Australian secondary school physical education. Quest, 44(3), 287-303.

Townsend, J., Mohr, D., Rairigh, R., Bulger, S., Wellborn, B., Mohr, C., McKenzie, J., \& Johnson, R. (2004). The effect of a PASE basketball season on motor skill performance 
and health-related physical fitness in middle school physical education students. Research Quarterly for Exercise and Sport, 75 (Suppl.), A-83.

Turner, A., \& Martinek, T. (1992). A comparative analysis of two models for teaching games (technique approach and game-centered (tactical focus) approach). International Journal of Physical Education, 29, 131-152.

Turner, A., \& Martinek, T. (1999). An investigation into teaching games for understanding: Effects on skill, knowledge, and game play. Research Quarterly for Exercise and Sport, 70, 286-296.

Turvey, J., \& Laws, C. (1988). Are girls losing out? The effects of mixed-sex grouping on girls’ performance in physical education. The British Journal of Physical Education, 19, 253-255.

U.S. Department of Health and Human Services (1996). Physical activity and health: A report of The Surgeon General. Atlanta, GA: Centers for Disease Control and Prevention. 


\section{Appendix A}

Letter to High School Assistant Principal

Dear Sir,

This letter is to ask for your permission to conduct a research study at your high school. I am currently a doctoral student in Physical Education Teacher Education at West Virginia University. I will be conducting my research in my doctoral dissertation titled, "Effects of a Curricular Model on Skill Development, Knowledge, and Game Performance.” This study will hopefully provide evidence that certain curricular models can improve physical education at the secondary level by improving students’ ability to play in sports. My research will last approximately eight weeks at your school. If you have any questions, please contact me. If you approve this opportunity for me to conduct my research, please sign at the designated area. Thank you for your time and support.

Tony Pritchard Doctoral Student WVU School of Physical Education PO Box 6116 Morgantown, WV 26506-6116 (304) 293-3295 ext. 5249 


\section{Appendix B}

\section{Consent Form}

Effects of a Curricular Model on Skill Development, Knowledge, and Game Performance Introduction

I, have been asked to allow my child to participate in this study. Tony Pritchard, who is conducting this research to fulfill the requirements for his doctoral dissertation in physical education teacher education and under the supervision of Dr. Andrew Hawkins in the School of Physical Education at West Virginia University, has explained the study to my child.

Purposes of the Study

The purpose of this study is to investigate the effectiveness of the Sport Education Curricular Model and the traditional instructional model on skill development, knowledge, and game performance in a secondary school setting.

\section{Description of Procedures}

During the fall semester, 100 participants enrolled in two physical education classes at University High School will be randomly assigned to either a Sport Education Model (SEM) group or a Extended Multi-Activity Model (EMAM) group. My child will be asked to answer two questions about how they feel about physical education then he or she will be measured on volleyball skills consisting of the serve, pass, and set-up, a 35 multiple choice knowledge test, and game performance. To measure game performance, my child will be placed on six person team then will play a 15-minute game of volleyball, which will be videotaped. The researcher will measure how my child played the sport of volleyball. After lesson 10, my child will be administered the same skill tests, knowledge test, and game play. The same procedures will be conducted after lesson 20. At the end of the unit, my child will be asked how he or she enjoyed the sport of volleyball.

Lessons will be videotaped to ensure that the teachers are following the models. Teacher and student behaviors will also be analyzed for both curricular models to interpret how the models may influence the behaviors.

Version date 10-7-03 Page 1 of 3

$\overline{\text { initials }} \quad \overline{\text { date }}$


Effects of a Curricular Model on Skill Development, Knowledge, and Game Performance

Risks and Discomforts

There are no known or expected risks from participating in this study other than from regular physical activity associated with participation in physical education.

\section{Alternatives}

I understand that my child does not have to participate in this study.

\section{Benefits}

I understand that this study is not expected to be of direct benefit to my child, but the knowledge gained may be of benefit to others.

\section{Contact Persons}

For more information about this research, I can contact Tony Pritchard, at 304/293-3295 ext. 5249, or his supervisor, Dr. Andrew Hawkins at 304/293-3295 ext. 5210. For information regarding my child's rights as a research participant, I may contact the Executive Secretary of the Institutional Review Board at 304/293-7073.

\section{Confidentiality}

I understand that any information obtained as a result of my child's participation in this research will be kept as confidential as legally possible. I understand that these research records, just like hospital records, may be subpoenaed by court order or may be inspected by federal regulatory authorities. Videotapes will be kept in a locked cabinet located in the office to the primary investigator. Tapes will be kept for future training of college students who want to be physical education teachers thus will not be destroyed. In any publications that result from this research, neither my child's name nor any information from which my child can be identified will be published without my consent.

Version date_10-7-03_ Page 2 of 3

$\overline{\text { initials }} \overline{\text { date }}$

Effects of a Curricular Model on Skill Development, Knowledge, and Game Performance

Voluntary Participation 
Participation in this study is voluntary and will not affect my child's grade in physical education class. I understand that I may withdraw my child from this study at any time. Refusal to participate or withdrawal will involve no penalty or loss of benefits for my child or me. I have been given the opportunity to ask questions about the research, and I have received answers concerning areas I did not understand.

I willingly consent to my child's participation in this research.

Signature of Parent or Guardian

Signature of Investigator or Investigator's Representative

\section{Date Time}

$\overline{\text { Date }} \quad \overline{\text { Time }}$

Version date _ 10-7-03

Page 3 of 3

$\overline{\text { initials }}$ date




\section{Appendix C}

\section{Assent Form}

Effects of a Curricular Model on Skill Development, Knowledge, and Game Performance Introduction

I, have been asked to participate in this study. Tony Pritchard, who is conducting this research to fulfill the requirements for his doctoral dissertation in physical education teacher education and under the supervision of Dr. Andrew Hawkins in the School of Physical Education at West Virginia University, has explained the study to me.

\section{Purposes of the Study}

The purpose of this study is to investigate the effectiveness of the Sport Education Curricular Model and the traditional instructional model on skill development, knowledge, and game performance in a secondary school setting.

\section{Description of Procedures}

During the fall semester, 100 participants enrolled in two physical education classes at University High School will be randomly assigned to either a Sport Education Model (SEM) group or a Extended Multi-Activity Model (EMAM) group. I will be asked to answer two questions about how I feel about physical education then I will be measured on volleyball skills consisting of the serve, pass, and set-up, a 35 multiple choice knowledge test, and game performance. To measure game performance, I will be placed on a six-person team then will play a 15-minute game of volleyball, which will be videotaped. The researcher will measure how I played the sport of volleyball. After lesson 10, I will be administered the same skill tests, knowledge test, and game play. The same procedures will be conducted after lesson 20. At the end of the unit, I will be asked how I enjoyed the sport of volleyball.

Lessons will be videotaped to ensure that the teachers are following the models. Teacher and student behaviors will also be analyzed for both curricular models to interpret how the models may influence the behaviors.

\section{Risks and Discomforts}

There are no known or expected risks from participating in this study other than from regular physical activity associated with participation in physical education.

Version date $\underline{10-7-03} \quad$ Page 1 of 2

$$
\overline{\text { initials }} \overline{\text { date }}
$$


Effects of a Curricular Model on Skill Development, Knowledge, and Game Performance Alternatives

I understand that I do not have to participate in this study.

\section{Benefits}

I understand that this study is not expected to be of direct benefit to me, but the knowledge gained may be of benefit to others.

\section{Contact Persons}

For more information about this research, I can contact Tony Pritchard, at 304/293-3295 ext. 5249, or his supervisor, Dr. Andrew Hawkins at 304/293-3295 ext. 5210. For information regarding my rights as a research participant, I may contact the Executive Secretary of the Institutional Review Board at 304/293-7073.

\section{Confidentiality}

I understand that any information obtained as a result of my participation in this research will be kept as confidential as legally possible. I understand that these research records, just like hospital records, may be subpoenaed by court order or may be inspected by federal regulatory authorities. Videotapes will be kept in a locked cabinet located in the office to the primary investigator. Tapes will be kept for future training of college students who want to be physical education teachers thus will not be destroyed. In any publications that result from this research, neither my name nor any information from which I can be identified will be published without my consent.

\section{Voluntary Participation}

Participation in this study is voluntary and will not affect my grade in physical education class. Refusal to participate or withdrawal will involve no penalty for me. I have been given the opportunity to ask questions about the research, and I have received answers concerning areas I did not understand.

I willingly consent to participate in this research.

Signature of Participant

Signature of Investigator or Investigator's Representative Version date __ 10-7-03_ Page 2 of 2
Date Time

$\overline{\text { Date }} \quad \overline{\text { Time }}$ 


\section{Appendix D}

Knowledge Test

1. Which skill should not be executed with one hand?
A. spike
B. dig
C. setup
D. serve

2. What is the most accurate method of directing the ball to a specific place on the court?
A. forearm pass
B. set
C. spike
D. dig

3. What is the optimum path, or trajectory, of a pass?
A. The ball falls directly over the setter's head so he or she does not have to shift position.

\section{B. The ball is moderately high so the receiver has time to shift position.}
C. The ball is very high so the setter has sufficient time to shift position and look for spikers.
D. The ball goes directly to the spiker so the opponents do not have time to set up the block.

4. For which is the forearm pass least likely to be used?
A. receive a serve
B. set for a spike
C. return low balls
D. receive a spike

5. Why are few balls illegally hit from a forearm pass?
A. Contact with the forearms can be made quickly.
B. The forearms do not give at contact. 


\section{The forearms present a solid surface from which the ball rebounds. \\ D. The forearm pass is used mostly to return hard hit balls.}

6. What is the most important factor to remember in setting?
A. to move quickly to get the bail
B. to push the ball out and up
C. to position oneself under the ball
D. to place the ball in the proper spiking zone

7. What is the most frequent use of the overhand pass?
A. to pass a low ball to the front line
B. to set the ball for a spike
C. to receive a serve
D. to change the direction of an approaching ball

8. Where is the ball held by the server to hit an underhand serve?
A. diagonally in front of the server with the arm extended
B. directly toward the net with the arm extended
C. directly toward the right side line with the arm slightly bent
D. toward the right net post with the elbow in close to the player's waist

9. Which quality should be of least concern in choosing a setter?
A. competitive spirit
B. mental alertness
C. size
D. speed

10. A playing area does not have the required clearance above the court. A serve hits the ceiling. What is the ruling?
A. play continues
B. reserve
C. second serve 


\section{D. side-out}

11. A player on the receiving team entered the game in the wrong position in the service order. His or her team is now serving and has scored two points since the player entered the game. What happens?
A. player removed, points kept, and side-out called
B. player removed, points lost, and side-out called
C. player's position corrected, points kept, and side-out called
D. player's position corrected, points lost, and serve kept

12. How long does the server have to put the ball in play after the first referee's readiness whistle?
A. 2 seconds
B. 3 seconds
C. 5 seconds
D. 10 seconds

13. The serve hits the top of the net and goes over into the opponents' court. What is the ruling?
A. play continues
B. side-out
C. reserve
D. second serve

14. A player serves out of order. While the player is serving, the error is discovered. What happens?
A. The order is corrected, the points scored are lost. and the correct player serves.
B. The order is corrected, the points scored are kept. and the correct player serves.
C. The order is corrected, the points scored are lost, and side-out is called.
D. The order is retained, the points scored are kept, and side-out is called.

15. With what parts of the body may a player legally contact the ball?
A. hands and forearms
B. hands and arms 


\section{C. any part of the body on or above the waist \\ D. any part of the body}

16. When may a player hit the ball twice in a row?
A. never
B. when the first hit was an attempted block
C. when the hits are made with different body parts
D. when the first hit was a ball recovered from the net

17. A player on the serving team is trying to keep the receiving team from watching the server hit the ball. What happens?
A. legal play
B. replay
C. warning
D. side-out

18. A player is hitting an overhand pass. The ball comes to rest in the palms of the player's hands. What happens?
A. legal play
B. held ball
C. double hit
D. palming

19. Who may block a spike?
A. any player on the defensive team
B. only the player opposite the spiker
C. only the two players closest to the spiker
D. only the front row players

20. A back row player on the serving team spikes the ball into the opponent's court. The spiker was at the net when the hit was made. What is the decision?
A. legal play
B. point 

C. side-out
D. replay

21. What is the basic attack pattern of play?
A. pass-set-spike
B. pass-pass-set
C. set-spike-block
D. serve-set-spike

22. Who is the "quarterback" of the team?
A. the captain
B. the coach
C. the left front
D. the setter

23. What do the numbers in offensive systems mean?
A. number of spikers and number of blockers
B. number of attackers and number of nonattackers
C. number of spikers and number of setters
D. number of front row players and number of back row players

24. Generally, how high should the ball be hit for a set?
A. 1 foot above the top of the net
B. 2 to 3 feet above the top of the net
C. 6 to 8 feet above the top of the net
D. 15 to 20 feet above the top of the net

25. What is the purpose of the two-set?
A. to give the spiker plenty of time to judge the ball
B. to create a one-on-one blocking situation
C. to attack the space between the outside and middle blocker 
D. to beat the blockers with quickness of execution

26. All the spikers have about the same ability. Which spiker should the setter send the ball to most often?
A. the left front
B. the center front
C. the on-hand spiker
D. the off-hand spiker

27. What is the easiest spike to hit?
A. on-hand crosscourt
B. on-hand down-the-line
C. off-hand crosscourt
D. off-hand down-the-line

28. The ball is set too close to the net. What should the spiker do?
A. Hit as hard as possible.
B. Aim between the two blockers.
C. Dink the ball.
D. Let the blockers hit the ball.

29. The spiker is against a one-player block. What is generally the best spike to attempt?
A. down-the-line
B. crosscourt
C. down-the-middle
D. dink

30. What is the main reason for the side set?
A. easiest for the spiker to hit
B. easiest for setter to set
C. provides longest spiking angle on the court
D. most difficult to block 
31. What adjustment should the outside blocker make from the usual blocking position?
A. Turn the hand nearest the side line toward the middle of the opponents' court.
B. Turn his or her body toward the middle of the opponents' court.
C. Tilt both hands toward the nearest sideline.
D. Jump about 6 inches lower than usual.

32. Which serve will generally cause the receiving team the greatest difficulty?
A. a serve to the front half of the court
B. a serve to the back half of the court
C. a serve to the back corners of the court
D. a serve to the middle of the court

33. Which is not a good serving strategy?
A. Hit away from the best spiker.
B. Hit to a known weak passer.
C. Serve to a substitute.
D. Attempt mostly difficult short or corner serves.

34. What should be changed about the regular set if the spiker is short?
A. Set the ball higher.
B. Set the ball lower.
C. Set the ball closer to the net.
D. Set the ball further from the net.

35. What is the purpose of the attack block?
A. To make it easy for teammates to hit the pass
B. To hit the ball before the spiker can
C. To hit the ball before it crosses the net
D. To hit the spiker with the blocked ball 


\section{Appendix E}

Volleyball Game Performance Assessment Instrument

Evaluator

Class

Categories

Decisions made - criteria two levels

1 = pass ball over the net

2 = pass to set up attack

Skill execution - criteria

Forearm and overhead pass = legal contact, playable ball

Spike = legal contact over the net into playing area

Adjust - criteria

Player moves to open up or in pursuit to save a ball

Recording procedures - Use tally to mark the appropriate category

\begin{tabular}{|c|c|c|c|c|c|c|}
\hline \multirow{2}{*}{ Participants } & \multicolumn{2}{|c|}{ Decision made } & \multicolumn{2}{c|}{ Skill execution } & \multicolumn{2}{c|}{ Adjust } \\
\cline { 2 - 7 } & A & IA & A & IA & A & IA \\
\hline A & & & & & & \\
\hline B & & & & & & \\
\hline
\end{tabular}

- Decision making index $(\mathrm{DMI})=$ number of appropriate decisions made $\div$ number of inappropriate decisions made.

- Skill execution index $(\mathrm{SEI})=$ number of efficient skill executions $\div$ number of inefficient skill executions.

- $\quad$ Adjust $(\mathrm{A})=$ number of appropriate supporting movements $\div$ number of inappropriate supporting movements.

- $\quad$ Game performance $=[\mathrm{DMI}+\mathrm{SEI}+\mathrm{A}] \div 3$ 
- Game involvement = total appropriate decisions + number of inappropriate decisions + number of efficient skill executions + number of inefficient skill executions + number of supporting movements. 


\section{Appendix F}

\section{Physical Education Survey}

1. Describe what you like about your physical education class. Give at least 3 examples.

2. Describe what you don't like about your physical education class. Give at least 3 examples.

3. Describe what you liked about the volleyball class. Give at least 3 examples.

4. Describe what you did not like about the volleyball class. Give at least 3 examples. 


\section{Appendix G}

Team Role Sheet

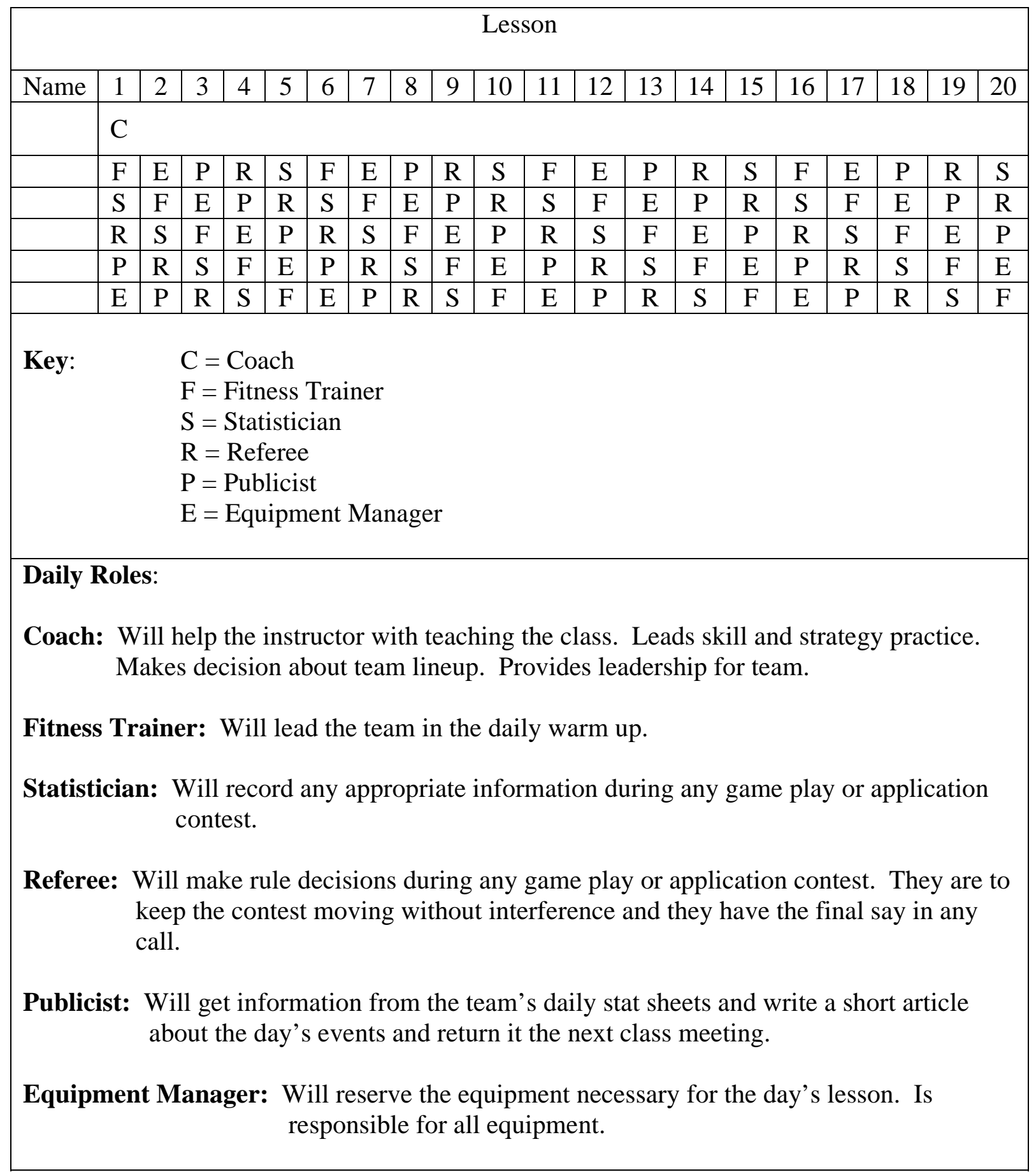




\section{Appendix $\mathrm{H}$}

Sport Education Curricular Model Unit Plan

Instructional Focus

$\begin{array}{llll} & & \text { Application } & \text { Sport Education Focus } \\ \text { Lesson Skill } & \text { Strategy/Tactic } & \text { Contest }\end{array}$

1

2

3

4

5

6

$\begin{array}{ll}\text { Overhand serve } & \begin{array}{l}\text { Setting } \\ \text { attack }\end{array}\end{array}$

Spike

$7 \quad$ Block and dink

$8 \quad$ Review of skills

\section{Scoring}

Scoring

Keeping ball in

play

Keeping ball in

play

Keeping ball in

play

Scoring

$9 \quad \begin{aligned} & \text { Setting up } \\ & \text { attack: review of }\end{aligned}$

skills Scoring

$10 \quad$ Referee signals

Defensive Plays

3 vs 3

3 vs 3

2 vs 2

3 vs 3

3 vs 3

Off-speed attack

3 vs 3

3 vs 3

3 vs 3

3 vs 3

Introduction Biography

Assign teams

Role responsibilities

Role responsibilities

Officiating rules

Role responsibilities

Officiating rules

Role responsibilities

Officiating rules

Role responsibilities

Statistics box scoring

Role responsibilities

Statistics box scoring

Role responsibilities

Statistics box scoring

Role responsibilities

Statistics box scoring

Role responsibilities

Officiating rules
Offensive Plays

4 vs 4
Role responsibilities 
Scoring

12

$$
\text { Rotation of }
$$
Serve

13 Statistics

14

4-2 Offense
Offensive Plays

Scoring

Defensive

Strategies

Review: strategies 5 vs 5

4 vs 4
Officiating rules

Role responsibilities

Officiating rules

Role responsibilities

Officiating rules

Role responsibilities

Officiating rules

Officiating

Statistics box scoring

Rites and rituals

Rites and rituals

Tourney

Rites and rituals

Tourney

from team game

performance

performance

As determined from 6 vs 6

Rites and rituals

from team game

team game

performance
Tourney

6 vs 6

Awards Ceremony

20 Festivity:

Championship 


\section{Appendix I}

Sport Education Curricular Model Point System

Behavior Points Earned

Team wears team colors

Up to 5

Team warms-up correctly at home base

Up to 5

Team performs daily roles

Up to 5

Team is enthusiastic (Team cheer)

Up to 5

Obeys the teacher

Up to 5

Sportsmanship

Up to 5

Application contests

Up to 5

Inappropriate behavior

-5 for each occurrence

Note: Teams can only earn up to 25 points per day. 


\section{Appendix J}

Extended Multi-Activity Model Unit Plan

\begin{tabular}{|c|c|c|}
\hline Lesson & Instructional Format Skill & Application Contest \\
\hline 1 & Management & None \\
\hline 2 & Forearm pass & None \\
\hline 3 & Overhand pass: set & None \\
\hline 4 & Underhand serve & None \\
\hline 5 & Overhand serve & None \\
\hline 6 & Spike & None \\
\hline 7 & Block, dink & None \\
\hline 8 & Review of skills & 2 vs 2 \\
\hline 9 & Setting up attack & 2 vs 2 \\
\hline 10 & Referee signals & 3 vs 3 \\
\hline 11 & Referee signals & 3 vs 3 \\
\hline 12 & Rotation of serve & 4 vs 4 \\
\hline 13 & Review of skills & 5 vs 5 \\
\hline 14 & 4-2 offense & 5 vs 5 \\
\hline 15 & None & 6 vs 6 \\
\hline 16 & None & 6 vs 6 \\
\hline 17 & None & 6 vs 6 Tourney \\
\hline 18 & None & 6 vs 6 Tourney \\
\hline 19 & None & 6 vs 6 Tourney \\
\hline
\end{tabular}


Curricular Models 148 


\section{Appendix K}

Curricular Model Checklist

Name of Observer:

Date:

Teacher:

Time:

1. __ Students go to a home base and begin warm-up with team.

2. __ _ _ Students peer teach by using a coaching plan.

3. __ Teacher provides instruction on new skill for the day.

4. _ _ Students go practice with team at home base.

5. __ Same teams play during application contest.

6. __ Teams compete against each other.

7. _ _ Students perform roles (e.g., fitness trainer, coach, equipment manager, etc.).

8. _ _ _ Teams are earning points for overall champion.

9. __ _ _ Students warm-up as a whole class.

10. _ _ Teacher reviews skills from previous lessons.

11. __ Skills are being practiced but not as a team.

Note. Items 1, 2, 4, 5, 7, and 8 are characteristics of the Sport Education Curricular Model. Items 9 and 11 are characteristics of the Extended Multi-Activity Model and items 3, 6, and 10 are characteristics of both models. 
Appendix L

West Virginia University Teaching Evaluation System Student and Teacher Behavior Code Definitions

Student Behavior Codes

Student Behavior Description

Motor appropriate Student is engaged in a subject matter motor activity in such a way as to produce a high degree of success.

Motor

inappropriate

Student is engaged in a subject matter motor activity but the task is either too difficult for the individual's capabilities or is so easy that practicing it could not contribute to lesson goals.

Cognitive Student is appropriately involved in a cognitive task such as listening to a teacher describe a game, listening to verbal instructions about how to organize, watching a demonstration, participating in a discussion, watching a film, etc.

Motor supporting Student is engaged in a subject matter motor activity the purpose of which is to assist others to learn or perform the activity.

On task management

Student is appropriately engaged in carrying out an assigned non subject matter task (management, transition, warm-up task, etc.) such as moving into squads, placing equipment, counting off, doing warm-up exercises, moving from the gym to a playing field, etc.

Off task

Student is either not engaged in the appropriate activity or is engaged in an appropriate one such as behavior disruptions, misbehavior, talking when a teacher is explaining a skill, misusing equipment, fooling around, fighting, or other wise disrupting a drill, etc.

Interim

Student is engaged in a non-instructional aspect of an ongoing activity such as retrieving balls, fixing equipment, changing sides of a court in a tennis match, etc. 
Waiting

Student has completed a task and is awaiting the next instructions or opportunity to respond such as waiting in line for a turn, waiting for the next teacher direction, standing on a sideline waiting to enter a game, or waiting for an activity to begin, etc. 
General

observation

Encouragement

Positive feedback

Corrective feedback

Management

Verbal instruction

Modeling

Physical guidance

Non-task verbal
Teacher is watching student groups or individuals engaged in any category of student behavior and must not be engaged in any other category of teacher behavior. This category includes passive supervision and there is no relationship of the observation to an instructional focus.

Teacher makes a verbal statement the purpose of which is to enhance the student's perception of their ability to accomplish a subsequent task.

Teacher makes a positive verbal statement or gesture following an appropriate student behavior (skill or organizational) designed to increase or maintain such responses in the future. The statement must follow soon enough after the behavior that the student clearly associates it with the behavior.

Teacher makes a critical verbal statement or gesture following an inappropriate student behavior (skill or organizational) clearly designed to decrease such responses in the future. The statement must follow soon enough after the behavior that the student clearly associates it with the behavior.

Teacher is engaged in carrying out a non-subject matter task (setting up equipment, taking roll, collecting papers, etc.) and may be directing students verbally in a management task.

Teacher is verbally describing to the student how to do a skill, or is using a verbal prompt to direct students in attempting a skill or activity.

Teacher demonstrates to students how to do a subject matter task, or participates with students in a subject matter task or activity.

Teacher physically guides a student through a subject matter task or activity.

Teacher talks to students about non-subject matter and non-managerial subjects. 
Off task

Specific observation
Teacher is not paying attention to what are his or her responsibilities regarding the class at hand.

Teacher is watching one student, pairs, or small groups engaged in a subject matter task in order to give feedback related to performance. Teacher must be close enough to the student that the observation of a specific performance is clear. 